\title{
Social Media for Government Use
}

\author{
by
}

\author{
Narges Shahsavarani
}

A thesis submitted to the faculty of Graduate and Postdoctoral Affairs in partial fulfillment of the requirements for the degree of

\author{
Doctor of Philosophy in Management
}

Carleton University

Ottawa, Ontario

December 2014

C 2014, Narges Shahasavarani 


\begin{abstract}
Social media use around the word is growing rapidly and governments similar to private sector firms are endeavoring to employ social media for a variety of purposes. Current research (McNutt, 2014; Snead, 2013; Chun \& Luna Reyes, 2012; Picazo-Vela et al., 2012; Lavender, 2013; Mergel, 2013b) supports the observation that governments use social media as a tool to provide information to the public, to engage with citizens, to improve service delivery, to enhance democratic engagement, to facilitate feedback and comments from citizens, to communicate with stakeholders and to collaborate across organizations. Although the use of social media may bring benefits to governments, successful deployment of these technologies also faces some challenges and barriers, such as an incompatible organizational culture, information security and privacy issues. While researchers have investigated some of the issues concerning these benefits and barriers, there is still a dearth of empirical evidence related to what citizens and employees, as potential stakeholders, want when interacting with different levels of government through social media tools.
\end{abstract}

This study aims to address two important objectives: 1) understanding social media as a phenomenon and its implications for government use; 2) understanding the perceptions of citizens, employees and government senior management in terms of government use of social media. The fundamental research question for this study is, what is the relative importance of the benefits and barriers linked to social media use by governments for different stakeholder groups?

By applying stakeholder theory this study differentiated between the perceptions of three stakeholder groups (i.e. citizens, government senior management, and employees). Using the concept of salience developed by Mitchell et al. (1997) who suggested that an organization needs to know competing stakeholders' claims and prioritize them, this work contributes to the literature by taking a step toward understanding potential stakeholders' needs, stakes and expectations so that the organizations concerned can integrate their information, feedback and opinions into innovative forms of interaction. Stakeholder theory provides a useful framework for considering these issues, which may assist organizations in identifying potential stakeholders and prioritizing their needs and concerns.

Citizens have been identified as using social media for diverse purposes such as receiving timely and relevant services, gaining faster access to government information, encouraging twoway communication, increasing levels of participation and engagement and promoting greater government transparency. On the other hand, governments (including employees and senior management) employ social media to fulfill different needs and objectives such as reaching out to stakeholders, sharing information and collaborating within and across government agencies, 
increasing government transparency, enhancing democratic engagement, and enhancing citizens' participation. These contrasting goals pose problems for the managers who deploy social media programs as well as the citizens who wish to interact with government using these channels.

This study used a mixed methods design for analyzing, interpreting and reporting data. The results strongly suggest that successful social media initiatives involve more than utilizing different tools; they require the effective engagement of different stakeholders, understanding their interests, needs and expectations and bringing these into alignment. This study also offers further evidence that at the moment governments tend to use social media as a tool to push information to the public rather than engaging in two-way interactions.

The results show that the risk-averse nature of organizational culture in most government agencies poses an important challenge for their use of social media. Although there have been some changes recently, the typical government culture remains bureaucratic, employs lengthy approval processes and relies on a command-and-control structure built around departmental silos. The findings presented here suggest that without shifting the organizational culture towards more open and transparent processes, initiatives to increase government use of social media will achieve only limited success. 


\section{Dedication}

This thesis is dedicated to my mother Fatemeh and my father Mohammad who have been and continue to be the inspiration in my life.

\section{Acknowledgements}

I would like to thank Dr. David Cray for his contributions to and support of every portion of this work from the initial proposal to the final product. $\mathrm{He}$ provided excellent guidance through this thesis.

I am also thankful to Dr. Gerald Grant and Dr. Ruth McKay for being part of my thesis committee and providing suggestions, which added a great deal to this research. 


\section{Table of Contents}

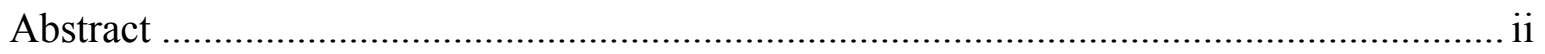

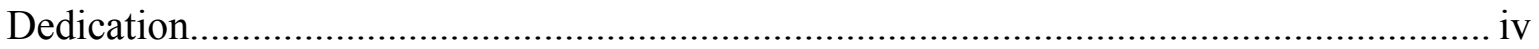

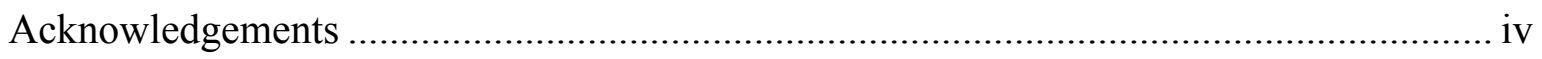

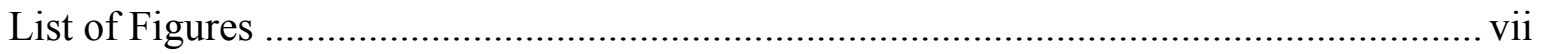

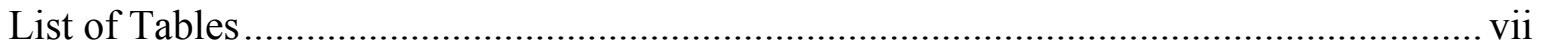

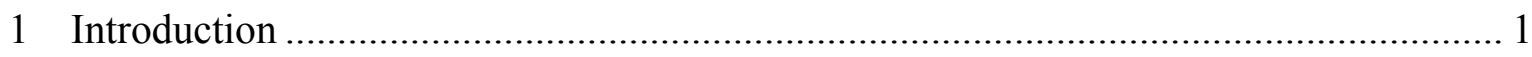

2 Literature Review: Web 2.0 and Social Media …………………………………..... 7

2.1 Web 2.0

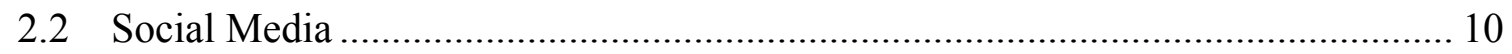

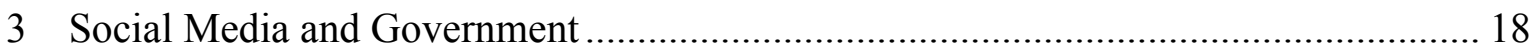

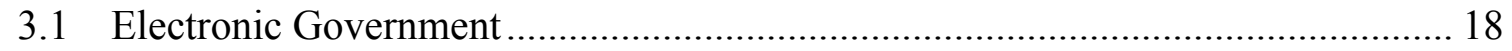

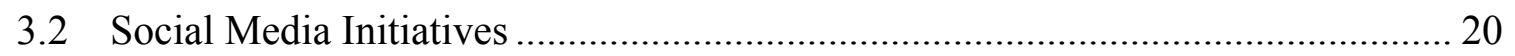

3.3 Use of Social Media Tools by National Governments ......................................... 22

3.4 Social Media Initiatives in the Government of Canada ......................................... 27

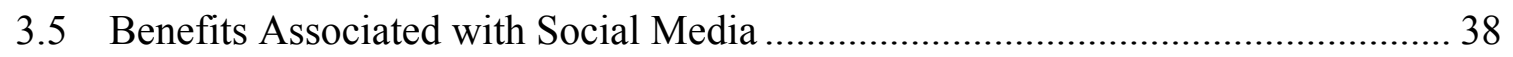

3.6 Possible Challenges/Barriers Associated with Social Media .................................. 47

3.7 Possible Risks Associated with Social Media ……………………......................... 51

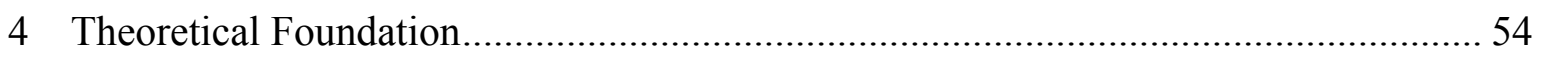

4.1 Stakeholder Theory: Historical Overview/Literature Review ………………….... 54

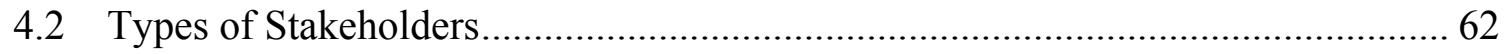

4.3 Stakeholders' Relationships with the Organization................................................. 69

4.4 Criticisms of Stakeholder Theory ………………............................................ 73

4.5 E-government Stakeholders ........................................................................... 76

4.6 Implications for Government.................................................................... 78

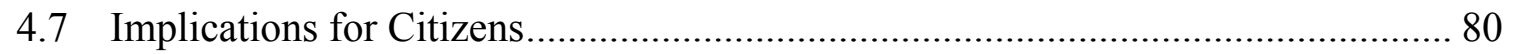

4.8 Recognizing Stakeholder Interests from Social Media Tools ................................ 81

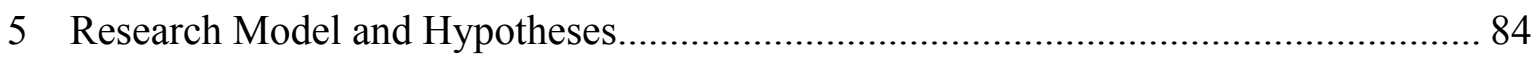

5.1 Research Question and Objectives ................................................................... 85 


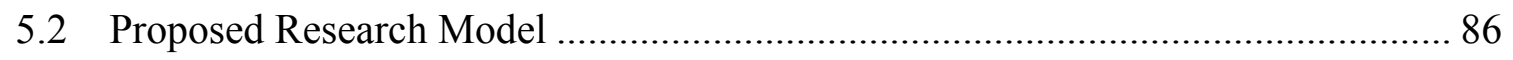

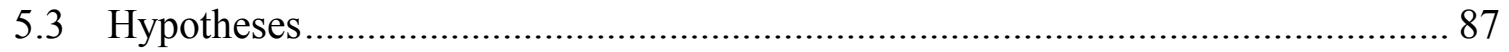

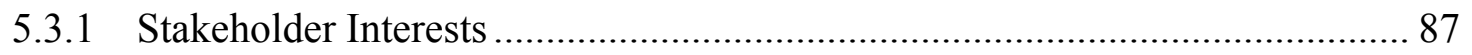

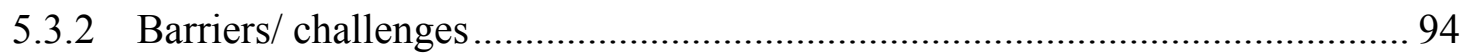

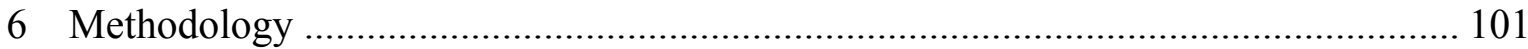

6.1 The Survey Validity and Reliability ……………………….......................... 105

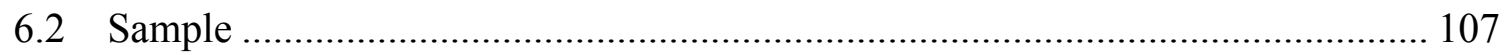

6.2.1 Data Collection Process …………………….............................................. 109

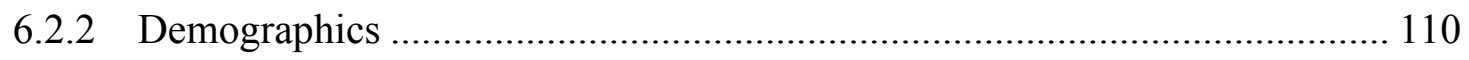

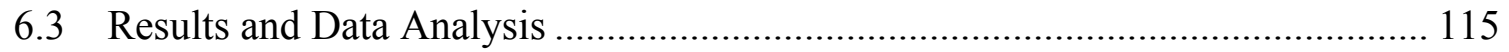

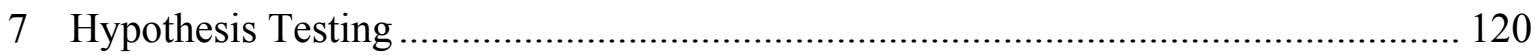

8 Qualitative Analysis: Data Discussion and Findings ………………………............... 141

9 Discussions, Conclusions, and Recommendations.................................................... 169

10 Contributions, Limitations, and Future Research....................................................... 183

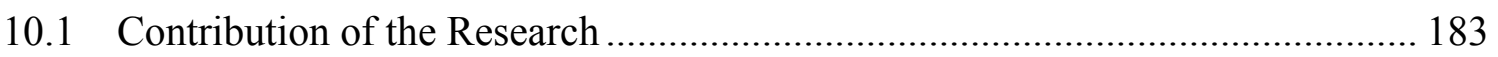

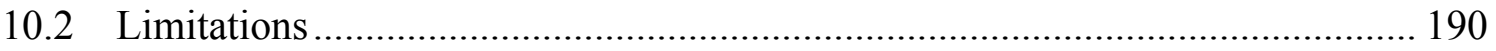

10.3 Recommendations for Future Research .......................................................... 192

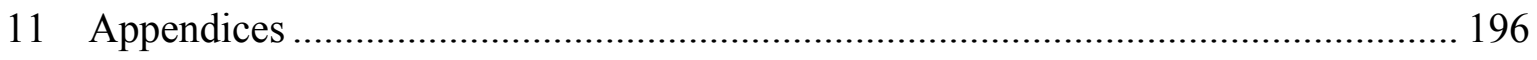

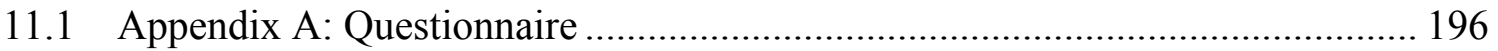

11.2 Appendix B: Quantitative Data - Descriptive Statistics ………............................ 204

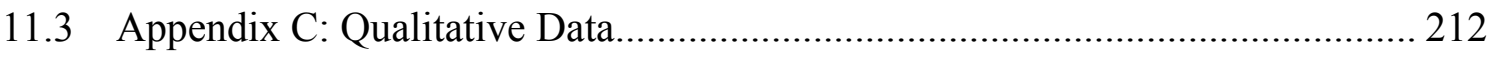

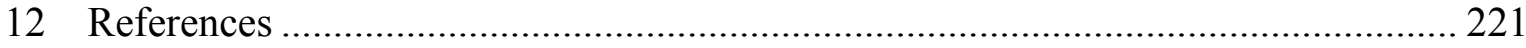




\section{List of Figures}

Figure 1-Three Aspects of Stakeholder Theory (Donaldson \& Preston, 1995) ................. 58

Figure 2-A Typical Stakeholder Map-Freeman (1984).............................................. 63

Figure 3-The Stakeholder Model (Donaldson \&Preston, 1995) ................................... 70

Figure 4 - Typology of Resource Relationship (Frooman, 1999) ................................ 71

Figure 5- Typology of Resource Relationships and Influence Strategies (Frooman, 1999)73

Figure 6- Research Model: Stakeholder Interests ................................................... 86

Figure 7 - Triangulation Design: Validating Qualitative Data Model ........................... 103

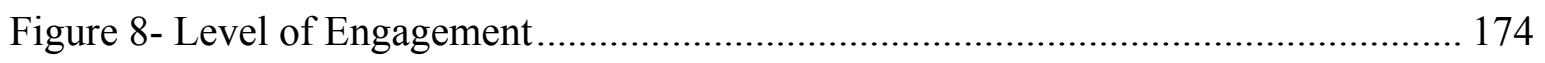

\section{List of Tables}

Table 1- Characteristics of Web 1.0 vs. Web 2.0 (adopted from O'Reilly, 2005)..............9

Table 2- Social Media Classification According to Domain Function ............................ 12

Table 3-Example of Use of Social Media Tools by National Governments .................... 24

Table 4-Example of Social Media Initiatives in the Government of Canada................... 32

Table 5-Social Media Tools and Their Implications for Government ........................... 36

Table 6 - Key Constructs in the Theory of Stakeholder Identification and Salience

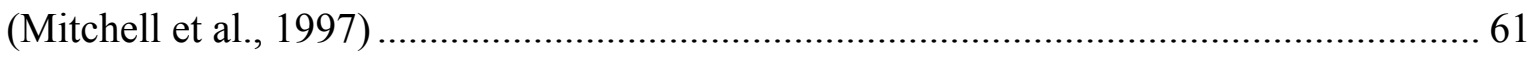

Table 7 -Example of Stakeholders Categorized by Different Authors............................ 68

Table 8-Stakeholders' Interests in the Use of Social Media ......................................... 82

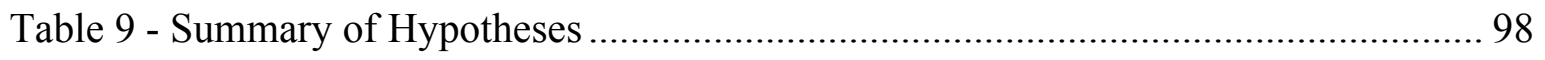

Table 10 - Respondents' Profile: Demographic Features and Education Level.............. 112 
Table 11 - Age of the Respondents ............................................................................ 113

Table 12- Respondents' Employment Status ……………………………………..... 114

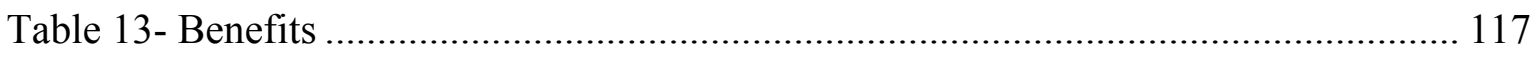

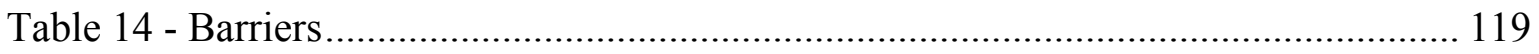

Table 15 - Two-Tailed Test: Benefits....................................................................... 121

Table 16 - One-Tailed Test: Benefits ...................................................................... 122

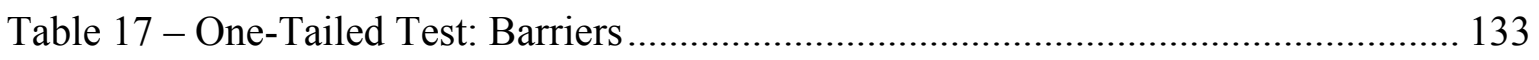

Table 18 - Two-Tailed Test: Barriers ………………………………………………... 136

Table 19- Social Media Definition: Text Analysis....................................................... 142

Table 20- Employee's Definition of Social Media.......................................................... 145

Table 21 - Some Examples of What Information You Would Like to Have Regarding Social Media Being Used in the Government ................................................................ 163

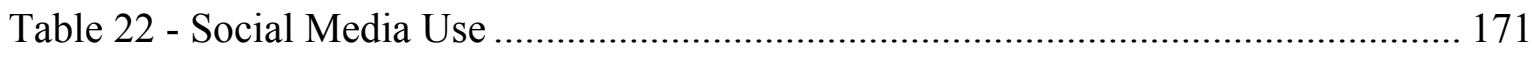




\section{Introduction}

The term "social media" refers to a wide range of Internet-based and mobile services that provide opportunities for users to participate in online exchanges, create content, or join virtual communities. Social media use web-based technologies to turn communication into an interactive dialogue. They build on the technological foundations of Web 2.0, which allows for the creation and exchange of user-generated content over the Internet (Dewing, 2010).

Interest in social media has been growing rapidly, for example Facebook has more than 829 million daily active users on average as of June 2014 (Facebook News Room, 2014). An Internet search for the term delivers over 200 million possibilities. In 2006, Time magazine found the topic of social media to be so significant, the publisher named "YOU" as its Person of the Year (Grossman, 2006). The statistics concerning the pervasiveness of this trend are astonishing. Among young users (18-29 year old) $86 \%$ are using social media tools everyday (Madden, 2010). As of March 2013, Facebook had more than one billion active participants with more than half of them using Facebook on their mobile devices (Facebook, 2014). Twitter has rapidly gained worldwide popularity, with 500 million users in 2012 generating over 340 million tweets per day (Twitter, 2013). YouTube officially launched in May 2005 and recently reported that more than one billion unique users visit YouTube each month (YouTube, 2014). As of May 2014, the English Wikipedia contains nearly five million articles that have been voluntarily written by users around the world. It has become the largest and most popular general reference work on the Internet. The number of readers of Wikipedia worldwide reached 365 million at the end of 2009 (Wikipedia, 2014). 
The concept of "Web 2.0" began with a conference brainstorming session between Tim O'Reilly and MediaLive International (O'Reilly, 2005). The essential difference between Web 1.0 and Web 2.0 is that Web 2.0 relies on the concept of the user as a content producer. Tim O'Reilly, founder and CEO of O'Reilly Media, suggested a definition of the term at the end of 2006:

"Web 2.0 is the business revolution in the computer industry caused by the move to the Internet as platform, and an attempt to understand the rules for success on that new platform. Chief among those rules is this: Build applications that harness network effects to get better the more people use them. (This is what I've elsewhere called 'harnessing collective intelligence')."(O’Reilly, 2006)

Since 1992, the Internet has revolutionized almost every facet of business and personal life. Today, we are facing another revolution that is being driven by generations with increasing technological awareness and facilitated by Web 2.0. The introduction and spread of Web 2.0 has made a significant change in the Internet, bringing with it a new platform and new culture for doing business, and strongly influencing how people interact with each other. The social dimension of Web 2.0 is associated with content sharing. As O'Reilly and Battelle said in their recent article the web is no longer just a platform, but that "the Web is now the world" (O'Reilly \& Battelle, 2009).

Around the world, social media is growing rapidly in terms of use and popularity (Chun \& Luna Reyes, 2012; Kavanaugh et al., 2012; Picazo-Vela et al., 2012; Nam, 2012; Snead, 2013; Bertot et al., 2012). Companies have focused on social media to engage their customers, to gain 
information about them, to leverage their knowledge for service and product development, and to participate in their conversations in order to influence their behaviour. As public organizations, governments have begun to emulate businesses in using social media to reinvent their relationships with citizens and with other organizations. Various government agencies are now focusing on investments in social media as a part of their communication strategy. This emerging participatory environment has the potential to radically transform government in terms of how it operates internally and interacts with citizens (Chun \& Luna Reyes, 2012; Kavanaugh et al., 2012). For example, social media have changed the way Americans get information about what is happening in their communities, and on the national and global stages. They provide new ways for citizens to share information and to interact with each other and with government agencies (Kavanaugh et al., 2012). A study conducted by Pew Research Center's Internet \& American Life in 2010, found that almost a third of all online adults in the USA used social media tools such as blogs, social networking sites, online video as well as email and text alerts to keep informed about government activities (Smith, 2010). It is likely that the percentage has increased since the study was completed.

Increasingly, citizens use social media tools to engage with public and private institutions, as well as with each other within and beyond their local and national borders. This trend, along with the growth of social media and enhanced users' capacity not only to access information but also to generate content, has heightened governments' interest in designing and implementing citizen-centric approaches to providing information and services. Placing citizens at the centre of their ways of doing business requires a shift of focus from governments deciding 
what citizens require to ensuring a better understanding of citizens' views of their own needs (Jeager \& Bertot, 2010; Anonymous $\left.{ }^{1}, 2011\right)$.

By recognizing the importance of social media, different levels of government in Canada have begun to take notice of these tools in their interaction with citizens. Although implementation of social media provides governments with opportunities to improve citizens' interactions, it also poses new challenges with different issues, such as connectivity, privacy, and trust. Social media comes in many evolving forms; this study will concentrate on a few of those most important in government communication strategies.

It is obvious that the rapid growth of Web 2.0 and social media has attracted the attention of researchers in different disciplines (e.g. Marketing, Information Systems (IS)) in order to generate insight into its several aspects. A number of these studies focus on social media and government transparency (Bertot et al., 2010; Bertot, Jaeger \& Grimes, 2010). Some studies have taken a more general approach to Web 2.0 technologies (O'Reilly \& Battelle, 2009; Kim et al., 2009; Wilson et al., 2011) and some researchers discuss the use of Web 2.0 for knowledge management (Nath et al., 2011; Yates \& Paquette, 2011). Although there has been speculation about the use of social media by governments, to date there has been very little empirical research related to what citizens want/expect from government through social media. Bertot et al. (2010) argued that the next step is to research the types of services people want; understanding users' needs, behaviours and expectations will be critical in developing social media embedded

\footnotetext{
${ }^{1}$ This is anonymous because it is government report.
} 
government services and resources. Some theorists have suggested that social media use by government can be expected to produce a positive impact in different areas such as citizens' engagement, increased government transparency, collaboration among employees and citizens, improvement of government service delivery, etc. (Bertot et al., 2012; Kavanaugh et al., 2012; Lavender, 2013; Picazo-Vela et al., 2012).

I faced these challenges when I was tasked with developing a social media policy for internal and external use, while working for a Canadian government department in 2010. There was no data about stakeholders' needs and expectations regarding social media use by government. Recognizing this need, I decided to examine social media in the government context, through the lens of stakeholder theory as the main purpose of this study. The central purpose of this application is to enable governments to understand their stakeholders providing basic information that will allow them to strategically manage these relationships.

This thesis has two important objectives with regard to understanding how to leverage social media for government-citizen interactions:

- Understanding social media as a phenomenon and its implications for government use

- Understanding the perceptions of citizens, employees and government senior management in terms of government use of social media

The Research Question for this study is, what is the relative importance of the benefits and barriers linked to social media use by governments for different stakeholder groups? 
The contributions of this study include a demonstration of the utility of stakeholder theory for analyzing social media use by governments and the identification of important similarities and differences in the attitudes of different stakeholder groups toward benefits of and barriers to social media use. It's also identified organizational culture as one of the most important barriers to governments' effective use of social media, as well as providing an empirical base for future research.

This thesis is organized into ten sections. Following this introduction to the main issues the second section will present a review of the relevant literature. The third section describes social media and their potential effects on governments. In this section, I will explain the concept of electronic government and various social media initiatives followed by a discussion of the use of social media tools by selected governments including that of Canada. The fourth section will develop the theoretical foundation for the research leading to the proposed research model, research question and related hypotheses that flow from this perspective which appear in section five. The sixth section will present the methodology employed in gathering and analyzing the data. The hypotheses will be evaluated in light of the evidence in chapter seven. Chapter eight will present the results of the qualitative analysis and findings of this research. Chapter nine consists of discussion, conclusions and practical recommendations. The final section outlines potential contributions from the research, some of its limitations as well as recommendations for future studies. 


\section{Literature Review: Web 2.0 and Social Media}

Fast emerging Internet-based collaboration tools, referred to as social media, have changed the way people communicate, interact, and collaborate by utilizing the Internet. Both business and government organizations have recognized the significance of social media tools in building relationships with customers, employees, and citizens, and in co-creating content and services that will benefit all stakeholders in their environments (Sedereviciute \& Valentini, 2011; Picazo-Vela et al., 2012). The growth of social media usage, with an adoption rate over $75 \%$ by citizens under the age of 25 in the USA, means that government organizations now need to plan and implement initiatives to engage and serve the citizens of today and tomorrow (Chang \& Kannan, 2008). Given the focus within government organizations at all levels on engaging citizens and understanding their needs and expectations an increasing emphasis on leveraging social media for government uses is understandable. Providing an empirical base for this expansion is one of the main motivations for this study (Chang \& Kannan, 2008).

This chapter is organized into two sections. The first section defines Web 2.0 and its implications. The second section describes different social media tools such as Wiki, Facebook, YouTube, and Twitter.

\subsection{Web 2.0}

As mentioned above, the term Web 2.0 was first coined at the 2004 O'Reilly Media Conference during a brainstorming session (O'Reilly, 2005). Web 2.0 refers to a collection of new technologies and the applications made possible by these technologies. Web 2.0 applications 
are interactive, web-based tools that encourage user participation in terms of content generation and distribution, collaboration, and application customization (Anonymous, 2009).

Web 2.0 is a platform where content and applications are no longer created and published by individuals or organizations, but instead are continuously modified by all users in a participatory and collaborative fashion (Kaplan \& Haenlein, 2010). Web 2.0 is considered a powerful platform for the evolution of social media. It is obvious that Web 2.0 is more than just the technology and web-based applications that allow easy online collaboration, sharing and publishing. It also represents a cultural shift to an online environment that views the Internet as a platform for services and embraces a common set of core values (e.g. collaboration, content sharing and engagement) (Anonymous, 2009). The emergence of web 2.0 and social collaborative technologies such as social networking sites, blogs, wikis, Twitter and etc. facilitate interaction between individuals with similar interests, needs and experience. It has also changed the nature of participation and engagement activities (McNutt, 2014). In this way, the Web 2.0 world is fundamentally different from the previous generation of web design and development.

Table 1 presents the primary differences between Web 1.0 and Web 2.0. Web 1.0 refers to the read only, static web page model in which content is published and controlled by site owners for users. The essential difference between Web 1.0 and Web 2.0 is that Web 2.0 relies on the concept of the user as a producer. In Web 1.0 the majority of users act only as consumers of content (Cormode \& Krishnamurthy, 2008). The focus during the first web generation was on establishing a presence on the Internet and migrating information and service delivery online. Web 2.0 as a social media platform provides two-way communication, participation and user 
engagement. As public organizations, governments have attempted to employ Web 2.0 initiatives to reinvent relationships and interactions with their citizens. As Government 2.0 (second generation e-government) is defined in reference to Web 2.0 the assumption is that a successful transition to Government 2.0 will not simply incorporate new digital tools, but that government will adopt an approach characterized by bidirectional flows of information, collaboration and engagement in contrast to Web 1.0 where information typically flowed only from the government to its clients. The concept of interaction and engagement with government has changed in the transition from Web 1.0 and Web 2.0. The bi-directional nature of Web 2.0 allows for higher levels of engagement and greater inclusion of multiple parties. Not only the amount of interaction has changed; the nature of engagement has changed as well.

Table 1- Characteristics of Web 1.0 vs. Web 2.0 (adopted from O'Reilly, 2005)

\begin{tabular}{|l|l|}
\hline Web 1.0 & Web 2.0 \\
\hline Read-only web & Read-write web \\
\hline Few authors & Everyone can be an author \\
\hline Publishing & Participation \\
\hline 1-way communications & Many to many communications \\
\hline Static web pages & Web as a service platform \\
\hline Surfing the web & Subscribing to websites \\
\hline Proprietary software & Open Source software \\
\hline
\end{tabular}

In summary, Web 2.0 facilitates interactive information sharing, user-centered design, engagement and collaboration on the web. Many governments see the Web 2.0 platform as a new 
channel for delivering services to citizens. The promise of Web 2.0 for government use lies in the idea that more direct citizen involvement leads to a more constructive view of public policies, governance and organizations (Anttiroiko, 2010). Public engagement through social media tools in the Web 2.0 era shifts social collaboration to involve more citizens in comparison with traditional (Web 1.0) online consultation tools by providing opportunities for two-way communication as well as openness, participation and collaboration (McNutt, 2014). In some circumstances these interactions could involve many to many communications and not simply two way exchanges. Especially among young individuals this type of activity is more common as they are accustomed to participating in many-sided discussions through social media tools such as Facebook. Thus, it is important to study and understand social media in the context of government attempts to capture citizens' needs and to engage them in improving citizen-centered government. Social media relies primarily on wide participation and open collaboration to facilitate public engagement. Open participation through social media connects people, provides interactive communication, and helps share their ideas. This also opens the way for collaboration to include citizen engagement in complex tasks or projects that aim to co-create specific outputs (Lee \& Kwak, 2012).

\subsection{Social Media}

Various attempts have been made to define social media. Kaplan and Haenlein (2010) defined social media as "a group of Internet-based applications that build on the ideological and technological foundations of Web 2.0, which allows the creation and exchange of user-generated content" (Kaplan \& Haenlein, 2010, p. 61). In their 2008 study Williams and Williams defined 
social media as "the online technologies and practices people use to share knowledge and opinions" that uses the "wisdom of crowds" to connect information in a collaborative manner, through different channels such as blogs, wikis and podcasts (Williams \& Williams, 2008, p. 34). Boyd (2007) offers a more wide-ranging definition:

It is the way that we are organizing ourselves to communicate, to learn, and to understand the world and our place in it. And we just won't accept any models for that that aren't intensely social: we won't put up with large organizations telling us what is right, or true, or necessary. We will now have those conversations among ourselves, here, at the edge. Social Media has released us, freed us: and we won't go back.

A historical precursor to social media can be found in Habermas' concept of a "public sphere". He argued that a bourgeois public sphere existed in the coffee houses and literary salons in Europe around the start of the $18^{\text {th }}$ century, "beyond the traditional control of feudal lords, and manifested through early newspapers, through public political debate, meeting halls, and other public spaces where participative discussion between private citizens was possible" (cited in Welch, 2006, p. 6). The concept of the public sphere beyond direct control of authorities has existed since the $18^{\text {th }}$ century, but nowadays instead of face-to-face communications we have the web as one of the main communication channels.

The underlying idea of all of these definitions is that social media is an umbrella term for different applications that utilize the platform of Web 2.0 technology and enable users to create and distribute content and participate and connect with people in a collaborative fashion. Our working definition of social media is a collection of new applications (tools) used to allow people to interact, communicate and collaborate easily with each other. This definition covers the 
main functions of social media and contains virtually all of those of interest to governments. There are a number of different social media applications with new versions appearing frequently. Some social media sites that dominate the global market in terms of social networking and user content are Facebook, LinkedIn, YouTube, Wiki, and Twitter. Cook (2008) offered some further insight into the functions of different social media. As shown in Table 2, he classified social media according to the way in which they perform four distinct functions: (1) communication, (2) cooperation, (3) collaboration, and (4) connection. However, there is significant potential for overlap among these categories. Depending on the tools or the purpose, a particular social media tool can perform more than one function (Cook, 2008).

Table 2- Social Media Classification According to Domain Function

\begin{tabular}{|l|l|l|l|}
\hline Communication & Cooperation & Collaboration & Connection \\
\hline $\begin{array}{l}\text { Discussion forum } \\
\text { (e.g. newsgroup) }\end{array}$ & $\begin{array}{l}\text { Media sharing (e.g. } \\
\text { YouTube, Flickr) }\end{array}$ & $\begin{array}{l}\text { Wikis (e.g. } \\
\text { Wikipedia) }\end{array}$ & $\begin{array}{l}\text { Social networking } \\
\text { (e.g. Facebook, } \\
\text { LinkedIn) }\end{array}$ \\
\hline $\begin{array}{l}\text { Instant messaging } \\
\text { (e.g. MSN messenger) }\end{array}$ & $\begin{array}{l}\text { Social bookmarking } \\
\text { (e.g. Del.ic.ious) }\end{array}$ & & Syndication (RSS) \\
\hline $\begin{array}{l}\text { Virtual worlds } \\
\text { (e.g. Second Life) }\end{array}$ & & & Tagging \\
\hline Blogs & & & Mashup \\
\hline $\begin{array}{l}\text { Social presence } \\
\text { applications (e.g. } \\
\text { status update in } \\
\text { Facebook and } \\
\text { Twitter) }\end{array}$ & & & \\
\hline
\end{tabular}

Communication: In performing a communication function, social media allow people to communicate with others by text, image, voice or video. Examples of tools in this category include discussion forums, instant messaging, virtual worlds, blogs and social presence 
applications. The discussion forum (e.g. newsgroup) is one of the oldest and simplest knowledge sharing technologies that allows for two-way discussion where participants can initiate, review and feed the conversation. In some organizations discussion forums operate through newer social media tools such as blogs and Wikis. Instant messaging is being used as a communication tool that allows one person to communicate with another over the Internet or an internal network in real time by using software installed on each person's computer (Cook, 2008; Bertot et al., 2012).

Social media also performs a communication function in virtual worlds (places where people meet and interact in an online environment mimicking some aspects of the real world). Second Life is one of the popular virtual worlds among young users creating their online profiles. In the virtual world, businesses hold meetings, conduct training, socialize with others and even conclude business transactions (Cook, 2008).

Weblogs (or blogs for short) are "frequently modified web pages in which dated entries are listed in reverse chronological sequence" (Herring et al., 2004, p. 1). Different federal agencies around the world have been using blogs and microblogs for various purposes (Bertot et al., 2012). Williams and Williams' study (2008) predicted blogs and RSS feeds would have the biggest impact on how organizations communicate with stakeholders. While blogs have received attention in the mainstream media, they have attracted less interest in the scholarly literature. Jackson et al. (2007) found blogging to serve both social and informational functions. They further found that one of the key functions of corporate blogging is to link "disparate, far-flung parts of the organization into constructive contact" (Jackson et al., 2007, p.8). Wright and Hinson 
(2008) found that blogs and other social media are dramatically changing public relations. Their study indicates that blogs and social media have changed the way their organizations communicate, especially to external audiences.

Social presence applications build on the concept of instant messaging between people. Stutzman (2007 as cited by Cook, 2008) suggested three kinds of social presence applications: informational (e.g. Facebook), temporal (e.g. Twitter) and a more obscure geolocational presence (e.g. Loopt). Stutzman (2007 as cited by Cook, 2008) described Twitter as an example of a temporal social presence application, but suggested it is increasingly being used for informational and geolocational purposes. Twitter describes itself as "a service for friends, family, and co-workers to communicate and stay connected through the exchange of quick, frequent answers to one simple question: What are you doing?" (Dunlap \& Lowenthal, 2009, p. 131). Miller (2008) defined Twitter as a "cross between social networking, blogging and text messaging" (p. 396). With 271 million active users in 2014 generating over 500 million tweets per day, one can find many examples of people and organizations using Twitter (Twitter, 2014). The status update feature of Facebook serves a similar role, making it perhaps the most popular micro blog today. Facebook is an example of an informational social presence application. By answering the question "what is on your mind? or providing a status update" Facebook users provide real time information for their friends and network. Today, over three-quarters (85\%) of online Canadians with a social network profile have one on Facebook (Ipsos, 2009). As of March 2013, Facebook currently has more than one billion active users (Facebook, 2014). 
Cooperation: Social media perform a cooperation function by allowing people to share content with others in structured and unstructured ways. Cook (2008) classified media sharing (e.g. YouTube) and social bookmarking (e.g. Del.ic.ious) as social media tools that illustrate the function of cooperation. Video sharing (e.g. YouTube) and photo sharing (e.g. Flickr) are popular uses of social software in consumer space. YouTube recently reported on its company website, that it was receiving more than one billion unique users each month, and that 100 hours of video are uploaded to YouTube every minute (YouTube, 2014). YouTube is a video-sharing website where users can upload, view and share video clips, including movie and TV clips, music videos, and amateur videos. They can also create channels to show their videos. Del.ic.iousis a popular example of a social bookmarking tool that allows people to post links that they find useful or interesting, either for their own private reference or to share with others (Cook, 2008).

Collaboration: Collaboration tools encourage people to work with each other on particular issues. Wikis are a popular tool in this category (Cook, 2008). A wiki is a website where anyone with access can easily contribute or modify the content. The online encyclopaedia Wikipedia is one of the best-known and largest wikis. Today, many public and private organizations use wikis to share information, experiences, and ideas. The multiple authoring capabilities of wikis make them effective tools for mass collaborative projects although their very openness can make some of the items they contain questionable in terms of accuracy and completeness. Kane at al. (2009) have argued for the importance of wikis for knowledge sharing practices in businesses and other types of organizations. It should be mentioned that wikis through rich peer-to-peer user interactions support positive elements of traditional knowledge 
management, such as suitability for business environment and avoid many of the disadvantages such as limited opportunities for simultaneous collaboration (Nath et al., 2011).

Connection: Networking technologies make it possible for people to make and maintain connections with others. Social networking is the most popular example of a connecting technology, although other technologies such as tagging, syndication and mashups can also be included in this classification. Facebook and LinkedIn are two of the most popular social networking websites. LinkedIn is described as a business-related social networking site for professionals to connect with like-minded professionals. With more than 300 million registered users from more than 196 countries and territories, organizations search this site for potential job candidates, reference checks and business leads (LinkedIn News Releases, 2014).

Syndication, also known as Really Simple Syndication (RSS), is a method of publishing timely web content, where subscribers can automatically receive updates from that particular website. RSS only provides content an individual wants to read. In business, RSS is useful for receiving notifications or updated content for news stories, blog posts, etc. (Wilson et al., 2011). Tagging is a technique employed by social software tools. Tagging is intended to make information increasingly easy to search, discover and navigate over time. The last social media tool in this category is Mashups. A mashup is "a user-driven micro integration of web accessible data" (Cook, 2008, p. 78). It makes web-based data more useful. In other words, a mashup is an application that is defined by the end user, integrated by technology in a single web interface. For example, Housingmaps.com is a mashup that applies real estate information, such as 
apartments for rent or homes for sale, from Craigslist to Google Maps. The end result is a system that lets a user sort available apartments and homes by price and location.

In this section I documented the rapid growth of social media in terms of use and popularity (Chun \& Luna Reyes, 2012; Kavanaugh et al., 2012). Social media are represented by a number of still-evolving forms, and as suggested by Cook (2008), they serve a variety of functions including communication, cooperation, collaboration, and connection. There is clearly some overlap between these categories, but the importance of social media for forming groups and maintaining interactions within them is clearly growing at a rapid pace. The proliferation of social media options provides people with more and more ways to access information. For a variety of reasons which will be discussed below, governments, as with commercial organizations, are becoming more interested in using these tools to interact with their clients. 


\section{Social Media and Government}

\subsection{Electronic Government}

Al Gore, former Vice President of the USA, said that: "In this fast-moving, fast-changing global economy — when the free flow of dollars and data are the source of economic and political strength, and whole new industries are born every day-governments must be lean, nimble, and creative, or they will surely be left behind" (Gore, 1993). This was part of the impetus that launched Electronic Government (e-government) initiatives when they were introduced in the area of Information and Communications Technology (ICT) (Hasin et al., 2011). Researchers from different disciplines, such as IS, political science, sociology and organizational studies have offered various definitions of e-government (Hasin et al., 2011). Egovernment essentially means that governments use ICTs to provide services and improve interactions with citizens, businesses and other stakeholders. However, some sources argue that the purpose of e-government goes beyond its electronic aspect since it facilitates citizen participation (changing the passive role that citizens have historically played), strengthens transparency thereby increasing accountability and leverages information technology to enhance the access to and delivery of services across government agencies (Bonson et al., 2012; Anonymous, 2009; Silcock, 2001, E-Government, 2011). It is clear that e-government programs aim to improve the operational efficiency of governments while allowing them to better serve the needs of their citizens. This can be made possible by introducing top quality, cost effective and efficient citizen-centric services (Hasin et al., 2011). 
Traditionally, the interaction between a citizen or business and a government agency took place in a government office. With emerging information and communication technologies, public service systems, governing functions, and societies are embracing a new wave of digital communities where interactions between stakeholders are conducted through ICTs. According to Internet World Stat on December 2011, 2,267,233,742 users around the world were using the Internet. Population use of the Internet has increased five hundred percent (528.1\%) since 2000 (Internet World Stat, 2012). This technology revolution is changing the way the public sector provides services and information to its stakeholders. At this time the majority of countries use or on the way to using the Internet to provide at least some access to government information on their websites. Some countries such as the USA, Canada, Singapore, UK, Finland, and Denmark are quite advanced in delivering e-government services through an integrated system where interaction among government agencies makes it possible to offer one stop service for certain interactions (Hasin et al., 2011). In Canada, the first generation of e-government was focused on modernization of traditional government processes such as the automation of basic administrative functions with the integration of new electronic channels and the production of massive websites. Later on the second generation e-government or Government 2.0 has focused more on social and political functions and democratic engagement, evidencing a greater concern with collaboration opportunities and openness (McNutt, 2014).

ICTs have been used in different ways to improve services, increase participation and empower citizens through more direct involvement in the policy making process. Governments aim to transform the way they interact with citizens by enhancing transparency, communication and participation (Abdallah \& Khalil, 2009). According to the World Bank, government 
activities that provide access to information and encourage engagement may lead to "less corruption, increased transparency, greater convenience, revenue growth, and/or cost reductions" (E-Government, 2011).

In general, e-government users include citizens, other types of residents, businesses, government employees, and other government agencies creating a diverse collection of groups that should be considered in the design, implementation and evaluation of e-government systems. As a result, there is a wide range of technical, language, and other issues involved that creates a number of challenges regarding the use of e-government services and resources. In addition, the various publics have different, often conflicting, interests that have to be considered by governments intent on employing social media (Bertot, 2003). The existing literature is mainly concerned with the issues seen from the government perspective in the adoption and use of social media in e-government. Work that examines the concerns of other points of view, for example those of users, providers or employees are notably lacking. Thus, it is important for policy makers to focus on the issues of how government can meet the needs of users and the ways they can improve citizen-centered government (Jeager \& Bertot, 2010).

\subsection{Social Media Initiatives}

A recent paradigm shift, enabled by Web 2.0 technologies, provides the potential for change from a static web presence for government information and services to using collaborative web technologies to engage citizens and employees, enabling collaboration, and encouraging transparency in government. Social media tools are creating new pathways among all stakeholders with the promise inherent in their ability to transform governance by increasing a 
government's transparency and its interaction with citizens (Wigand, 2012, Bertot at al., 2010).

The same type of transformation happened beginning with the arrival of the Internet in the 1990s. This original move to utilizing electronic means of communication had a huge impact on governmental service delivery. The new channels, embodied in the Web 2.0 platform, provide more opportunities to improve public service delivery, increase citizen satisfaction, and reduce costs for different government agencies. Some of these efforts will be described in more detail in this section (Pieterson, 2010).

The most widespread social media tools adopted by government agencies are related to communication and information sharing such as RSS feeds, Twitter, etc. (Snead, 2013). These tools are not only useful for facilitating quick communication or short messaging, but also for keeping citizens informed in terms of government activities (Anttiroiko, 2010). The other common social media tools that governments use are social networking and content sharing sites, such as Facebook, Second Life and YouTube. However, some government agencies are interested in setting up their own sites in social networking services. Among other social networking sites, Facebook has gained high popularity in the public sector, with many US and UK local governments subscribing to some services from Facebook to distribute information to their users (Anttiroiko, 2010). Wikis are also recognized as collaboration tools to share information, experiences, and ideas by different public sectors around the world (Kane at al., 2009).

Web 2.0 technologies and applications are being quickly adopted by many organizations in the public and private sectors, but governments around the world have been much slower to 
take advantage of the interactive and collaborative tools offered by Web 2.0 (Anonymous, 2009).

A Harvard Business Review Analytics Services study reports that $44 \%$ of government organizations $^{2}$ surveyed were using social media (Gillin, 2010). There are different reasons why governments have been slow in adopting social media tools. Implementation challenges addressed by researchers range from institutional barriers and technological problems through policy and legislative concerns, to employee capacity and training issues (Picazo-Vela et al., 2012). Understanding these barriers, their causes and implications is a primary task for governments. They need to determine whether these represent actual implementation barriers or are merely common perceptions; such analysis is necessary before potential solutions can be considered.

\subsection{Use of Social Media Tools by National Governments}

The benefits of using social media have been recognized by a wide range of government agencies around the world. Social media tools have been adopted by different government agencies to achieve benefits such as effective dissemination of government information, better communication, improved policy outcomes, raising awareness, better service delivery, citizen participation, transparency and openness (Picazo-Vela et al., 2012; Snead, 2013). Criado et al. (2013) defined social media in the public sector as "a group of technologies that allow public agencies to foster engagement with citizens and other organizations using the philosophy of Web 2.0". In response to this trend, U.S. President Obama issued a call for increased openness in government and on December 2009, the White House issued the federal government's Open

\footnotetext{
${ }^{2} 54 \%$ of the organizations surveyed were based in North America, 23\% were in EMEA (Europe, the Middle East and Africa); 19\% were based in Asia
} 
Government Directive which emphasizes three principles: transparency, participation and collaboration (Lee \& Kwak, 2012). The Obama administration envisions social media technologies as mechanisms that have the capacity to increase participation with government, where participation comes through the provision of user-generated content (Snead, 2013). In some countries, social media have even helped drive regime change, as we observed with the uprisings against authoritarian rule that spread across the Middle East and North Africa in 2012 (Nineteenth Annual Report to the Prime Minister on the Public Service of Canada, 2012). The British Columbia (BC) Public Service stated that by using social media tools they save citizens' time in their interactions with government and make it easier to access better quality services. They encouraged collaboration in the public service because they believe "it is integral to delivering quality service to citizens" (Citizens @ the Centre: B.C. Government 2.0, 2011). Current research (Snead, 2013; Chun \& Luna Reyes, 2012; Picazo-Vela et al., 2012; Lavender, 2013) shows that governments typically use social media as a tool to push information to the public, and to a lesser extent, to pull individuals to government websites.

According to Anttiroiko (2010), social media applications can generally be divided into two main application areas: 1) internal use and communication processes and 2) external governance and stakeholder relations. The first area mainly focuses on networking and information sharing for internal uses and work processes. One of the best-known examples is found in wikis that are used as a place to store work materials and records which facilitates collaborating and communicating with colleagues. External applications can be used to inform citizens and provide up to date information on what is happening in government, collaborate with stakeholders, and encourage feedback. RSS feeds, Twitter, social networking and content 
sharing sites are examples of media that have been employed in this manner (Anttiroiko, 2010; Mergel, 2013a).

The Government 2.0 Best Practices Wiki was created in 2008 to compile a central list of current initiatives related to government Web 2.0 projects. Wiki users responded by posting information on what their governments are doing with social media. When last visited (June 2012), the wiki had over 200 projects that employ different social media tools such as RSS feeds, Twitter, YouTube, wikis, Facebook, and Second Life among others. These were reported from government agencies in Canada, the US, Australia, New Zealand and the UK. Table 3 provides some examples of Web 2.0 initiatives by national governments.

Table 3-Example of Use of Social Media Tools by National Governments

\begin{tabular}{|l|l|l|l|}
\hline \multicolumn{1}{|c|}{ Location } & \multicolumn{1}{|c|}{$\begin{array}{c}\text { Government } \\
\text { Organization }\end{array}$} & Social Media Tools & \multicolumn{1}{c|}{ Purpose(s) } \\
\hline Australia & $\begin{array}{l}\text { Australian Government } \\
\text { Information Management } \\
\text { Office -Government 2.0 } \\
\text { Taskforce }\end{array}$ & Blog & $\begin{array}{l}\text { To increase the } \\
\text { openness of } \\
\text { government, and } \\
\text { encourage online } \\
\text { engagement }\end{array}$ \\
\hline Australia & $\begin{array}{l}\text { Australian Taxation } \\
\text { Office (ATO) }\end{array}$ & $\begin{array}{l}\text { Facebook, Twitter, } \\
\text { YouTube } \\
\text { To engage taxpayers } \\
\text { in new and innovative } \\
\text { ways }\end{array}$ \\
\hline Australia & Australian War Memorial & $\begin{array}{l}\text { Blog, Flickr, } \\
\text { Facebook, YouTube, } \\
\text { Twitter }\end{array}$ & $\begin{array}{l}\text { To share information } \\
\text { on Australia's military } \\
\text { history }\end{array}$ \\
\hline Canada & Canada Revenue Agency & $\begin{array}{l}\text { YouTube, Twitter, } \\
\text { RSS feeds }\end{array}$ & $\begin{array}{l}\text { Reach multilingual } \\
\text { audiences in an } \\
\text { alternative format }\end{array}$ \\
\hline Canada & $\begin{array}{l}\text { Citizenship and } \\
\text { Immigration Canada }\end{array}$ & $\begin{array}{l}\text { YouTube, Twitter, } \\
\text { RSS feeds, Facebook }\end{array}$ & $\begin{array}{l}\text { Raise awareness } \\
\text { around upcoming } \\
\text { legislative changes to } \\
\text { the Canadian } \\
\text { Citizenship Act. }\end{array}$ \\
\hline
\end{tabular}




\begin{tabular}{|c|c|c|c|}
\hline Location & $\begin{array}{c}\text { Government } \\
\text { Organization }\end{array}$ & Social Media Tools & Purpose(s) \\
\hline Canada & $\begin{array}{l}\text { Human Resources and } \\
\text { Skills Development } \\
\text { Canada (HRSDC) }\end{array}$ & $\begin{array}{l}\text { YouTube, Twitter, } \\
\text { Widgets, Facebook, } \\
\text { knowledge portal } \\
\text { (internal) }\end{array}$ & $\begin{array}{l}\text { Raise awareness } \\
\text { around HRSDC web } \\
\text { site }\end{array}$ \\
\hline Netherlands & $\begin{array}{l}\text { National Archive of } \\
\text { Netherlands }\end{array}$ & Flickr & $\begin{array}{l}\text { Publish historical } \\
\text { material }\end{array}$ \\
\hline New Zealand & $\begin{array}{l}\text { National Library of New } \\
\text { Zealand }\end{array}$ & $\begin{array}{l}\text { Flickr, Twitter, RSS } \\
\text { feeds, Blog }\end{array}$ & $\begin{array}{l}\text { To enrich the cultural } \\
\text { and economic life of } \\
\text { New Zealand }\end{array}$ \\
\hline United States & $\begin{array}{l}\text { US Agency for } \\
\text { International Development } \\
\text { (USAID) }\end{array}$ & $\begin{array}{l}\text { YouTube, Twitter, } \\
\text { RSS feeds, Facebook }\end{array}$ & $\begin{array}{l}\text { Raise awareness and } \\
\text { stay connected }\end{array}$ \\
\hline United States & The White House & $\begin{array}{l}\text { YouTube, Twitter, } \\
\text { Google+, Facebook, } \\
\text { Flickr, LinkedIn, } \\
\text { Vimeo, iTunes }\end{array}$ & $\begin{array}{l}\text { Raise awareness and } \\
\text { stay connect }\end{array}$ \\
\hline United Kingdom & $\begin{array}{l}\text { The power of Information } \\
\text { Taskforce }\end{array}$ & Blog & $\begin{array}{l}\text { Better use of data that } \\
\text { government holds and } \\
\text { setting out how much } \\
\text { further the } \\
\text { government has to go } \\
\text { to capitalise on these }\end{array}$ \\
\hline United Kingdom & $\begin{array}{l}\text { National } 10 \text { Downing } \\
\text { Street }\end{array}$ & E-petition & $\begin{array}{l}\text { Hosted on the } \\
\text { Downing Street } \\
\text { website, E-Petition } \\
\text { enables citizens, } \\
\text { charities and } \\
\text { campaign group to } \\
\text { address and deliver a } \\
\text { petition directly to the } \\
\text { Prime Minister. }\end{array}$ \\
\hline Sweden & Swedish embassy & Second Life & $\begin{array}{l}\text { To create an } \\
\text { information portal for } \\
\text { Sweden }\end{array}$ \\
\hline Japan & $\begin{array}{l}\text { Ministry of Foreign } \\
\text { Affairs }\end{array}$ & Twitter and Facebook & To deliver latest news \\
\hline
\end{tabular}


Web 2.0 opens a horizon towards post-modern governance. The traditional relationship between government and citizens is changing now with innovations enabled by instantaneous communication and collaboration technologies. Citizens want a greater role in public policy development and in the design and delivery of services. They demand greater access to government data and more openness and transparency from their institutions (Nineteenth Annual Report to the Prime Minister on the Public Service of Canada, 2012; Anttiroiko, 2010). Currently in Canada, social media tools are being used for different purposes (e.g. communication, outreach, engagement, collaboration, etc.). Following the example of United States President Barack Obama in his 2009 campaign, social media are now an integral part of election campaigns in Canada as in many other countries. Politicians are using Facebook and Twitter to interact with voters, and more particularly as a way to connect with younger voters known as being tech savvy. For the election of 2011, the Conservative Party launched Torynation.ca (lanationbleue.ca in French), a private social network where supporters can find friends in their riding, organize events, get talk-radio and letter-writing talking points and create fundraising campaigns. At nearly the same time, the New Democratic Party launched its iPhone app, from which voters could follow the campaign. Besides politicians, there is a growing number of Canadians who use social media platforms to express their political views.

Snead (2013) studied 25 executive agencies' uses of social media and public participation with social media in the U.S. from which they identified the seven most common types of social media tools including: Twitter, Facebook, podcasts \& video, RSS feeds, YouTube, and Flickr. The results show that individuals do interact with government websites and use social media to stay informed about government activities (Snead, 2013). Studies also find that governments 
employ social media to communicate official agency interests, for professional development and for personal use. In the United States, an Open Government Working group has been set up to publish government information (Lee \& Kwak, 2012; Snead, 2013). Similar to the U.S., Canada joined the International Open Government Partnership on April 18, 2012. Open government in Canada includes providing an online presence for departments and agencies that serve the public (Canada Joins International Open Government Partnership, 2012). Many other countries are exploring or are close to launching social media strategies (Wigand, 2012). The United States, the United Kingdom, Australia and New Zealand all have open data initiatives. In Canada, a number of cities have adopted an open data approach including Vancouver, Edmonton, Ottawa, and Toronto. At the federal level, innovative tools such as Working in Canada and CanLearn.ca proved to be valuable to Canadians and newcomers to Canada by proactively making information easier to find and more accessible, using the Web 2.0 technologies (Anonymous, 2011). The next section will provide more specific examples regarding social media use in the government of Canada.

\subsection{Social Media Initiatives in the Government of Canada}

In 2010, the Canadian Internet use survey conducted by Statistics Canada found that $80 \%$ of individuals aged 16 years and older used the Internet for personal use. Currently, over half of Canadians (54\%) visit a social media site such as Facebook, Twitter, Pinterest, etc. every day. Not only social media sites are popular, but $26 \%$ of Canadians go online everyday to find information or to discuss policy/social/political issues (Colledge, 2013). Regionally, Internet usage has increased in every province since 2005 . British Columbia with $86 \%$ is the highest 
followed by Alberta 84\% and Ontario 81\% (Individual Internet use and E-commerce, 2010). A study by Phoenix Strategic Perspective Inc. (2009) mentioned that urban-rural differences in Internet use continue, but cities with a younger demographic, and a more educated and higher earning population are strong predictors of Internet activity. Government efforts to connect rural and remote Canada to the Internet appear to be having a positive impact. Overall, Canadian Internet users are increasing every day and Canadians spend a considerable amount of time online (Anonymous, 2009).

As new technologies are integrated into daily life, citizens want them employed to provide easy and timely access to government services through the Internet. Social media technologies are shifting organizations towards a work culture based on co-production, open communication, and collaboration. These tools also can provide information about user needs, opinions, expectations, behaviours and characteristics (Chun \& Luna Reyes, 2012). In the same manner, the Government of Canada has begun to adapt to and make better use of social media tools. However, they can do more to take full advantage of the opportunities that social media tools present for more efficient service delivery, faster knowledge and information sharing, and more effective collaboration. The Harper government has stated that social media are going to be used to reach out to Canadians, especially younger Canadians who are familiar with these newer media. The main idea for the proposal is to fully engage citizens in a two-way dialogue and to encourage public participation (Rubin, 2012).

In adapting to meet these new realities, in 2013, the Treasury Board of Canada Secretariat (TBS) released two very important documents including a policy on Acceptable Network and 
Device Use and a Standard on Social Media Account Management. This was to ensure consistent and efficient use of electronic networks to support communication and collaboration and to enable a comprehensive strategic approach for the management of Government of Canada official social media accounts (Standard on Social Media Account Management, 2013). Prior to that, in November 2011, Treasury Board of Canada Secretariat released its guidelines for the external use of Web 2.0. The guidelines addressed three uses of Web 2.0 tools and services by public servants: official use, professional use, and personal use. These guidelines were intended to help organizations develop their own standards for employee use of Web 2.0 tools and services. Tony Clement, president of the TBS suggested that the use of new Web 2.0 tools and technologies such as blogs, wikis, Facebook, Twitter and YouTube creates a more modern, open and collaborative workplace and leads to more just-in-time communication with the public. These tools and services provide additional channels for interaction acting as modern town halls. They can be used for various purposes such as recruitment, crisis communications, service delivery, stakeholder outreach and as tools for collaboration and consultation (Clement, 2011). As stated on the TBS website "effective communication and quality service delivery are key priorities for Canadians and the government of Canada" (Standard on Social Media Account Management, 2013).

This approach was supported in a report to the Prime Minister on the public service of Canada from the Clerk of the Privy Council and Secretary which argued that the Canadian government has made some real progress in their campaign to modernize the way public servants work and how they serve Canadians (Nineteenth Annual Report to the Prime Minister on the Public Service of Canada, 2012). For example, more than 80 federal organizations use Web 2.0 
technologies and social media to share accurate and timely information or to collect data and engage with citizens. The Canada Border Services Agency (CBSA) uses Facebook, YouTube and Twitter to engage directly with citizens on border-related issues. The Agency has even created Twitter accounts for all ports of entry, making it faster and more efficient for Canadians to receive border wait-time updates. Moreover, the Government expanded its commitment to Open Government through three main streams: Open Data (making greater amounts of government data available to citizens), Open Information (proactively releasing information about Government activities) and Open Dialogue (expanding citizen engagement with Government through Web 2.0 technologies) (Nineteenth Annual Report to the Prime Minister on the Public Service of Canada, 2012). These initiatives are also supported in the Action Plan that will be implemented over the next three years (Canada Joins International Open Government Partnership, 2012).

In 2007-2008, 23 federal departments and agencies participated in a project to assess the potential use of social media tools for government communications. According to the results of a qualitative research project conducted by Phoenix Strategic Perspective Inc. for Agriculture and Agri-Food Canada, participants felt that government should use applications appropriate to specific needs, determined on a case-by-case basis (Anonymous, 2008). The study found that Canadians are aware of most Web 2.0 tools but are less likely to use them than the Internet in general. However, people aged 16 to 24 use social networking sites, music and video sharing sites twice as much as older age groups. In this study respondents supported the idea that the use of social media tools (such as YouTube, Facebook or blogs) would provide more convenient and faster access to government information and technologies. In conclusion, 87 percent indicated 
support for government investment in Web 2.0 technologies to communicate with and provide services for citizens. According to this research, not only was raising awareness of the Government of Canada's use of these types of applications seen to be of central importance, but also informing Canadians about new ways to use non-traditional channels of communication is needed (Anonymous, 2009). Other than this general survey, there is relatively little quantitative research regarding Web 2.0 use among Canadians and most of the available data are not comparable because they have different audiences and measure the use of different tools (Anonymous, 2009).

Since 2008, several federal departments have launched social media initiatives to engage Canadians. For instance, the Public Health Agency of Canada (PHAC) has been very active on Facebook, Twitter and YouTube. During the 2009 H1N1 pandemic, PHAC registered 50,000 Facebook referrals to its official website and 35,000 mobile devices accessed the PHAC site. Web 2.0 is also used in certain departments for recruitment. Natural Resources Canada uses Facebook to post job openings and to provide guidance to applicants. Health Canada's DrugsNot4Me Campaign, a youth drug prevention campaign, under the National Anti-Drug Strategy, is the first Government of Canada campaign to target 13 to 15 -year olds using social media tools, including Facebook, Twitter and YouTube. This campaign promotes peer-to-peer dialogue regarding the harmful effects of drugs and how to say "no." The response rate from youth was very positive (over 647,500 visits to the DrugsNot4Me site, 45,000 fans of its Facebook page and 97,000 YouTube viewings) (Eighteenth Annual Report to the Prime Minister on the Public Service of Canada, 2011). 
In terms of internal use, the Government of Canada is taking advantage of these new social media tools. For instance, GCpedia, a government-wide wiki, which was launched in 2008, is accessible to 250,000 employees in more than 150 departments and agencies. It serves to share information, experiences and ideas and enhance the agility and breadth of consulting within horizontal functional communities (GCpedia, 2013). Public servants use GCpedia primarily for information sharing, feedback gathering and building collaborative environment. GCpedia works to build support networks across a wide range of topics. Table 4 presents some examples of different social media tools currently being used by the government of Canada.

Table 4-Example of Social Media Initiatives in the Government of Canada

\begin{tabular}{|l|l|l|l|}
\hline $\begin{array}{l}\text { Department/ } \\
\text { Agency Name }\end{array}$ & Business Driver & $\begin{array}{l}\text { Objectives (Internal and } \\
\text { External) }\end{array}$ & $\begin{array}{l}\text { Social Media } \\
\text { Channel(s) Used }\end{array}$ \\
\hline $\begin{array}{l}\text { Agriculture and } \\
\text { Agri-Food } \\
\text { Canada } \\
\text { (AAFC) }\end{array}$ & $\bullet$ Collaboration & $\begin{array}{l}\text { Internal: Facilitate } \\
\text { communication and } \\
\text { collaboration }\end{array}$ & $\begin{array}{l}\text { Internal: AgriWiki, } \\
\text { AgriForum, Blog }\end{array}$ \\
& $\begin{array}{l}\text { External: Provide timely and } \\
\text { relevant news efficiently via } \\
\text { RSS. } \\
\text { Facilitate communication and } \\
\text { collaboration }\end{array}$ & External: RSS Feeds \\
\hline $\begin{array}{l}\text { Canada } \\
\text { Revenue } \\
\text { Agency (CRA) }\end{array}$ & $\begin{array}{l}\bullet \text { Collaboration } \\
\bullet \text { Outreach }\end{array}$ & $\begin{array}{l}\text { Internal: training, learning, } \\
\text { collaboration }\end{array}$ & $\begin{array}{l}\text { Internal: Wiki } \\
\text { External: Twitter } \\
\text { (@CanRevAgency) } \\
\text { YouTube- } \\
\text { CanRevAgency } \\
\text { RSS Feeds }\end{array}$ \\
\hline $\begin{array}{l}\text { Foreign Affairs } \\
\text { and } \\
\text { International } \\
\text { Trade Canada } \\
\text { (DFAIT) }\end{array}$ & $\begin{array}{l}\text { External: Reach multilingual } \\
\text { audiences in alternative format }\end{array}$ & $\begin{array}{l}\text { Collaboration } \\
\text { Communication }\end{array}$ & $\begin{array}{l}\text { Internal objective: collaboration } \\
\text { Facebook } \\
\text { Twitter } \\
\text { YouTube Channel } \\
\text { RSS Feeds }\end{array}$ \\
\hline
\end{tabular}




\begin{tabular}{|c|c|c|c|}
\hline $\begin{array}{l}\text { Department/ } \\
\text { Agency Name }\end{array}$ & Business Driver & $\begin{array}{l}\text { Objectives (Internal and } \\
\text { External) }\end{array}$ & $\begin{array}{l}\text { Social Media } \\
\text { Channel(s) Used }\end{array}$ \\
\hline $\begin{array}{l}\text { Health Canada } \\
\text { (HC) }\end{array}$ & - Engagement & $\begin{array}{l}\text { External: Citizens' engagement } \\
\text { Internal: employee engagement, } \\
\text { collaboration }\end{array}$ & $\begin{array}{l}\text { External: Twitter, } \\
\text { YouTube, Facebook } \\
\text { (DrugsNot4me, } \\
\text { HealthyCanadians) } \\
\text { Internal: Wiki }\end{array}$ \\
\hline $\begin{array}{l}\text { Human } \\
\text { Resources and } \\
\text { Skills } \\
\text { Development } \\
\text { Canada } \\
\text { (HRSDC) - } \\
\text { Working In } \\
\text { Canada }\end{array}$ & $\begin{array}{l}\text { - Overseas and } \\
\text { local outreach } \\
\text { - Increased } \\
\text { product usage } \\
\text { and awareness } \\
\text { among target } \\
\text { audience } \\
\text { - Attributing } \\
\text { outreach } \\
\text { activities to } \\
\text { results }\end{array}$ & $\begin{array}{l}\text { External: To increase client } \\
\text { traffic to the Working in Canada } \\
\text { website, to better understand the } \\
\text { target population, to increase } \\
\text { client knowledge of the subject } \\
\text { matter, and to continuously } \\
\text { improve Working in Canada's } \\
\text { online presence. }\end{array}$ & $\begin{array}{l}\text { Facebook (working in } \\
\text { Canada) } \\
\text { Twitter- } \\
\text { @workingincanada } \\
\text { YouTube } \\
\text { Widgets } \\
\text { Mobile }\end{array}$ \\
\hline $\begin{array}{l}\text { Natural } \\
\text { Resources } \\
\text { Canada } \\
\text { (NRCan) }\end{array}$ & • Recruitment & $\begin{array}{l}\text { External: To drive traffic to the } \\
\text { NRCan career site, to promote } \\
\text { on campus events and job } \\
\text { postings }\end{array}$ & $\begin{array}{l}\text { Twitter } \\
\text { (@NRCanjobs) } \\
\text { Facebook-Natural } \\
\text { Resources Canada- } \\
\text { Jobs }\end{array}$ \\
\hline $\begin{array}{l}\text { Public Health } \\
\text { Agency of } \\
\text { Canada } \\
\text { (PHAC) }\end{array}$ & $\begin{array}{l}\text { - Outreach } \\
\text { - Crisis } \\
\text { communications }\end{array}$ & $\begin{array}{l}\text { External:Improve reach } \\
\text { Build relationships } \\
\text { Understand the opinions of } \\
\text { Canadians and fine tuning the } \\
\text { social media communications } \\
\text { approach } \\
\text { Correct misinformation and } \\
\text { Understand the impact of PHAC } \\
\text { Communication approaches }\end{array}$ & $\begin{array}{l}\text { Facebook (public } \\
\text { health agency of } \\
\text { Canada) } \\
\text { Twitter@PHAC_GC } \\
\text { YouTube Channel } \\
\text { RSS Feeds } \\
\text { Widgets } \\
\text { Mobile }\end{array}$ \\
\hline Veteran Affairs & $\begin{array}{l}\text { - Outreach } \\
\text { - Marketing }\end{array}$ & $\begin{array}{l}\text { External:To engage Canadians } \\
\text { in remembrance }\end{array}$ & $\begin{array}{l}\text { Facebook (Canada } \\
\text { remembers) } \\
\text { YouTube (Canada } \\
\text { remembers) } \\
\text { Twitter } \\
\text { (@VeteransENG_CA) } \\
\text { RSS Feeds }\end{array}$ \\
\hline
\end{tabular}


According to preliminary analysis, the use of social media tools in the context of government-citizen relations mainly focuses on outreach, citizens' engagement, public education, service delivery, consultation, recruitment, and communications. Research suggests that external use of social media tools and services can act as an efficient and effective additional channel to interact with citizens (Anonymous, 2008). For example, currently Citizenship and Immigration Canada (CIC) is using Twitter to distribute press releases and messaging around certain departmental campaigns, e.g., Citizenship Week. They are looking at what is involved in answering questions from their followers to get more feedback.

There is a suggestion that users should be engaged as co-developers and real-time testers for assessing new products and services (Mergel, 2011). The same argument can apply when a government decides to introduce new products and services by using social media. The agency can actively monitor how the product or service is working in the actual world (O'Reilly, 2006). Social media can help governments monitor the public environment and provide insight about what kinds of conversations are taking place concerning their organization/program/service. Knowing this helps government set communications goals and objectives, determine which social media tools may best serve their purposes and choose the right language to get the message across. Social media monitoring complements other more formal monitoring tools such as public opinion research and helps identify concerns, interests, and information gaps related to the program (Anonymous, 2009).

In terms of the internal use of social media tools, collaboration, knowledge sharing and employee engagement are the primary objectives. Public managers use wikis as collaborative 
tools to improve information sharing and to distribute capacities across organizational boundaries and hierarchies (Chang \& Kannan, 2008; Mergel, 2011). Table 5 summarizes four functions of social media tools according to Cook's (2008) classifications and presents the objectives of stakeholders by using social media tools. As mentioned above Cook sees the most important functions of social media as including (1) communication, (2) connection, (3) collaboration, and (4) cooperation. Although each of these is conceptually distinct, there is potential for substantial overlap among these concepts both in theory and in practice. Depending on the social media tools or the purposes for which they are deployed, a particular tool can have more than one function (Cook, 2008). This uncritical use of these terms can create confusion in understanding the use and importance of social media tools.

- The communication function allows citizens, employees and governments to communicate with each other through text, image, voice, video, or a combination of media. Examples include Twitter, discussion forums, blogs, instant messaging, social presence, and virtual worlds. These channels provide opportunities for government to have effective communication with its clients, reach out to citizens, and provide information services for the public.

- Connection enables citizens, employees and governments to network with each other through websites such as Facebook and LinkedIn. Connection tools provide for information sharing among employees and citizens, engagement within and across groups, participation and recruitment. 
- Collaboration tools encourage citizens, employees and governments to directly or indirectly work together. An example of a social media facilitation collaboration tool can be found in wikis. The main objectives behind collaboration tools are knowledge sharing, engagement and participation among stakeholders.

- Cooperation enables citizens, employees and organizations to share content with others in structured and unstructured ways, as well as training opportunities, for instance through image and video sharing. Cooperation involves sharing information that allows associated groups to make decisions on future actions.

Table 5-Social Media Tools and Their Implications for Government

\begin{tabular}{|l|l|}
\hline Functions & Objective \\
\hline Connection & $\begin{array}{l}\text { Information services, employee and citizen engagement, participation, } \\
\text { recruitment }\end{array}$ \\
\hline Collaboration & $\begin{array}{l}\text { Work place collaboration, knowledge sharing, employee and citizen } \\
\text { engagement, participation }\end{array}$ \\
\hline Communication & $\begin{array}{l}\text { Crisis communication, effective communication, outreach, } \\
\text { information services }\end{array}$ \\
\hline Cooperation & Information services, Information sharing \\
\hline
\end{tabular}

Even though the concept of Web 2.0 is relatively new, similar applications have been used in the public sector for some time. For example, discussion forums are examples of early forms of e-democracy that emerged around the mid-1990s and reflect the basic ideas behind Web 2.0. It was some years later in the mid-2000s that Web 2.0 emerged with two dimensions: a technology dimension focused on new trends in web technologies and a social dimension reflecting the vision of an active and constructive role for users in public service processes (Anttiroiko, 2010). The social dimension is about content creation, peer-to-peer interaction, 
collaboration and exchange of user-generated content over the Internet. Web 2.0 technology enables collaborative value creation among users and creates dynamic new services and business models for the public and private sectors (Nath et al., 2011).

The rapid pace of technological change is altering how citizens expect to interact with government and access government services. Although governments around the world have been much slower than the private sector to take advantage of the interactive and collaborative tools offered by Web 2.0, the development of citizen-centered e-government has been considered by different bodies and preliminary initiatives have been adopted. Citizen-centered e-government means that governments are able, in theory, to provide services and resources tailored to the actual needs of citizens (Anonymous, 2011). Realizing this goal will not be possible without uncovering public attitudes, involving citizens in the development of such systems and monitoring users' reactions to their deployment. It is important for governments to understand what kinds of conversations are taking place about their products or services. Knowing this helps them design new programs/products/services involving social media platforms in their delivery. In general, citizens want easy and timely access to government services. In addition to the powerful forces of demographics, fiscal pressures, technological change and shifting citizens' expectations, the application of new technologies to deliver better services to support citizens and help them meet their needs can require systematic changes. The rise of collaborative social media is changing the way citizens interact with each other, with organizations and with information. Nowadays, more and more citizens are becoming active participants in public conversations in addition to being consumers of services (Citizens @ the Centre: B.C. 
Government 2.0, 2011). Thus far these efforts are limited by a lack of research on what the various stakeholders want from social media-delivered services.

\subsection{Benefits Associated with Social Media}

By allowing and encouraging users to generate content, Web 2.0 technologies have helped create a new public sphere where people and organizations are able to engage beyond local and national frontiers. In this context the public sphere has expanded to include a virtual community with permeable boundaries in which citizens can provide their opinions to their government and participate in decision making by having open discussion through using social media tools. Social media are not about technologies but more about relationships. These relationships, built into communities of practice ${ }^{3}$, blogs and others virtual groups, generate and enhance collaboration and knowledge sharing for the benefit of individual citizens, private, public and not-for-profit organizations (Kaplan \& Haenlein, 2010).

As public organizations, governments in many democratic and economically advanced nations have implemented social media initiatives to reinvent their relationships and interactions with citizens and with other organizations. In using social media, governments have different purposes such as reaching out to citizens and other stakeholders (Chang \& Kannan, 2008; Dorris, 2008), sharing information within and across government agencies (Chang \& Kannan, 2008;

\footnotetext{
3 “'Community of Practice' is a special term that was coined to refer to certain forms of social organization in the workplace" (Nickols, 2033, p.2).
} 
Dorris, 2008; Picazo-Vela et al., 2012), increasing government transparency (Bonson et al., 2012; Picazo-Vela et al., 2012; Bertot et al., 2010) and enhancing citizens' participation (Bonson et al., 2012; Picazo-Vela et al., 2012; Chun \& Luna Reyes, 2012). Many governments see social media as a new channel for delivering information and services to citizens (Fyfe \& Crookall, 2010). Social media tools can provide information about citizens' opinions, interests, intentions, behaviours and characteristics. This change is also considered a "technological innovation and a transforming agent in generating citizen engagement from campaigns and grassroots-activism to shared governance promoting democracy" (Chun \& Luna Reyes, 2012). Social media are recognized as a conferring a strategic advantage for innovation and revolution in government by bringing new communication channels between governments and citizens (Chun \& Luna Reyes, 2012).

Some of these potential benefits relate to advantages governments might gain while others relate to employees' and citizens' concerns. The following section will review some of the more widely perceived benefits from these perspectives.

Perspective of the Organization: The following section will highlight some of the benefits that have been mentioned by researchers, including interacting with and improving services to citizens, citizens' engagement and participation, innovation, collaboration, recruitment, effective communication, increased transparency and positive public relations, that can help generate political efficiency and increase public trust (Kavanaugh et al., 2012).

Interacting with citizens and improve service delivery: Some theorists have argued that a citizen-centric approach is essential for modern governments. To move toward citizen-centric 
approach governments need to interact with their citizens to understand their needs and expectations. Social media tools provide a flexible platform for making the interactive connections implied by this aspect of e-government. The main objective is to deliver services effectively and efficiently with the provision of timely information to facilitate informed decision-making by citizens (Picazo-Vela et al., 2012; Anonymous, 2011; Bertot et al., 2012; Kavanaugh et al., 2012). Governments around the world are experimenting with social media tools to improve service delivery (McNutt, 2014). As suggested by Bertot et al. (2012), coproduction of government services and programs is one of the key opportunities that social media can offer government. Co-production in which government and citizens jointly develop, design and deliver government services can improve quality, delivery and responsiveness (Bertot et al., 2012).

Citizen's engagement and participation: Social media can open the door to public engagement. Public engagement can enhance the government's effectiveness, improve the quality of its decisions and help develop effective public policy responses. Governments can harness this interest to produce policies that are better understood, more broadly supported and more effective. This has the potential to improve the political image of governments through better feedback, better collaboration and engagement, legitimizing their decisions and giving them more credibility (McNutt, 2014; Nam, 2012; Picazo-Vela et al., 2012). Mergel (2013b) in her study found that the second most frequently mentioned objective for maintaining social media accounts by government departments and agencies in the USA is citizen engagement. Besides providing information to the public, governments actively seek feedback from citizens through social media tools (Mergel, 2013b). Nam (2012) argued citizens' participation and 
engagement may help governments obtain legitimacy and political support when adopting new policies or testing novel objectives.

Innovation: As suggested by Tapscott and Williams (2006), corporations that change traditional top-down organizational structures through the introduction of social media tools will ultimately speed innovation by increasing employee participation. On the other hand, according to a recent study of social media adoption in the U.S. federal government, all social media directors acknowledged that the use of social media brings innovation for government that is driven by audiences' behaviour (Mergel, 2013a). Citizens can provide governments with novel and innovative ideas on a given topic. Their behaviour, knowledge and skills outside government when combined with employees' knowledge can contribute to problem solving through their feedback by contributing suggestions and offering expertise. Government agencies can observe stakeholders' behaviour online and react to their needs and interests by using social media as a new preferred information channel (Nam, 2012; Mergel, 2013a).

Collaboration: Many have argued that social media enhance the potential for collaboration. Collaboration between government and citizens indicates a higher level of engagement in a joint relationship by allowing them to directly engage with government content and co-create government innovations (Mergel, 2013b). As the results of Mergel's study show, reciprocated feedback and interaction with citizens are highly desirable goals for government senior management leading them to focus their future use of social media on becoming more collaborative (Mergel, 2013b). 
From an internal perspective, the effective utilization of social media lies in the development of inter-organizational networks between government agencies that facilitate knowledge sharing. Internal collaboration can help employees connect across functional branches and different geographic locations. Cross-agency collaborations, which have remained very difficult in many government settings even though many public sector employees value networks that allow them to share experiences, and interact with other people at other levels and in agencies outside their own (McNutt, 2014; Picazo-Vela et al., 2012). Intellipedia is an online system for collaborative data sharing used by the United States Intelligence Community (IC). It was established as a pilot project in late 2005 and formally announced in April 2006 and consists of three wikis running on JWICS ${ }^{4}$, SIPRNet ${ }^{5}$, and Intelink-U (Keyes, 2013). The Government of Canada is also taking advantage of these new tools, for instance, with GCpedia, a governmentwide wiki that was launched in 2008 to connect federal public servants (Fyfe \& Crookall, 2010).

Another example of this type of outreach is Patient Opinion, which has been set up as an independent mediator of both the National Health Service (NHS) in the UK and the government with the intent of building trust among service users (Anttiroiko, 2010). The NHS is interested in improving its service by utilizing the experiences and opinions of its users. In Patient Opinion, patients and carers can find what others think of local hospitals, hospices and mental health services. People can also share stories concerning what happened to them or their family members when they were ill. One of the main benefits of social media collaboration, which is especially relevant in this instance, is their reach across geographical boundaries. The fact that

\footnotetext{
${ }^{4}$ Joint Worldwide Intelligence Communications System (JWICS)

${ }^{5}$ Secret Internet Protocol Router Network (SIPRNet)
} 
they do not require real time communication and are increasingly portable facilitates timely interaction and feedback.

Recruitment: Natural Resources Canada (NRCan) started a pilot project in 2010 regarding the use of social media for recruitment. Their main goals were to enhance the perception of Natural Resources Canada (NRCan) as an employer of choice, to increase the number of qualified applicants for positions in the department and to build a network of online partners who are using LinkedIn and are willing to help promote the NRCan job postings and events on their faculty or university LinkedIn profile. The results suggested by the growth in followers indicates a continuing interest by job seekers in having information relevant to them available via social media tools. As a result an open forum has developed that allows the department to provide information to specific individuals as well as interested parties that may have similar questions about a job posting or event (Anonymous, 2010). The effectiveness of these approaches are, however, limited by legal restrictions on direct interaction with applicants through social media.

Effective communication/two way communications: Government officials seek to leverage social media resources to improve services and communication with citizens (Bertot et al., 2012). Social media tools have moved organizations from utilizing static communication channels with no interaction to two-way communication channels (Lavender, 2013). These provide direct communication between citizens and governments in a more friendly way. Participants in a study by Picazo-Vela et al. (2012) agreed that social media allowed better communication between the government and its citizens as well as enhancing trust and democracy. 
Another study by Phoenix Strategic Perspective Inc. (2009) suggested that social networking sites, especially Facebook in the Canadian context, could be a good tool for government to communicate with citizens, particularly youth who are more likely the main users of these sites and women over 55 years who currently are the fastest growing demographic on Facebook (Anonymous, 2009).

Increased Transparency: Citizens want greater access to government data and more openness and transparency from their institutions. (Nineteenth Annual Report to the Prime Minister on the Public Service of Canada, 2012, Anttiroiko, 2010). Basically, transparency provides information for citizens about what their government is doing (Mergel, 2013b). For the purpose of this study, transparency is interpreted as the broadcasting of government information through social media channels. One of the important goals of government is to increase transparency by voluntarily releasing government information through other than traditional channels (Mergel, 2013b). In this regard, some governments aim to transform the way they interact with citizens by enhancing communication via different social media channels and participation (Abdallah \& Khalil, 2009). These efforts can be limited by internal resistance to transparency initiatives in government use of social media. Such concerns, especially as they refer to security and confidentiality are not unusual and may be the basis of onerous restrictions on the release of information or even the use of social media by government employees. Without a significant change in organizational culture the objective of increased transparency is likely unachievable (Bertot et al., 2010). Despite these difficulties social media are creating new pathways among all stakeholders with the promise inherent in their ability to transform governance by increasing a government's transparency and its interaction with citizens (Wigand, 
2012; Bertot at al., 2010). Increased transparency is important because, as suggested by the World Bank, governments that encourage citizens' engagement might have less corruption, more transparency, and greater convenience (E-Government, 2011).

Perspective of employees: Government employees use social media for official government interests, professional development and personal use. The following section will highlight some of the benefits for employees that have been mentioned by researchers, including knowledge sharing and workplace collaboration, employee participation, and enhanced productivity (Hrdinova et al., 2010). However, the literature examining the perspective of employees is still quite limited.

Research suggests that social media have the potential to enhance collaboration and knowledge sharing. Some agencies value the potential opportunities for professional development for employees through collaborative, educational and knowledge sharing activities promoted by open access to social media tools (Picazo-Vela et al., 2012; Hrdinova et al., 2010; McNutt, 2014). While some have argued that the use of social media during office hours leads to productivity losses, others claim that the adoption of social media in their organizations has led to increased productivity through work efficiencies (HR Focus, 2010; Cook, 2008). Cook (2008) also suggested that social media tools such as wikis, RSS and blogs can enhance productivity by providing workplace collaboration opportunities for employees. A multi-country study conducted by the Harvard Business School found that firms with superior information technology reported greater growth, leadership and productivity (Iansiti et al., 2006). An example of a social media knowledge sharing tool is the GCpedia that is accessible to all 
government employees to share information, experiences and ideas and enhance employees' productivity. Employees use GCpedia for knowledge sharing and gather feedback and build collaborative and interdepartmental communities of practice (GCpedia, 2013).

Perspective of Citizens: This section will present some of the benefits that have been mentioned by researchers, such as citizens' participation and engagement, two-way communication and greater sharing of ideas and concerns that lead to increased awareness. By using social media tools, governments can communicate more efficiently with their publics, saving money and resources, than when using traditional communication methods (Kavanaugh et al., 2012; PicazoVela et al., 2012).

Citizen's participation and engagement: Social media can open the door to more intense citizen engagement with various levels of government. Most likely, the notable potential impact of social media tools on government is increasing citizen participation (Mergel, 2013b; Anonymous, 2009). As suggested by Picazo-Vela et al. (2012) based on the study from 250 public servants from central Mexico, developing a culture of citizen participation is one of the main benefits to be derived from implementing social media in the public sector. There is general agreement in the literature that citizens' engagement will improve the citizen-government relationships and facilitate policy implementation. It can strengthen the links between governments and their constituents, improve the quality of government decisions, develop effective public policy responses and smooth the conventional tension between those who govern and the governed (Nam, 2012; Kavanaugh et al., 2012; Picazo-Vela et al., 2012). Advocates argue that social media adoption will result in greater collaboration allowing governments to 
understand and use citizens' interests to produce policies that are better understood, more broadly supported and more effective.

Two-way communication: An important aspect of increased citizen engagement through the use of social media tools lies in their ability to provide direct channels of communication between citizens and their government (Picazo-Vela et al., 2012). Nowadays, citizens rely more and more on social media for communication with their family, friends, colleagues, businesses, and government (Kavanaugh et al., 2012). Social media tools, unlike more traditional media such as newspaper or radio, provide opportunities for instant two-way communication between government and citizens. Citizens are able to directly post audio, video, and text to government social media sites and receive feedback from government spokespeople (Hrdinova et al., 2010). As mentioned earlier government officials also seek to leverage social media tools to improve service delivery and better communication with citizens (Bertot et al., 2012).

\subsection{Possible Challenges/Barriers Associated with Social Media}

Although, the adoption of social media may bring important benefits for government, the implementation process also poses some challenges and barriers. Some of these barriers relate to organization (e.g. organizational culture), technology (e.g. security), policy, and legislative issues (e.g. privacy).

\section{Institutional Challenges/Barriers:}

Organizational culture: The organizational culture of government is an important challenge for the utilization of social media in promoting the open government concept. 
Although there have been some changes made recently, the typical government culture can still be characterized as hierarchical, top-down, command-and-control, composed of virtually independent siloes and populated with risk averse managers. Without shifting the organizational culture towards more openness and transparency, successful implementation of social media initiatives seems unachievable (Lee \& Kwak, 2012; Bertot et al., 2010). As suggested by McNutt (2014) there are still numerous barriers to public service implementation, "layering old managerial approaches and institutional cultures onto new digital media will not enhance public engagement even if it does expand communication capacity" (McNutt, 2014, P. 53).

Creating and sustaining public engagement: An important challenge in capitalizing on the potential advantages of social media is creating and sustaining public interest and engagement. Even though they may employ different social media tools, governments should not presume that citizens would automatically participate if they build venues for citizens to access government information and services. Moreover, when public engagement opens up discussion, it is possible for such conversations to get out of control or go in unexpected directions. If the government tries to limit public comment tightly, participation will likely decline over time. This may also result in negative publicity as the government is seen to be stifling debate. As a result, keeping the right balance between control and autonomy in public engagement is an important issue for the implementation of social media. It is also important for government to link public input/feedback to policy-making or the use of social media will be seen mainly as a publicity device with little real influence (Lee \& Kwak, 2012). 


\section{Technological Issues:}

Security related issues: Security is a priority with governments involving a heavy focus on safeguarding critical infrastructure and ensuring protection against various types of cyber threats (McNutt, 2014). Web 2.0 technologies often do not have the same management and security capabilities as more traditional enterprise systems (Anonymous, 2009). Bray (2008) argued that social networking offers governments a new tool to generate consensus, promote programs and policies, better communication, but as with other emerging communication technologies, its use implies a range of IT security challenges. He mentioned that social networking is by its very nature insecure and some organizations, especially governments, have looked at social networking technologies as enemies to productivity and as "bandwidth bandits" (Bray, 2008).

\section{Policy and legislative concerns:}

Issues of privacy and information security: One of the challenges in building trust between public and government lies in concerns related to privacy and information security. Governments are responsible for protecting any personal information that is collected (McNutt, 2014). Shareef et al. (2011) argued that important factors enabling the public to adopt interactive online government services include perceived security, perceived uncertainty, and perceived trust. Because of the open and autonomous nature of social media and Web 2.0 technologies, the public and government agencies are concerned about the risk of accidentally disclosing confidential information and the vulnerability of systems to hacking (Lee \& Kwak, 2012). Use of social media increases the risk that sensitive information might be available to thousands or 
millions of subscribers in an online community. The expansion of social media networks will increase the ease of communication and hence the number of individuals who can compromise an organization's ability to control the flow and content of information (Anonymous, 2009). Government organizations have become sensitive about losing control of information. For example, the internal policies of some government departments indicate that classified and protected information cannot be posted on a blog, wiki or other social media site. Such material can only be posted on a site that is situated within a classified network and has controls in place to ensure that the rules of "need to know" are respected.

Data quality and integrity: Data quality and integrity are other challenges that government agencies need to consider to ensure the accuracy, consistency, timeliness, usability and usefulness of data that they publish online. To do so, agencies need to have formal processes governing the lifecycle of data collection and sharing. Taking advantage of different social media tools to provide different communication channels is desirable since these offer options to citizens, but managing multiple communication channels requires skilled employees, effective management processes and appropriate governance structures (Lee \& Kwak, 2012). As suggested by Chun and Luna Reyes (2012) citizen engagement in public disclosure using social media may generate large amounts of information called "big social data". The data may contain emotional and subjective statements often called "sentiment" data. Data overload will be a huge challenge for government and citizens who rely on this information for decision-making. Effective processing and analysis of these social media generated data to identify salient points and sentiments will help government to understand their citizens and to reflect their opinions in program and policy making to achieve true democracy. Sentiment data often suffers from low 
quality and low reliability posing further concerns. Recognizing main trends and filtering these data for decision-making poses a substantial challenge for government (Chun \& Luna Reyes, 2012). As a result governments need to have data models and strategies in place to manage and integrate appropriate data in a rapid manner and to share these insights with the public.

\subsection{Possible Risks Associated with Social Media}

While social media tools and services bring many positive elements to the workplace, they also bring numerous risks and tensions in a government context. One of the shadowy prospects is the possibility of a chaotic relationship between a government and its citizens in the absence of clear leadership. There are also privacy and security risks associated with online interactions and the actions of empowered web users as mentioned above (Anttiroiko, 2010). In the general context, citizen participation could be negative because of a lack of information regarding government achievements and public criticism of government policies and procedures (PicazoVela et al., 2012). There is an argument that there are also risks related to digital exclusion. Digital exclusion means that those people who lack access to modern technologies will become partially disenfranchised. For example, not everyone knows how to use these technologies so some segments of the population could feel as if they had limited or no access to the services they provide. But in a growing knowledge economy and evolving information society we are moving toward digital inclusion, which means more and more individuals have access to ICTs and appropriate skills to benefit from new technologies through school, work or civil society (McNutt, 2014). Other risks are related to identity and information theft (Picazo-Vela et al., 2012). There are also some risks related to the underlying technology and infrastructure such as 
the reliability of networks, security of websites, system failures and downtime and the adequacy of technology infrastructure in municipalities (Picazo-Vela et al., 2012). There is also the possibility of misinterpretation of information and views that can be spread very quickly and widely through social media. Once online material becomes public there is little control or influence over how it might be used or modified (ACT Government Social Media Policy Guidelines, 2012).

In this section, I have discussed the increasing popularity of social media use by national governments highlighting the activities of the government of Canada. Social media tools have been adopted by different government agencies to achieve a variety of benefits. From an organizational perspective, social media tools encourage stakeholders' participation, improve service delivery, provide better communication with stakeholders (such as two way communication and advanced democratic dialog), and increase transparency, public education and innovation. From the citizens' perspective, social media tools offers citizens participation and engagement, raising public awareness and two-way communication. From the employees' perspective, social media facilitate workplace collaborations across organizations, employees' participation, and enhanced productivity (McNutt, 2014; Picazo-Vela et al., 2012; Anttiroiko, 2010; Snead, 2013; Bertot et al., 2010). While the adoption of social media tools can bring benefits to governments, it may also bring some challenges and encounter barriers such as organizational, cultural, legislative, privacy, and security issues (Lee \& Kwak, 2012; Anonymous, 2009; McNutt, 2014). As suggested by McNutt (2014), "the most significant barriers to social media adoption are organizational, cultural, and legal - not technological" (McNutt, 2014, p. 66). 
It is clear that social media tools are creating new pathways among many government stakeholders. However, understanding stakeholder interests and needs is crucial if governments want to serve their citizens effectively through social media. In the next chapter I will investigate this concern by applying stakeholder theory to examine social media in the government context. 


\section{Theoretical Foundation}

As mentioned in previous chapters, the existing literature on the effective use of social media by governments has raised questions about potential benefits and existing barriers. Since these issues will be realized differently by various groups, the lens of stakeholder analysis with its emphasis on the contrasting views of an organization and its purposes is both appropriate and useful for this research project.

\subsection{Stakeholder Theory: Historical Overview/Literature Review}

The concept of the stakeholder has developed in various disciplines such as sociology, economics, ethics and politics and especially in the literatures of systems theory, strategic planning and management and corporate social responsibility (Carroll 1979; Freeman 1984; Langtry 1994; Mainardes et al., 2011). A large number of researchers (e.g. Donaldson \& Preston, 1995; Freeman, 1984; Frooman, 1999; Goodijk, 2003; Preble 2005, Rowley 1997) still position stakeholder theory within the strategic management literature where it originated. The notion of the stakeholders of an organization as an important consideration in strategy formulation has been recognized since Freeman published his foundational book in 1984. He remains one of the most cited and popular researchers in the area due to his ongoing contributions. Freeman (1984) originally defined "a stakeholder in an organization is (by its definition) any group or individual who can affect or is affected by the achievement of the organization's objective" (p. 25). This view is based on the empirical reality that companies can have an impact on or be influenced by a large number of varied constituencies. Freeman's definition is one of the broadest in the literature and is particularly important for its emphasis on the relationship between the company 
and its external environment and the impact of this relationship on corporate behaviour within this context. In contrast to this broad view, a more narrow view defines stakeholders as those groups "on which the organization is dependent for its continued survival" (Freeman \& Reed, 1983, P. 91). Narrow views of stakeholders are based on the practical reality of limited resources, limited time and attention, and the limited patience of managers for dealing with external constraints. In general, narrow views of stakeholders attempt to define relevant groups in terms of their necessity for the firm's survival (Mitchell et al., 1997) rather than identify all those who may potentially be associated with corporate actions.

Savage et al. (1991) took a position between these two extremes stating that stakeholders "have an interest in the actions of an organization and ... the ability to influence it" (p. 61). The authors considered two attributes necessary for identifying a stakeholder: (1) a claim on the organization and (2) the ability to influence a firm. From a strategic point of view the main purpose of stakeholder theory is to enable managers to understand the organization's stakeholders and to manage them. This stance led Mitchell et al. (1997) to argue that in addition to defining stakeholders, managers should consider stakeholder salience by which they mean "the degree to which managers give priority to competing stakeholder claims" (P. 854). The dynamics inherent in each relationship involve complex considerations that are not explained in the original formulation of stakeholder theory. Mitchell et al. (1997) suggested that what is required is a theory of stakeholder salience that can explain "to whom and to what managers actually pay attention" (Mitchell et al., 1997). In their theory they do not argue that managers should pay attention to specific types of stakeholders. Rather, they argue that to achieve certain 
ends managers offer different levels and types of attention to stakeholders with certain attributes (Mitchell et al., 1997).

Later Freeman and McVae (2001) expressed the need for a stakeholder theory that is flexible enough to handle environmental shifts. They proposed that as the world becomes flatter and more turbulent and interconnected with fewer boundaries between firms, industries and public and private organizations, a stakeholder approach should focus more on both values and value creation (Freeman \& McVae, 2001). In his recent writings, Freeman (2008) has emphasized that stakeholder theory is about value creation, how people create value for each other. He also claims that stakeholder theory should be about what good management is. Managing stakeholders is all about creating value for them (Freeman, 2008).

Essentially, the management literature has discussed stakeholder theory on the basis of three perspectives: a descriptive perspective, an instrumental perspective and a normative perspective (Donaldson \& Preston 1995). The descriptive perspective seeks to explain what the corporation is through defining its essential characteristics and organizational behaviours relative to stakeholders, including the nature of firms (Brenner \& Cochran, 1991), how managers perceive their companies, how organizations are managed, and the concept of target-stakeholders (Mitchell et al., 1997; Mainardes et al., 2011; Donaldson \& Preston, 1995). This perspective attempts to describe the components of organizational reality including company-stakeholder relations. The work of Brenner and Cochran (1991) represents an early effort to provide a descriptive stakeholder theory of the firm. They argued that "the stakeholder theory of the firm posits that the nature of an organization's stakeholders, their values, their relative influence on 
decisions and the nature of the situation are all relevant information for predicting organizational behaviour" (Brenner \& Cochran, 1991, p. 462). Research carried out under this perspective is usually exploratory (Mainardes et al., 2011).

Instrumental stakeholder theory mainly explores the causes and effects of relations between stakeholders and organization. This perspective explores how the stakeholder model may be deployed as a tool in strategic decision making, to attain the performance objectives of an organization. It seeks to explain the conditions under which engagement maximizes shareholder value or corporate value by using the stakeholder model (Donaldson \& Preston 1995; Mainardes et al., 2011). A fundamental assumption is that the main objective of corporate decisions is marketplace success, so that stakeholder theory is used to support efforts to obtain strategic advantage (Jawahar \& Mclaughlin, 2001). Studies adopting the instrumental theory generally use statistical methodologies and focus on mutual relationships between stakeholders and organization.

The normative perspective is based on moral premises about how actors and organizations should go about their activities, why the organizations need to satisfy their stakeholders and how to achieve this (Donaldson \& Preston, 1995; Mainardes et al., 2011; Crilly, 2011). In general, scholars having normative perspectives focus on how all stakeholders should be treated on the basis of some underlying moral or philosophical principles. This aspect of stakeholder theory has had a significant influence on research into corporate governance generating differing approaches to managing the relationships between stakeholders and the organization (Jawahar \& Mclaughlin, 2001). The three aspects of stakeholder theory are nested within each other (Figure 
1) (Donaldson \& Preston, 1995). The external level of the theory is its descriptive aspect, which presents relationships that are observed in the external world. The second level is instrumental; if certain practices are carried out then certain results will be achieved. The central level of the theory is normative motivating the other two.

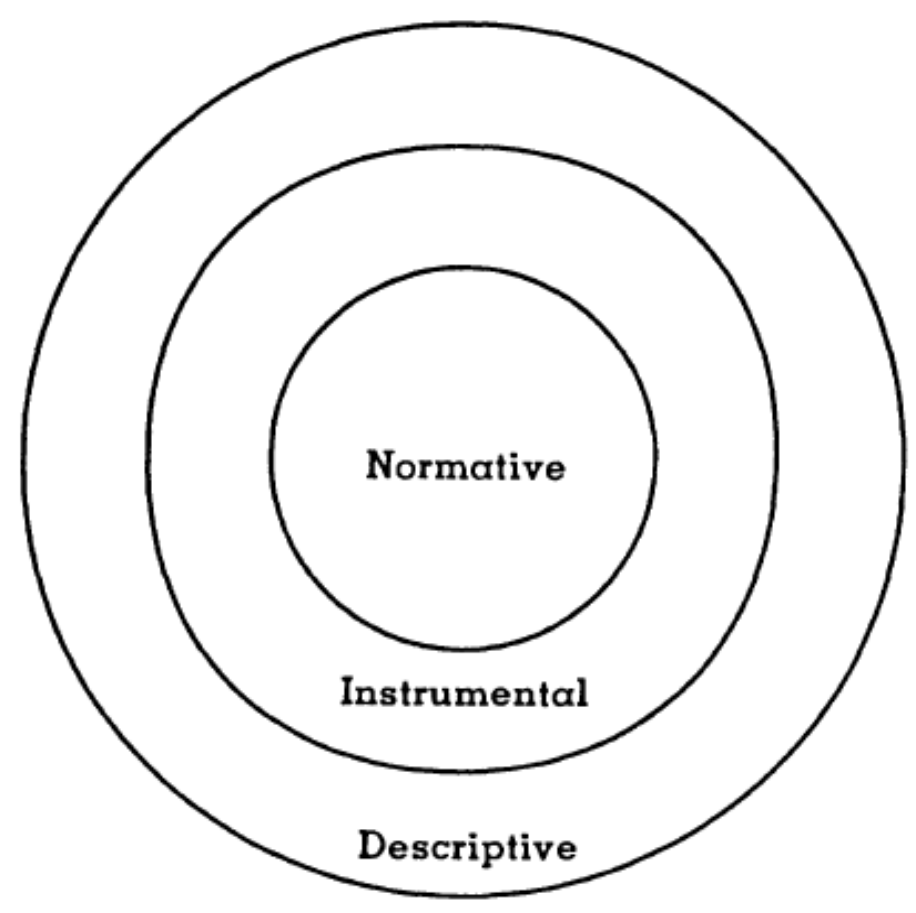

Figure 1-Three Aspects of Stakeholder Theory (Donaldson \& Preston, 1995)

The instrumental aspects of the Donaldson and Preston (1995) model were important for Mitchell et al. (1997), who studied managers' perceptions of stakeholders' characteristics and suggested three variables to identify stakeholder classes: (1) the stakeholder's power to influence the firm, (2) the moral legitimacy of a stakeholder's claim, and (3) the urgency of the 
stakeholder's claim on the firm. They particularly mentioned that stakeholder management is important for business projects in institutional environments.

Power: Weber (1947) defined power as "the probability that one actor within a social relationship would be in a position to carry out his own will despite resistance" (Weber, 1947, p. 152). Power means the ability to make someone do something that would not otherwise have been done. The power of the stakeholder over the organization could be coercive (strength or threat), normative (legislative, the media) or utilitarian (holding resources or information) (Mainardes et al., 2011). Any organization should take into consideration their powerful stakeholders when making decisions or seeking to analyze their environment. According to Mitchell et al. (1977), the more powerful stakeholders will have greater salience for decision makers. A powerful stakeholder might have influence on other stakeholders and organizations, thus it is important for government or any organization to recognize influential or powerful stakeholders and address their needs and expectations.

Legitimacy: "The principle of who or what really counts" is based on the idea of legitimacy, which is defined as the attribution of authority to an individual or position by others (Mitchell et al., 1997, p. 866). Agle et al. (1999) defined stakeholder legitimacy as "a generalized perception or assumption that the actions of an entity are desirable, proper, or appropriate within some socially constructed system of norms, values, beliefs, and definitions" (p. 574). Weber (1947) argued that legitimacy and power are distinct attributes that can combine to create authority. In Weber's view, authority is the legitimate use of power, but these two attributes can exist independently as well (Mitchell et al., 1997). 
Urgency: Urgency is defined as the degree to which stakeholder claims require immediate attention. Mitchell et al. (1997) argued that urgency is based on the following two attributes: (1) the time sensitivity that relates to the need for speed in the organization's response, and (2) criticality - the importance of the claim or the relationship to the stakeholder.

Power and legitimacy are defined as core constructs that are expected to affect stakeholder salience and when combined constitute authority. Urgency adds a dynamic component to the process whereby stakeholders achieve greater importance in the managers' minds (Mitchell et al., 1997; Agle et al., 1999). There is an argument that salience might be influenced by managerial perceptions. The priorities that managers assign to stakeholders are influenced by their perceptions so that they may differ on the salience of stakeholder groups as well as stakeholder claims (Freeman, 1984). Despite this uncertainty, in any organization it is important for managers to understand salience. For example, government senior management needs to understand the degree of priority given to competing stakeholder claims in order to apply appropriate social media tools.

Table 6 summarizes key constructs of stakeholder theory and salience (Mitchell et al., 1997): 
Table 6 - Key Constructs in the Theory of Stakeholder Identification and Salience (Mitchell

et al., 1997)

\begin{tabular}{|l|l|}
\hline Construct & Definition \\
\hline Stakeholder & $\begin{array}{l}\text { Any group or individual who can affect or is affected by the achievement } \\
\text { of the organization's objectives }\end{array}$ \\
\hline Power & $\begin{array}{l}\text { A relationship among social actors in which one social actor, A, can get } \\
\text { another social actor, B, to do something that B would not have otherwise } \\
\text { done }\end{array}$ \\
\hline Legitimacy & $\begin{array}{l}\text { A generalized perception or assumption that the actions of an entity are } \\
\text { desirable, proper or appropriate within some socially constructed system of } \\
\text { norms, values, beliefs and definitions }\end{array}$ \\
\hline Urgency & $\begin{array}{l}\text { The degree to which stakeholder claims call for immediate attention } \\
\text { claims }\end{array}$ \\
\hline Salience &
\end{tabular}

The Stakeholder Salience Model (Mitchell et al., 1997) can provide a direction and a conceptual solution that would help organizations to identify which of their potential stakeholders must receive attention. However, organizations must know that stakeholder analysis based on Mitchell's Salience model should be conducted on a regular basis, because power, legitimacy and urgency change over time and situations (Sedereviciute \& Valentini, 2011). In conclusion, any organization should take into consideration the needs, interests and influences of people and groups who either impact on or may be impacted by its policies and operations.

According to this preliminary review, the stakeholder concept contains three fundamental factors: the organization; the other actors; and the nature of the organization-actor relationships (Mainardes et al., 2011). For the purpose of this study, I will apply Mitchell et al's salience model, which is built mainly on the instrumental aspects of the Donaldson and Preston (1995) framework. The instrumental aspect focuses on relationships between stakeholders and the focal 
organization in order to guide managers in the engagement of different stakeholders to attain the organization's performance objectives. Thus organizations including governments need to identify stakeholder groups (who are the organization's stakeholders and potential stakeholders), their relationship with other stakeholders and analyze their preferences, goals, and expectations for their impact on strategic decisions.

\subsection{Types of Stakeholders}

Friedman (2006) states that the organization itself should be consider as a grouping of stakeholders and the objective of the organization should be to manage their interests, claims and viewpoints. Stakeholder theory encourages the identification of stakeholders, which has led to the development of stakeholder typologies as researchers attempt to understand which stakeholders are more important and how their relationships to the organization are defined. In this section, I will examine some of the most influential typologies and investigate how they may influence approaches to managing stakeholders.

Internal and External Stakeholders: Freeman (1984) simply categorizes stakeholders as internal stakeholders (owners, customers, employees, and suppliers) and external stakeholders (governments, competitors, consumer advocates, environmentalists, special interest groups, media). Figure 2 is a map of the firm, which includes a sample of those groups and individuals that can affect, or are affected by, organizational activity. Each of these groups has the potential to play a vital role in the success of the firm in today's environment and each of these groups has a stake in the modern corporation. I should say that for the purpose of this study, this classification is very simple and might omit some relevant stakeholder groups. Freeman's 
classification does not assign differential weights to stakeholders nor does it consider who the primary stakeholder(s) for the organization might be. As suggested by Rowley (1997), most stakeholder theories such as the Freeman model, do not consider any analysis that goes beyond dyadic relationships, which is an important omission for understanding stakeholder management in the social media context.

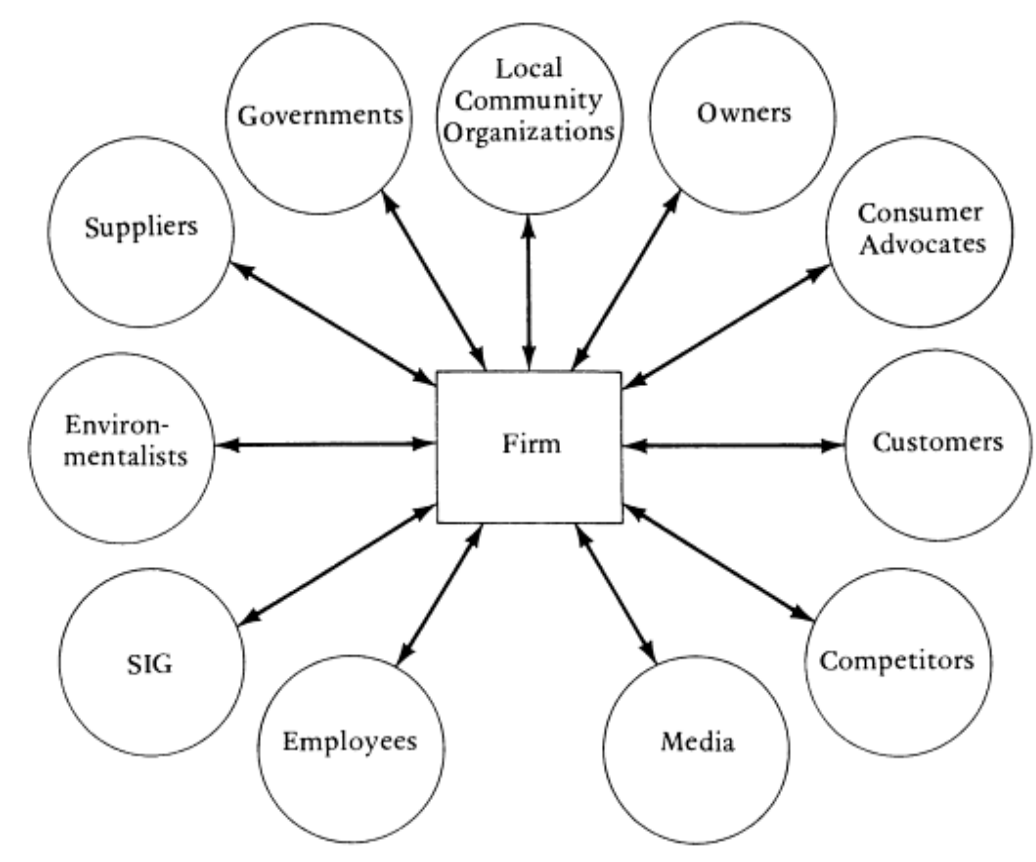

Figure 2-A Typical Stakeholder Map-Freeman (1984)

Primary vs. Secondary: Clarkson (1995) also classified stakeholders into two groups that he called primary and secondary. According to him, primary stakeholder groups are those without whose participation the firm cannot survive. Primary stakeholder groups usually include "shareholders and investors, employees, customers, and suppliers, together with what is defined as the public stakeholder group: the government and communities that provide infrastructures 
and markets, whose laws and regulations must be obeyed, and to whom taxes and other obligations may be due" (Clarkson, 1995, p.106). Donaldson and Preston (1995) have suggested that trade associations and environmental groups should be added to Clarkson's (1995) list of primary stakeholders. Secondary stakeholder groups are defined as "those who influence or affect, or are influenced or affected by, the corporation, but they are not engaged in transactions with the corporation". Secondary stakeholders are not essential for a firm's survival, but they have an interest in its activities. In addition, they may disagree with the policies or programs that a corporation adopts to satisfy the needs and expectation of its primary stakeholder groups. Based on Clarkson's (1995) definition, the media and a wide range of special interest groups are considered as secondary stakeholders. It is important to note that some secondary stakeholders could conceivably have an important impact on firm performance and image.

Salience: As indicated above Mitchell et al. (1997) differentiate stakeholders on the basis of "salience". Salience indicates that all stakeholders are not equal in the way that they are perceived by the organization's managers. There is variation among stakeholders' based on the relative power, legitimacy and urgency of their claims that needs to be acknowledged. Stakeholder theory supports consideration of competing viewpoints, objectives, and claims, recognizing the conflicts that arise from these differences and the processes whereby these differences are negotiated. The Mitchell at al., (1997) Stakeholder Salience Model is still the most used and functional model for identifying and prioritizing stakeholder groups. This model extends Rowley's proposition of understanding the complex relational systems that exist between actors instead of mapping stakeholders in the classic way by presenting a focal 
organization or project at the centre of a nexus of stakeholders and examining only dyadic relationships between different stakeholder groups (Sedereviciute \& Valentini, 2011).

Claimants vs. Influencers: According to Mitchell et al. (1997) in order to define the idea of stake we need to differentiate between groups that have a legal, moral or presumed claim on the firm and groups that have the ability to influence the firm. Influencers are those who have power over the firm, whether or not they have valid claims or any claim at all. They might or might not wish to press their interests depending on the type of claims they hold and the circumstances that obtain at the moment. However, claimants may have legitimate or illegitimate claims and may or may not have any power to influence the firm (Mitchell et al., 1997). This classification highlights the concepts of power and legitimacy attached to claims that need to be considered by managers.

Actual vs. Potential: There is an argument that a stakeholder may be an entity that exists without being in an actual relationship with the firm. Mitchell et al. (1997) stressed that "the potential relationship can be as relevant as the actual one" (p. 859). Clarkson's (1995) idea of involuntary stakeholders as those individuals or groups with something not wilfully placed at risk supports the same argument. It is suggested that stakeholder theory needs to consider "latent stakeholders" because this consideration can at a minimum help organizations avoid problems and enhance effectiveness (Mitchell et al., 1997). This can be especially important for governments given the reach of some of their policies. For example, in this study, younger generations could be considered as potential stakeholders who might prefer to use government services through social media in the future and government needs to address this. 
Varies by Organizational Life Cycle: Jawahar and Mclaughlin (2001) argued that the types of relevant stakeholders change as an organization evolves through the stages of formation, growth, maturity, and decline. This is because certain stakeholders, due to their potential to satisfy critical organizational needs will be more important than others. They argue that to address competing claims, organizations need to use evolving strategies to deal with the same stakeholders over time instead of having different strategies to deal with diverse stakeholders at a given time. For example, in the start-up stage stockholders, creditors, and customers will be addressed proactively, and employees and suppliers will be accommodated. At this stage the organization also needs to interact with government and community stakeholders and deal with trade associations and environmental stakeholder groups. On the other hand, in the growth/mature stage, employees will be addressed proactively and then only accommodated in the decline stage. The strategy an organization uses to deal with a stakeholder will vary at different life cycle stages of the organization because the relationship with various stakeholder groups shift over time (Jawahar \& Mclaughlin, 2001).

Managers as stakeholders: Managers can also be considered as a distinct stakeholder group. Mitchell et al. (1997) who studied the effects of managers' perceptions of stakeholders suggested the concept of salience as a means of understanding how these views may affect strategy. Managers' perceptions of stakeholder priority will be based on their regard for different groups as well as the specific claims they pursue (Freeman, 1984). Donaldson and Preston (1995) mentioned the essential role of management in the identification of stakeholders as well as the fact that managers are at the same time a privileged class of stakeholders in most corporations (Donaldson \& Preston, 1995, p. 86). Thus managers are usually integrated into 
discussions of stakeholders in terms of their management duties rather than as a separate stakeholder group.

Normative stakeholder theory seeks to explain managers' moral duty to protect the corporation as a whole and to engage with all stakeholders (Donaldson \& Preston, 1995). In Evan and Freeman's words, "management, especially top management, must look after the health of the corporation, and this involves balancing the multiple claims of conflicting stakeholders" (1988, p. 151). Freeman suggested that a manager for each important category of stakeholders would be responsible for several key tasks: 1) insuring responsiveness to stakeholder concerns and claims; 2) becoming a stakeholder expert; 3) keeping score between organization and stakeholder; 4) insuring organizational program integration; and 5) serving as ombudsperson between organization and stakeholder to resolve disputes (Freeman, 1984). Again this emphasizes the managers' role in accommodating stakeholder claims rather than as holders of claims themselves.

Friedman and Miles's (2006) classification: Friedman and Miles do not provide a specific classification for stakeholders although they suggested that in general the main group of stakeholders are customers, employees, local communities, suppliers, distributors and shareholders. In addition, other groups who are considered to be stakeholders, are the media, the public in general, business partners, future generations, past generations (founders of organizations), academics, competitors, NGOs or activists, stakeholder representatives such as trade unions or trade associations of suppliers or distributors, financiers other than stockholders (debt holders, bondholders, creditors), competitors, government, regulators, and policymakers 
(Friedman, 2006). In general, his classification is very simple, merely listing different stakeholder groups without any underlying dimensions or structure.

Table 7 -Example of Stakeholders Categorized by Different Authors

\begin{tabular}{|l|l|}
\hline Source & Stakeholder Categories \\
\hline Freeman (1984) & $\begin{array}{l}\text { Internal stakeholders (owners, customers, } \\
\text { employees, and suppliers) } \\
\text { External stakeholders (governments, } \\
\text { competitors, consumer advocates, } \\
\text { environmentalists, special interest groups, and } \\
\text { the media) }\end{array}$ \\
\hline Clarkson (1995) & $\begin{array}{l}\text { Primary: shareholders and investors, } \\
\text { employees, customers, suppliers, government } \\
\text { and communities } \\
\text { Secondary: media and special interest groups }\end{array}$ \\
\hline Donaldson \& Preston (1995) & $\begin{array}{l}\text { Investors, political groups, customers, } \\
\text { communities, employees, trade associations, } \\
\text { supplier, governments }\end{array}$ \\
\hline Mintzberg (1996) & Customers, clients, subjects, and citizens \\
\hline Mitchell et al. (1997) & $\begin{array}{l}\text { Actual vs. potential } \\
\text { Claimants vs. influencers } \\
\text { Salience produces seven different types of } \\
\text { stakeholder groups: definitive, dominant, } \\
\text { dependent, dangerous, dormant, discretionary, } \\
\text { demanding, non-stakeholder. }\end{array}$ \\
\hline Heeks (2006) & $\begin{array}{l}\text { Citizens/customers, businesses, communities, } \\
\text { government, other agencies, non-profits }\end{array}$ \\
\hline Friedman and Miles (2006) & $\begin{array}{l}\text { Customers, employees, local communities, } \\
\text { suppliers and distributors, shareholders, the } \\
\text { media, The public in general, business } \\
\text { partners, future generations, past generations } \\
\text { founders of organizations), academics, } \\
\text { competitors, NGOs or activists - considered } \\
\text { individually, stakeholder representatives, } \\
\text { Stakeholder representatives such as trade } \\
\text { unions or trade associations of suppliers or } \\
\text { distributors, financiers other than stockholders }\end{array}$ \\
\hline
\end{tabular}




\begin{tabular}{|l|l|}
\hline Source & Stakeholder Categories \\
\hline & $\begin{array}{l}\text { (debt holders, bondholders, creditors), } \\
\text { competitors, government/ regulators/ } \\
\text { policymakers }\end{array}$ \\
\hline
\end{tabular}

Table 7 illustrates examples of stakeholder categorizations by different authors. This table indicates that there are both general categorizations and specific categorizations mainly related to different contexts. Within the context of social media use, salience category from Mitchell et al. (1997) lends itself to more detailed analysis.

\subsection{Stakeholders' Relationships with the Organization}

Jensen and Sandstrom (2011) mentioned that stakeholders give meaning to the organization because they situate it in its context. In addition, there is an argument that the relationships between the firm and its stakeholders are not unidirectional. Donaldson and Preston (1995) argued that all persons and groups with legitimate interests participating in an enterprise expect to obtain benefits. Hence, the arrow between the firm and its stakeholders should run in both directions. As presented in Figure 3, all the stakeholder relationships are the same size and shape and the black box of the firm located in the center. This implies that all relationships a) are equal and b) they are all mediated through the firm. Donaldson and Preston (1995) mentioned that stakeholders are affected by firm decisions and policies but they also actively seek to influence firm policies and outputs (Donaldson \& Preston, 1995). 


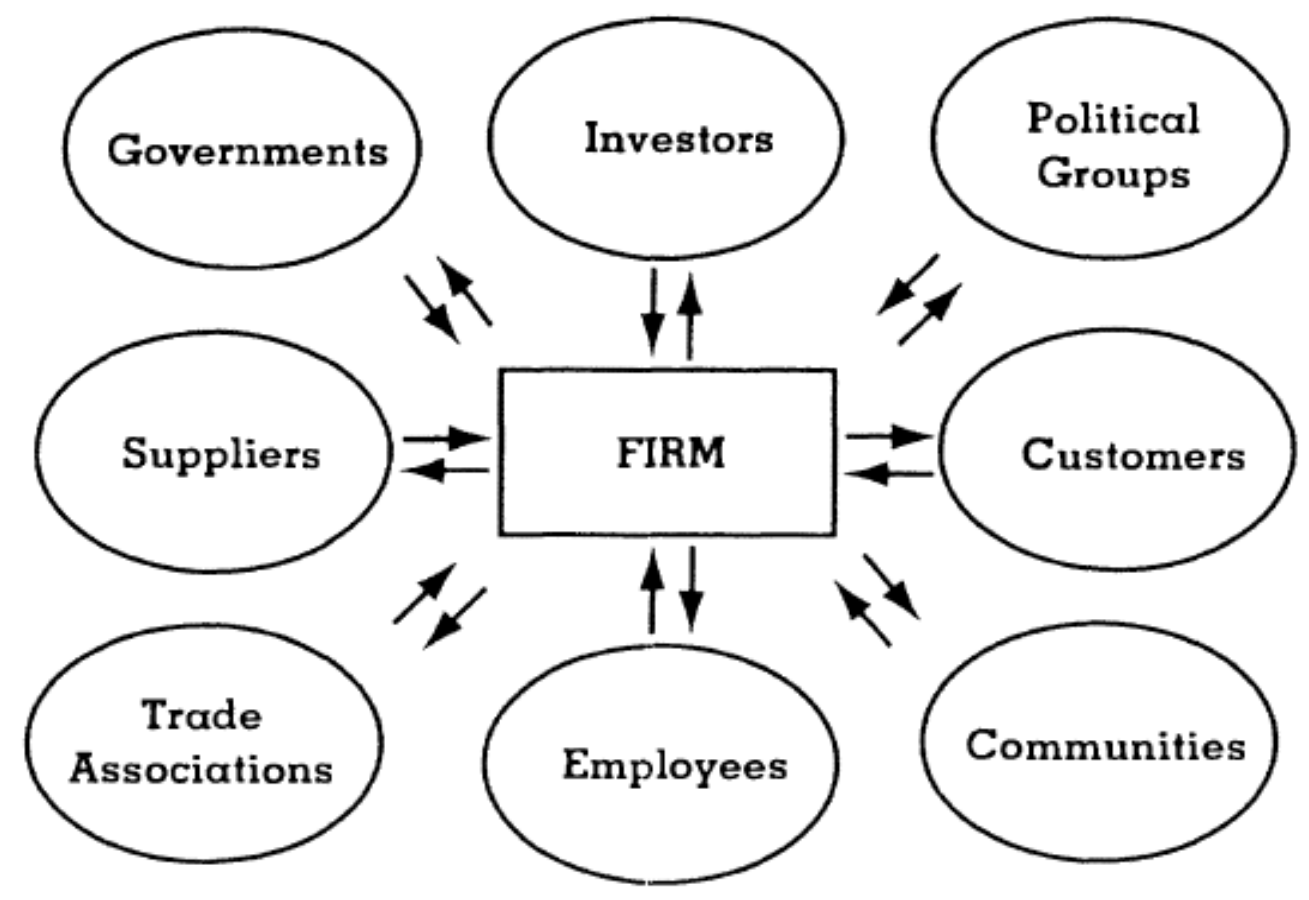

Figure 3-The Stakeholder Model (Donaldson \&Preston, 1995)

Frooman (1999) suggested a typology of stakeholder-firm relationships derived from resource dependence theory as shown in Figure 4. The typology is based on two dimensions, the degree of interdependence (low or high) and the predominance of power between the firm and the stakeholder. Power is the central determinant of outcomes in those situations where a stakeholder and a firm have different interests. Stakeholder power occurs when the stakeholder is less dependent on the firm than the firm is on the stakeholder. However, firm power occurs when the stakeholder is more dependent on the firm. The other two quadrants occur when there is symmetry in the exchange relationship either both parties are not dependent on each other or highly dependent. 


\begin{tabular}{|c|c|c|c|}
\hline \multirow[b]{2}{*}{ 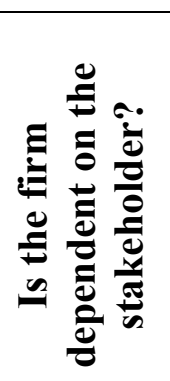 } & \multirow[b]{2}{*}{$\begin{array}{l}\text { No } \\
\text { Yes }\end{array}$} & \multicolumn{2}{|c|}{ Is the stakeholder dependent on the firm? } \\
\hline & & $\begin{array}{c}\text { No } \\
\text { Low interdependence } \\
\text { Stakeholder power }\end{array}$ & $\begin{array}{c}\text { Yes } \\
\text { Firm power } \\
\text { High interdependence }\end{array}$ \\
\hline
\end{tabular}

Figure 4 - Typology of Resource Relationship (Frooman, 1999)

Frooman, basing his argument on the power relationship between firm and stakeholder, suggested two types of resource control strategies: (1) withholding strategies -where stakeholders intentionally discontinue providing a resource to make the firm change a certain behaviour; and (2) usage strategies - in this situation the stakeholder continues to supply resources but with strings attached. Since some stakeholder groups do not have the power to use either withholding or usage strategies, they could find others who have such a relationship with firm to execute these strategies. Frooman identifies this approach as including types of influence pathways and divides them into two: direct pathways and indirect pathways. Direct pathways exist when the stakeholder directly controls the flow of resources for the firm. Indirect pathways occur where a stakeholder does not have formal relationships with the firm. In addition, both types of influence pathways could be employed either with withholding or usage strategies (Frooman, 1999).

By combining resource relationships and influence strategies, Frooman (1999) suggested four propositions (Figure 5) relating to the choice of pathway (direct or indirect) and strategy (withholding or usage). Power relationships between the firm and the stakeholders have 
important roles in the choice of pathway-strategy combinations. The balance of power between the stakeholders and the firm mainly determines which of the types of strategy a stakeholder will use. However, in this century, as suggested by Jensen and Sandstrom (2011) globalization shifts power and responsibilities, which makes relationships complex and problematizes some of the foundations of stakeholder theory and stakeholder management. The complex relationships implicit in globalization emphasize the simplification inherent in the theory's boundary conditions and how these boundaries make it difficult for different stakeholders to provide credible and useful answers to two central stakeholder questions: "who gets to define what a stake and a stakeholder are and where do the corporation's responsibilities begin and end?" (Jensen \& Sandstrom, 2011, p. 485).

In this section, I examined the stakeholder's relationship with the organization. Power differentials play an important role in defining the relationship between the organization and stakeholders. Because the balance of power essentially suggests which type of strategy a stakeholder will use, it is important for an organization to understand dependency issues and each stakeholder's expectations in the relationship. For example, in the case of a citizensgovernment relationship, citizens are dependent on government for receiving some services such as drivers' licences, health cards, etc. On the other hand, a government is also its depends on its citizens for tax revenue. Based on these two examples, the citizens-government relation could vary depending on the context, but the main point is to understand these differences and address them in an appropriate way. 


\begin{tabular}{|c|c|c|c|}
\hline \multicolumn{4}{|c|}{ IS THE STAKEHOLDER DEPENDENT ON THE FIRM? } \\
\hline \multirow{3}{*}{ 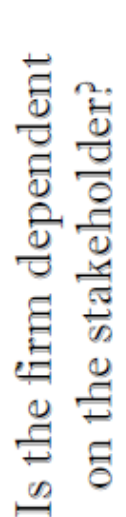 } & & NO & YES \\
\hline & No & $\begin{array}{l}\text { P1: When the relationship is one } \\
\text { of LOW INTERDEPEND- } \\
\text { ENCE, the stakehoder will } \\
\text { choose indirect-withholding } \\
\text { strategy to influence the firm. }\end{array}$ & $\begin{array}{l}\text { P2: When the relationship is one } \\
\text { of FIRM POWER, the stake- } \\
\text { holder will choose indirect-usage } \\
\text { strategy to influence the firm. }\end{array}$ \\
\hline & YES & $\begin{array}{l}\text { P3 : When the relationship is } \\
\text { one of STAKEHOLDER } \\
\text { POWER, the stakeholder will } \\
\text { choose direct-withholding strat- } \\
\text { egy to influence the firm. }\end{array}$ & $\begin{array}{l}\text { P4: When the relationship is one } \\
\text { of HIGH INTERDEPEND- } \\
\text { ENCE, the stakeholder will } \\
\text { choose direct-usage strategy to } \\
\text { influence the firm. }\end{array}$ \\
\hline
\end{tabular}

Figure 5- Typology of Resource Relationships and Influence Strategies (Frooman, 1999)

\subsection{Criticisms of Stakeholder Theory}

Many of the criticisms of stakeholder theory are related to the practical problems that have arisen in trying to implement its implications. The theory also faces other problems such as those relating to justification, lack of conceptual clarity and possible inconsistency (Humber, 2002). Humber (2002) has argued that normative stakeholder theory fails as a moral theory and suggested that corporations should be allowed to determine their moral responsibilities in any way they see fit. In addition to moral issues, he argued that Freeman is not clear that the claims of stakeholders broadly defined (see section 4.1) are as legitimate as the claims of stakeholders in the narrow view. Humber claimed whenever Freeman use "stakeholder" in the narrow view, he believes that the claim by this group should be given higher consideration (Humber, 2002). 
Mainardes et al. (2011) also criticised Freeman claiming that he neglected the connections between actors and between internalities and externalities. They claim Freeman failed to distinguish between internal and external interest groups and that he implied unlimited connections between these groups and individual actors. Based on his definition, an actor may be part of multiple internal and external stakeholder groups. To solve this issue Rowley (1997) suggested that the most appropriate way of segmenting stakeholders is to consider roles rather than groups. For e-government in particular it is important to recognize that both individuals and organizations can play several roles, either concurrently or sequentially.

Kaler (2006) argued that stakeholder theory is difficult to implement in practical terms with the normal range and diversity of stakeholder groups as it is difficult for companies to balance so many divergent interests. A further critique posed by Key (1999) refers to the fact that stakeholder theory considers the environment as something static and mainly focused on the organization and its stakeholder groups. She also mentioned that the element of change that occurs over time is not explained using Freeman's model. There is no provision for understanding how to manage environmental change and its effects on stakeholders. One contribution towards solving this problem was made by Rowley (1998) who suggested network analysis to evaluate environmental influence on the relationships between a company and its stakeholders. Besides inadequate environmental assessment and paying insufficient attention to the system within which an organization operates, Key (1999) criticized Freeman's theory for its inadequate explanation of process. He argues that Freeman's approach focuses mainly on the actors in the environment and less directly on the process of organization-social engagement thus 
ignoring an important level of analysis as well as providing an incomplete linkage of internal and external variables.

Mainardes et al. (2011) suggested that the stakeholder theory literature might need a new and more robust model because Freeman's original formulation includes an incorrect interpretation of stakeholder theory, i.e. that a company should take into account the claims of all participants and that they should be treated equally. As Mitchell et al. (1997) observed, the level of attention and obligation may vary among stakeholder groups. Freeman's original graphical model of the stakeholder theory suggests equality among all stakeholders although this may have been mainly for reasons of simplicity and clarity. Another weakness in developing stakeholder theory according to Rowley (2011) is the lack of understanding and modeling of stakeholder-tostakeholder relationships. She also argued that there is a potential weakness in stakeholder theory since individuals and groups may not be the best representation of those involved with an organization. She suggested that for e-government the most appropriate way of categorizing stakeholders is in terms of roles rather than as groups or individuals (Rowley, 2011). Similarly, in this study at some points I will focus on roles because both organizations and individuals can play several roles. For example, an individual can be citizen, service user and an employee in a government department who provides service for citizens.

Despite the critiques it has attracted, this study utilizes stakeholder theory to review the benefits and barriers of social media tool from the perspectives of different interested groups. Many of the criticisms of stakeholder theory refer to its operationalization in terms of what groups should be included, how they relate to each other and their effects on the focal 
organization. For the purposes of this research, stakeholder theory was not difficult to implement as only three stakeholder groups were considered and all were easily defined. No claim was made that this was an exhaustive list, rather that these represented some of the more important groups in relation to government. Finally, the research approach did not specify the nature of the links to government, but set out to discover these through an examination of the groups' perceptions of social media connections. Thus the research avoids many of the weaknesses attributed to stakeholder theory while capitalizing on its strengths.

\subsection{E-government Stakeholders}

There is an increasing recognition that various stakeholders have significant roles to play in regard to the success of the e-government enterprise. While a number of disparate stakeholders are potentially involved, there has been very little comparative analysis of their respective claims (Rowley, 2011). Understanding stakeholder interests and needs, in particular those of clients, is crucial if government agencies are to serve their citizens effectively. If potential users cannot find the information and services that they need due to organizational, educational, policy or management issues, if they do not have the skills to interact appropriately with e-government, if they do not understand the results they obtain, or do not trust the information and services that they receive, then e-government will not effectively serve its citizens (Jeager \& Bertot, 2010).

There is general agreement that government is a complex of organizations involving many different stakeholders and that this complexity impacts the design and operations of egovernment (Rowley, 2011). Rowley (2011) argued that a potential weakness of stakeholder 
theory as it applies to e-government lies in its definition of the concept in terms of individuals or groups. She suggested that for e-government the most suitable way of classifying stakeholders is to consider roles instead of groups. This is because it is important to recognize that in egovernment both individuals and organizations can play several roles, either concurrently or sequentially. She proposed the following typology of e-government stakeholder roles (Rowley, 2011):

- People as service users

- People as citizens

- Businesses

- Small to medium sized enterprises

- Public administrators (employees)

- Other government agencies

- Non-profit organizations

- Politicians

- E-government project managers

- Design and IT developers

- Suppliers and partners

- Researchers and evaluators

If we compare Rowley's (2011) classifications with Freeman's (Internal vs. External stakeholder groups) a role such as researcher and evaluator could be either internal or external. The same applies for politicians and IT developer roles. Some roles are mainly external such as businesses, enterprises, and other government agencies. Whether they are internal or external likely influences the stakeholders' perspectives and expectations as well as those of the government agency launching e-government initiatives. Rowley's roles may help distinguish how each would relate to e-government initiatives, but since each person may have multiple 
roles, this approach may not be useful in understanding the overall stance of individuals toward e-government initiatives.

Considering that it would be impossible to investigate all relevant stakeholder groups in this research I will focus on a few key groups. To select the target stakeholders I need a basic model that will help situate the issues. For the purpose of this research I will examine the following three sets of stakeholders: citizens, employees, and government senior management. Citizens (people as service users) are the ultimate consumers of government services; they decide whether such programs succeed or not through their access to and use of the facilities available. Employees (people as public servants who work for government) are another important stakeholder group because they deliver services to citizens. To this point there is no research that specifically considers employees' needs in terms of social media in government. Both citizens and employees engage in actions designed to influence government and are not passive recipients of proposals and actions. Citizens are especially active in seeking to influence government policy output. Finally, I have included government senior management or government officials as a separate stakeholder group since they fashion the policies that determine which services will be offered on social media and what policies will determine the conditions for their use.

\subsection{Implications for Government}

Using social media has both positive and negative implications for organizations including governments. Among other benefits suggested by industry experts, social media allows organizations to engage in timely and direct customer relationships with relatively low cost and 
high efficiency in comparison to more traditional communication tools. This enables organizations to engage in direct conversations with different stakeholder groups (Picazo-Vela et al., 2012; Kuzma, 2010; Landsbergen, 2010). Similarly, Snead's (2013) study suggests that government use of social media has the potential to increase citizen participation. This research found that some government agencies in the U.S. experience high user participation counts with social media tools such as Twitter, Facebook, RSS feeds, and YouTube. User participation counts are lower for other social media tools such as blogs.

Governments are using social media with different purposes such as reaching out to citizens and other stakeholders (McNutt, 2014; Chang \& Kanan, 2008; Dorris, 2008), sharing information and collaboration within and across government agencies (McNutt, 2014; Chang \& Kanan, 2008; Dorris, 2008; Picazo-Vela et al., 2012), increasing government transparency and enhancing democratic engagement (Picazo-Vela et al., 2012; McNutt, 2014; Bertot et al. 2010), and promoting citizens' participation (Picazo-Vela et al., 2012; Chun \& Luna Reyes, 2012). Social media tools can provide information about citizens' opinions, interests, intentions, behaviours and characteristics. Social media use in government is considered a "technological innovation and a transforming agent in generating citizen engagement from campaigns and grassroots-activism to shared governance promoting democracy" (Chun \& Luna Reyes, 2012, p. 442). It is also recognized as a strategic advantage for innovation and revolution in government by establishing new communication channels between governments and citizens (Chun \& Luna Reyes, 2012). 
In order to plan social media activities, to decide whether and how to relate to stakeholder groups, organizations need to identify their stakeholder groups and analyze their preferences, goals and abilities. In these circumstances an analysis based on stakeholder theory (Mitchell et al., 1997) by recognizing and mapping stakeholders and identifying what they want and which ones are important to monitor, engage, follow and establish relationships with might be beneficial (Sedereviciute \& Valentini, 2011). As suggested by Mitchell, at al., (1997) the level of attention and obligation will vary between stakeholder groups. Stakeholder theory can provide an analytical framework and a conceptual solution for these issues, which would help organizations to identify and prioritize their potential stakeholders.

\subsection{Implications for Citizens}

Kavanaugh et al. (2012) mentioned that social media have changed the way Americans get information about what's going on in their communities, as well on national and global issues. They provide new ways for citizens to share information and interact with each other and with government agencies (Kavanaugh et al., 2012). A study conducted by Pew Internet \& American Life in 2010 found that almost a third of all online adults in the USA used social media tools such as blogs, social networking sites and online video as well as email and text alerts to keep informed about government activities (Smith, 2010). Similarly, a Phoenix study in Canada suggested that social media is a youth-driven movement and the adoption rate is very high among younger Canadians. When it comes to Government of Canada use of Web 2.0, Canadians believe these social media will assist the government in communicating with and providing better services to citizens. Positive perceptions of social media tools exist among most 
Canadians and they think that the Government of Canada can use social media tools as one of the best ways for governments to communicate with Canadians (Anonymous, 2009).

In 2009, an online survey conducted by the American Red Cross in the USA showed that $75 \%$ of respondents reported that they would use social media in a crisis or civic-related situation (e.g., traffic jam, car crash, potential crime, or downed power lines) (American Red Cross, 2011). The use of Twitter in crises and during disasters and conditions of social convergence such as mass political demonstrations is another example of the growing importance of social media for citizens (Kavanaugh et al., 2012).

Citizens are using social media with different purposes such as receiving timely and relevant services, information sharing, collaboration in policy making, engagement with government and two-way communication (Kavanaugh et al., 2012; Picazo-Vela et al., 2012; Kim et al., 2009; McNutt, 2014). In order to improve services, governments need to understand citizens' needs and expectations regarding social media resources.

\subsection{Recognizing Stakeholder Interests from Social Media Tools}

Successful e-government requires the engagement of stakeholders, which, in turn, necessitates a shared understanding of the interests, needs, perspectives, and benefits required from e-government by the various stakeholders (Rowley, 2011). Table 8 lists and summarizes the needs and goals of the three stakeholder groups that I will consider in this study as well as some of the challenges/barriers that government might face for each stakeholder group through social media implementation and use. 
Table 8-Stakeholders' Interests in the Use of Social Media

\begin{tabular}{|c|c|c|c|}
\hline Stakeholders & Perspective & Needs and Expectations & Challenges/Barriers \\
\hline $\begin{array}{l}\text { Citizen (as a } \\
\text { service user) }\end{array}$ & $\begin{array}{l}\text { Individual } \\
\text { perspective }\end{array}$ & $\begin{array}{l}\text { - Improve service delivery/ timely } \\
\text { and relevant services (Bertot et al., } \\
\text { 2012; Kavanaugh et al., 2012; } \\
\text { Lavender, 2013; Picazo-Vela et al., } \\
\text { 2012) } \\
\text { - } \text { Facilitate communication/ two way } \\
\text { communication (Chun \& Luna } \\
\text { Reyes, 2012; Picazo-Vela et al., } \\
\text { 2012; Lavender, 2013) } \\
\text { Participation }{ }^{6} \text { and engagement } \\
\text { (McNutt, 2014; Picazo-Vela et al., } \\
\text { 2012; Nam, 2012; Snead, 2013, } \\
\text { Mergel, 2013b) } \\
\text { Collaboration }{ }^{7} \text { and knowledge } \\
\text { sharing (Picazo-Vela et al., 2012; } \\
\text { Lavender, 2013; Chang \& Kannan, } \\
\text { 2008; Mergel, 2011; Kim et al., } \\
\text { 2009) } \\
\text { Increase government transparency } \\
\text { (Picazo-Vela et al., 2012; Mergel, } \\
\text { 2013b) }\end{array}$ & $\begin{array}{l}\text { Issues of privacy } \\
\text { and information } \\
\text { security (Gil- } \\
\text { Garcia et al., } \\
\text { 2009; Lee \& } \\
\text { Kwak, 2012; } \\
\text { McNutt, 2014) } \\
\text { Data quality and } \\
\text { integrity (Lee \& } \\
\text { Kwak, 2012) }\end{array}$ \\
\hline $\begin{array}{l}\text { Employee } \\
\text { (as a service } \\
\text { provider) }\end{array}$ & $\begin{array}{l}\text { Individual } \\
\text { perspective }\end{array}$ & $\begin{array}{l}\text { - Workplace collaboration (learning, } \\
\text { and knowledge sharing) (Picazo- } \\
\text { Vela et al., 2012; Lavender, 2013; } \\
\text { McNutt, 2014; Chang \& Kannan, } \\
\text { 2008; Mergel, 2011; Kim et al., } \\
\text { 2009) }\end{array}$ & $\begin{array}{l}\text { - Issues of privacy } \\
\text { and information } \\
\text { security (Gil- } \\
\text { Garcia et al., } \\
\text { 2009; Lee \& } \\
\text { Kwak, 2012) }\end{array}$ \\
\hline
\end{tabular}

${ }^{6}$ In Web 2.0 participation means "the way that an application and service is actually designed to improve and facilitate massive user with low barriers to use"(Kim et al., 2009, p. 662). For the purpose of this study participation means citizens can engage in preparing policy-making decisions by providing feedback for government through social media channels (Mergel, 2013b).

${ }^{7}$ Collaboration can be considered "as an advanced form of participation in which participants directly or indirectly contribute to focused creation of contents serving a common purpose shared by the community" (Kim et al., 2009, p. 662). For the purpose of this study, collaboration is considered as including new forms to solicit citizens feedback and exchange with citizens or other stakeholders to improve their level of collaboration and to identify new opportunities for innovation (Mergel, 2013b). 


\begin{tabular}{|c|c|c|c|}
\hline & & $\begin{array}{l}\text { - Two way communication (Bertot } \\
\text { et al., 2012; Kavanaugh et al., } \\
\text { 2012; Lavender, 2013; Picazo- } \\
\text { Vela et al., 2012) } \\
\text { - Employee participation and } \\
\text { engagement (Picazo-Vela et al., } \\
\text { 2012; Nam, 2012; Snead, 2013) }\end{array}$ & \\
\hline $\begin{array}{l}\text { Government } \\
\text { Senior } \\
\text { Management } \\
\text { (as a } \\
\text { supplier) }\end{array}$ & $\begin{array}{l}\text { Organizational } \\
\text { perspective }\end{array}$ & $\begin{array}{l}\text { - Improved service delivery/ timely } \\
\text { and relevant services (Kavanaugh } \\
\text { et al., 2012; McNutt, 2014) } \\
\text { Effective communication/improve } \\
\text { communication /two way } \\
\text { communication (Chun \& Luna } \\
\text { Reyes, 2012; Picazo-Vela et al., } \\
\text { 2012) } \\
\text { - Participation and engagement } \\
\text { (McNutt, 2014; Picazo-Vela et al., } \\
\text { 2012; Nam, 2012; Snead, 2013; } \\
\text { Mergel, 2013b) } \\
\text { Increase government transparency } \\
\text { (Picazo-Vela et al., 2012; Mergel, } \\
\text { 2013b; McNutt, 2014) } \\
\text { Collaboration and knowledge } \\
\text { sharing (Picazo-Vela et al., 2012; } \\
\text { Lavender, 2013; Chang \& Kannan, } \\
\text { 2008; Mergel, 2011; Kim et al., } \\
\text { 2009; McNutt, 2014) } \\
\text { Cost saving (Lavender, 2013; } \\
\text { Landsbergen, 2010; Gillin, 2010; } \\
\text { Kuzma, 2010; Picazo-Vela et al., } \\
\text { 2012) }\end{array}$ & $\begin{array}{l}\text { - Organizational } \\
\text { culture (Lavender } \\
\text {, 2013; Gil- } \\
\text { Garcia et al., } \\
\text { 2009; Bertot et } \\
\text { al., 2010; } \\
\text { McNutt, 2014) } \\
\text { - Creating and } \\
\text { sustaining public } \\
\text { engagement (Lee } \\
\text { \& Kwak, 2012) } \\
\text { - Issues of privacy } \\
\text { and information } \\
\text { security (Gil- } \\
\text { Garcia et al., } \\
\text { 2009; Lee \& } \\
\text { Kwak, 2012; } \\
\text { McNutt, 2014) } \\
\text { Data quality and } \\
\text { integrity (Lee \& } \\
\text { Kwak, 2012; } \\
\text { Chun \& Luna } \\
\text { Reyes, 2012) }\end{array}$ \\
\hline
\end{tabular}




\section{Research Model and Hypotheses}

Increasing utilization of social media is changing the nature of public engagement activities. Governments around the world are experiencing the promise and difficulties of employing social media tools for a variety of purposes. On the other side of this development as citizens increasingly rely on their online networks and portable devices to manage their daily life, the demand for government to provide access through social media will continue to grow. As mentioned earlier, the advent of Web 2.0 is fundamentally changing how people communicate, socialize and participate with their society. As suggested by McNutt (2014), government capacity to use social media tools depends on the organizational and cultural shift from the "broadcast paradigm" with Web 1.0 towards a "communicative paradigm" associated with Web 2.0.

There is a gap in the literature related to what citizens and employees want/need from government through social media tools. The literature has raised questions about the benefits and barriers of social media use by governments without providing solid empirical evidence about their importance. This study attempts to link certain stakeholders' needs and the barriers to achieving them through social media use by considering the relative importance of a number of issues suggested by the literature. This section will present the research question, proposed research model and the hypotheses for this study, which is designed to elicit information concerning the three groups mentioned above. 


\subsection{Research Question and Objectives}

There have been few empirical studies related to what citizens and employees want/expect from government through social media tools. Seeing this need, Bertot et al. (2010) suggested that the next step toward effective e-government is to research the types of services people want. Understanding users' needs, and expectations will be critical in developing social media tools and strategies for the government. As a result, the aim of this study is to examine social media use in the government context through the lens of stakeholder theory.

This study has two objectives with regard to understanding how to leverage social media for government-citizen interactions:

- Understanding social media as a phenomenon and its implications for government use

- Understanding the perceptions of citizens, employees and government senior management in terms of government use of social media

Research Question: What is the relative importance of the benefits and barriers linked to social media use by governments for different stakeholder groups? 


\subsection{Proposed Research Model}

Figure 6 presents the proposed research model. In the next section, the hypotheses based on this proposed research model will be elaborated.

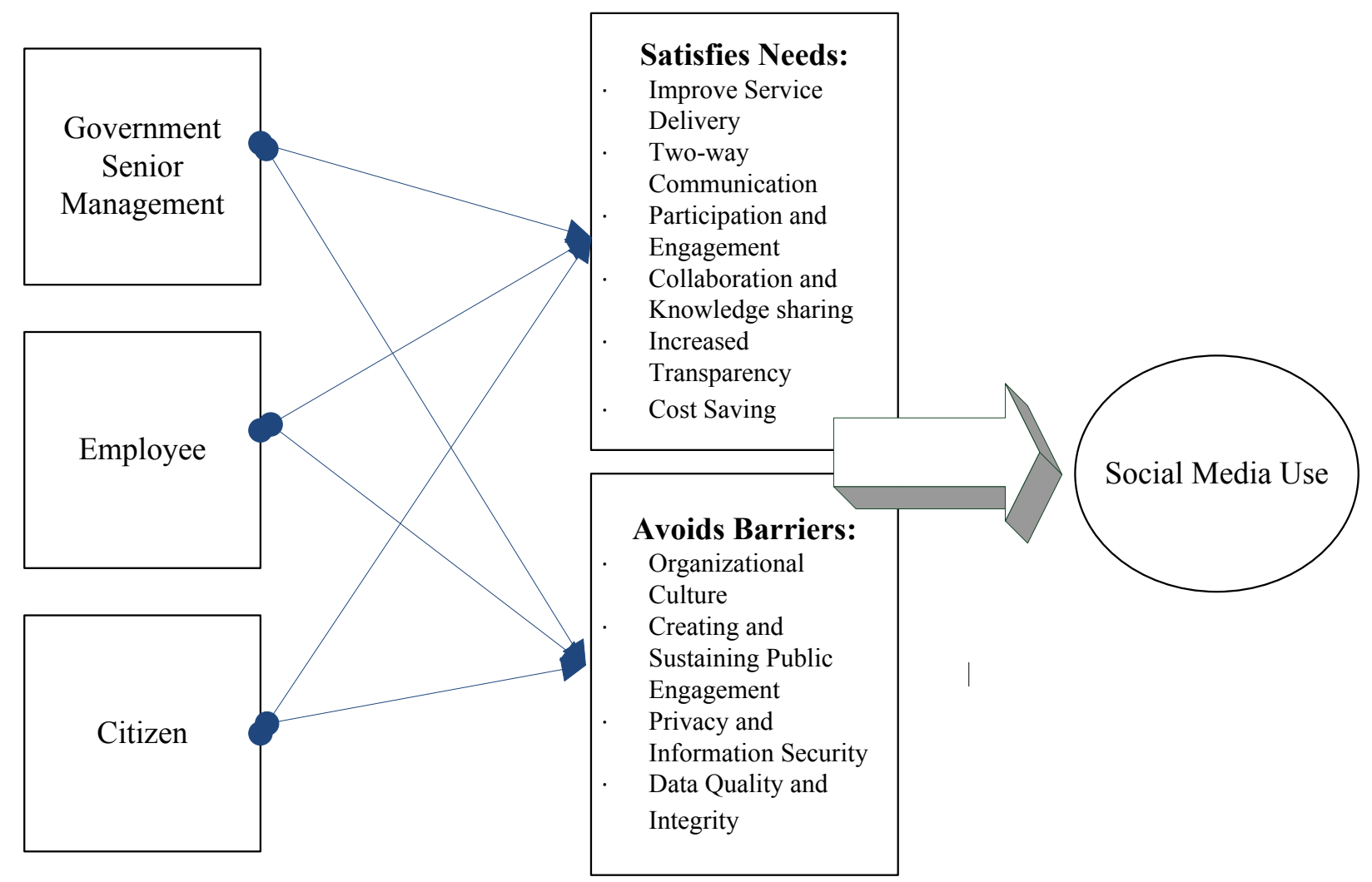

Figure 6- Research Model: Stakeholder Interests 


\subsection{Hypotheses}

Academics in a few cases have acknowledged the need to understand social media (Web 2.0), but there are numerous related and unexplored topics such as the different aspects of services citizens and employees want. I will frame the hypotheses in terms of how important different aspects of social media use are for the three stakeholder groups (i.e. citizens, government senior management, and employees). Considering that it would not possible to examine all relevant stakeholder groups in this study I will focus on only a three key groups, citizens who consume the services offered by government, government senior management who frames the policies for delivery and government employees below senior management who are charged with delivering these services within the framework designed by their superiors.

\subsubsection{Stakeholder Interests}

- Improved service delivery

Social media with user generated content (e.g. Twitter, Facebook, Youtube, etc.) have made available a huge amount of information providing resources that government officials seek to leverage to improve services for citizens (Kavanaugh et al., 2012). From the perspective of government senior management, citizen participation and engagement are two of the key opportunities that social media can offer. Access to this information will allow these two parties to jointly develop, design and deliver government services to improve quality, delivery and responsiveness (Bertot et al., 2012).

Not only is improved service delivery important for government senior management, but it is also important for citizens. Picazo-Vela et al. (2012) mentioned that social media can act as a 
direct communication channel between citizens and government in a more friendly way and provide opportunities for governments to understand citizens' needs, providing well-targeted specific services that benefit the end user. This benefits citizens especially in terms of receiving timely and relevant services from their government officials, which will lead to customer satisfaction (Kavanaugh et al., 2012; McNutt, 2014). It has also been suggested by Lavender (2013) that social media will "improve customer service". The authors believe that by receiving feedback and thus having the ability to identify implementation issues government providers have the ability to make their customers happier than before. In conclusion, citizens and government senior management mainly care about improving government services but employees are less concerned about this aspect. They may even believe that utilizing social media requires extra effort on their part in providing an additional channel for service delivery. These mid-range employees get paid whether they provide fast or slow services. It is accordingly expected that:

Hla: For government senior management vs. citizens there will be no significant differences in terms of improved service delivery through social media.

H1b: Improved service delivery will be more important for government senior management and citizens than for employees.

\section{- Two-way communication}

From a citizen's perspective, social media tools have moved organizations from earlier models of e-government (Web 1.0) that only provided static information with no means for 
customer interaction to providing two-way communication channels (Lavender, 2013). It is suggested that social media provide a direct communication channel between citizens and government so that citizens can easily provide feedback regarding various services (Picazo-Vela et al., 2012).

From the government perspective using social media tools enhances communication between government senior management and other stakeholders leading to disseminating information to the public and internal employees as well as obtaining valuable feedback (Lavender, 2013). This enables organizations to engage in direct conversations with different stakeholder groups as well as enhancing trust and democracy (McNutt, 2014; Kuzma, 2010; Landsbergen, 2010). This may not necessarily make it easier to meet the conflicting needs of stakeholders, but it will help to clarify overlaps and contradictions.

From the employee perspective, there is an argument that adding another communication channel might create extra work that leads to the possibility that employees charged with responding to citizens may not be seen as supportive if their replies are slow or perceived as inadequate. It is possible that simply utilizing Web 2.0 methodologies will lead to expectations of quicker, more tailored responses. Employees who are tasked with reacting to citizens' needs must have enough knowledge and resources to generate adequate answers (Picazo-Vela et al., 2012). Thus it is expected that:

H2a: There will be no significant difference between citizens and government senior management in the importance of two-way communication by using social media. 
H2b: Two-way communication will be significantly more important for citizens and senior management than for employees.

\section{- Participation and engagement}

Social media provide enhanced opportunities for citizen and employee engagement. Nam (2012) suggested that citizens' participation and engagement might help government increase its legitimacy and mobilize political support facilitating the adoption of new policies and programs. Citizen participation and engagement enhances the government's effectiveness and can improve the quality of its decisions and help develop feasible public policy responses although it may have a negative effect if citizens feel that their expressed concerns are not being taken into account.

From the government senior management perspective, this means they can employ citizens' interests to produce policies that are more broadly supported and more easily implemented. This will improve the political image of governments through better feedback, better collaboration and engagement, legitimizing their decisions and giving them more credibility (Nam, 2012; Picazo-Vela et al., 2012). DiStaso et al., (2011) interviewed 25 communication and public relations executives to identify their opinions about the impact of social media in their organizations. The results show that organizations are using social media to "to engage in important conversations" and to enhance their understanding of markets, customers, competitors, and employees. 
Employee engagement provides an opportunity for government to understand employees' needs and obtain valuable feedback regarding their work environment. The literature examining the employee perspective is quite limited. What literature exists suggests that governments can tap into these needs and interests to develop effective rules and regulations that are better understood and supported by employees. As with the citizens' perceptions, if these opinions and concerns are ignored such consultation can have a contrary effect. Assuming that governments take these steps, it is hypothesized that:

H3: There will be no significant difference between the three stakeholder groups for the importance of participation and engagement in using social media

\section{- Collaboration and knowledge sharing}

Research has shown that social media facilitate interactive knowledge sharing, engagement and collaboration on the web. These emerging tools provide the potential for a change from a static web presence for government information and services to using collaborative web technologies to engage citizens, enabling collaboration, and encouraging transparency in government (Bertot et al., 2012; Lavender, 2013; McNutt, 2014; Kim et al., 2009).

In terms of the internal use of social media tools by employees, collaboration, knowledge sharing and employee engagement are the primary objectives. Public managers use Wikis as collaborative tools to improve information sharing and to distribute capacities across organizational boundaries and hierarchies (Chang \& Kannan, 2008; Mergel, 2011). Picazo-Vela et al. (2012) suggested that one important benefit of social media use lies in the development of 
inter-organizational networks between government agencies that facilitate knowledge sharing between employees.

Knowledge sharing is also favoured by citizens but not to the same degree as the other two stakeholder groups. Citizens can find what others think of government services and share stories regarding government services through different social media tools. One of the benefits of social media collaboration in this instance is their reach across geographical boundaries (Anttiroiko, 2010). Therefore, it is expected that:

H4a: There will be no significant difference between government senior management and employees for the importance of collaboration and knowledge sharing through using social media.

H4b: Collaboration and knowledge sharing will be significantly more important for employees and senior management than it is for citizens.

\section{- Increased transparency}

Citizens want a greater role in public policy development and in the design and delivery of government services. They demand greater access to government data and more openness and transparency from their institutions (Nineteenth Annual Report to the Prime Minister on the Public Service of Canada, 2012; Anttiroiko, 2010). On the other hand, governments aim to transform the way they interact with citizens by enhancing transparency, communication and participation (Abdallah \& Khalil, 2009). It is important for citizens to have access to government information and engage with their government. Social media promise to increase transparency in 
governments through providing access to information and engaging citizens in policy development (Picazo-Vela et al., 2012; Nineteenth Annual Report to the Prime Minister on the Public Service of Canada, 2012).

According to the World Bank, government activities that provide access to information and encourage engagement may lead to "less corruption, increased transparency, greater convenience, revenue growth, and/or cost reductions" (E-Government, 2011). Social media are creating new pathways among all stakeholders with the promise inherent in their ability to transform governance by increasing a government's transparency and its interaction with citizens (Wigand, 2012, Bertot at al., 2010). Therefore, it is expected that:

H5: There will be no significant difference between government senior management and citizens for increased transparency by using social media.

\section{- Cost saving}

Among other benefits recognized by industry experts, social media allow organizations to engage in timely and direct customer relationships at relatively low cost with high efficiency in comparison with more traditional communication tools (Gillin, 2010; Picazo-Vela et al., 2012; Kuzma, 2010; Landsbergen, 2010). Current research on Open Government and the use of Web 2.0 technologies by Lavender (2013) supports the managers' position that social media tools contribute to cost saving by providing training for employees in place, promoting easier access to customer feedback, reaching customers in remote areas and educating and training customers as well as employees. These technologies could be used to publish a knowledge database, i.e. 
FAQs, and contribute to cost savings by establishing a standard for how an organization responds to inquiries (Lavender, 2013). Managing a budget is an important aspect of a senior manager's role, while lower level employees only concern themselves with budgets when they are impacted directly. Costs are usually not a consideration for citizens unless they are reflected in higher taxes. Accordingly, it is hypothesized that:

H6: Cost saving will be significantly more important for government senior management than for either citizens or employees.

\subsubsection{Barriers/ challenges}

Although, the adoption of social media brings some benefits for stakeholders, it might also face some barriers and challenges as well. There are a number of reasons suggested by the literature why governments have been slow in adopting social media tools. Some of these barriers relate to organization level factors (e.g. organizational culture), technology (e.g. security), policy, and legislative issues (e.g. privacy). Understanding these barriers/challenges and their causes and implications is very important for governments in analyzing implementation issues for social media and considering potential solutions.

\section{- Organizational culture}

Government culture in general can present a barrier to the adoption of social media tools. Although there have been some recent changes, the typical government culture can still be characterized as hierarchical, top-down, command-and-control, silo structured and risk averse (Mergel, 2013a). There is widespread agreement that social media tools could have an important 
impact on government, especially in opening up government operations and decisions to greater scrutiny. Greater deployment of social media tools is expected to involve broad changes to government culture and structure that will bring more collaborative, efficient, effective, and transparent government (Gil-Garcia et al., 2009; Anonymous, 2009).

Lavender (2013) examined individual (employee) adoption behaviour and management priorities regarding the adoption of Web 2.0 technologies and the business value derived from their use. The results from end users found that employees' adoption behaviour and management priorities were impacted by organizational culture that subsequently influenced the amount of business value obtained from Web 2.0 technologies. Thus, government culture plays a key role in social media implementation. Without shifting the organizational culture towards more openness and transparency, successful implementation of social media initiatives seems unachievable (McNutt, 2014; Lee \& Kwak, 2012; Bertot et al., 2010). Therefore, it is expected that:

H7a: Organizational culture will be a more important barrier for government senior management than for citizens

H7b: Organizational culture will be a more important barrier for employees than for citizens

- Creating and sustaining public engagement

Another important challenge for government is creating and sustaining public interest and engagement in specific issues. Adopting different social media tools does not mean that citizens 
will automatically participate in government discussions. On the other hand, when public engagement opens up discussion, it is possible for public conversations to develop in unexpected and perhaps undesirable ways. If government tries to constrain public comments too tightly, participation will decline over time and the reputation of the government may suffer. As a result, keeping the right balance between control and autonomy in public engagement is an important issue for social media implementation. It is also important for government to link the public input/feedback to policy-making or the use of social media will be seen mainly as a publicity device with little real influence (Lee \& Kwak, 2012). Therefore, it is expected that:

H8a: Creating and sustaining public engagement will be significantly more important for government senior management than for citizens.

H8b: Creating and sustaining public engagement will be significantly more important for government senior management than for employees.

- Privacy, and information security

Security and privacy issues are important barriers for social media implementation in a number of areas; this is especially true for government. In the open and informal environment provided by social media tools, sensitive and classified information can be shared intentionally or unintentionally. The open environment facilitated by Web 2.0 poses greater challenges than the traditional web where most resource owners can implement control mechanisms regarding individual access requests (Gil-Garcia et al., 2009). As a result the damage that stems from leaking sensitive information through social media could be more problematic than 
communication strategies based on static web presentations. In summary, due to the open and autonomous nature of social media and Web 2.0 technologies, the public and government agencies are concerned about the risk of accidentally disclosing confidential information and the vulnerability of systems to acts of hacking or similar attempts to appropriate private and personal data (Lee \& Kwak, 2012). Accordingly, it is hypothesized that:

H9: There will be no significant difference between the three stakeholder groups on issues of privacy and information security in using social media.

\section{- Data quality and integrity}

Data quality and integrity are other challenges that government agencies need to consider to ensure the accuracy, consistency, timeliness, usability and usefulness of data that they publish online. To do so, governments need to have formal processes governing the lifecycle of data collection and sharing. Taking advantage of different social media tools to provide varied communication channels is desirable since these offer options to citizens, but managing multiple communication channels requires skilled employees, effective management processes and appropriate governance structures (Lee \& Kwak, 2012). Therefore, it is expected that:

H10: Data quality and integrity will be significantly more important for government senior management than for citizens and employees. 


\section{Table 9 - Summary of Hypotheses}

H1a: For government senior management vs. citizens there will be no significant differences in terms of improved service delivery through social media.

H1b: Improved service delivery will be more important for government senior management and citizens than for employees.

H1b1: Improved service delivery will be more important for government senior management than for employees

H1b2: Improved service delivery will be more important for citizens than employees

H2a: There will be no significant difference between citizens and government senior management in the importance of two-way communication by using social media.

H2b: Two-way communication will be significantly more important for citizens and senior management than for employees.

H2b1: Two-way communication will be significantly more important for citizens than for employees

H2b2: Two-way communication will be significantly more important for senior management than for employees

H3: There will be no significant difference between the three stakeholder groups for the importance of participation and engagement in using social media.

H4a: There will be no significant difference between government senior management and employees for the importance of collaboration and knowledge sharing through using social media.

H4b: Collaboration and knowledge sharing will be significantly more important for employees and senior management than it will be for citizens.

H4b1: Collaboration and knowledge sharing will be significantly more important for employees than it will be for citizens

H4b2: Collaboration and knowledge sharing will be significantly more important for senior management than it will be for citizens

H5: There will be no significant difference between government senior management and citizens for increased transparency by using social media.

H6: Cost saving will be significantly more important for government senior management than it 


\section{Table 9 - Summary of Hypotheses}

will be for either citizens or employees.

H6a: Cost saving will be significantly more important for government senior management than it will be for citizens

H6b: Cost saving will be significantly more important for government senior management than it will be for employees

H7a: Organizational culture will be a more important barrier for government senior management than for citizens.

H7b: Organizational culture will be a more important barrier for employees than for citizens.

H8a: Creating and sustaining public engagement will be significantly more important for government senior management than for citizens.

H8b: Creating and sustaining public engagement will be significantly more important for government senior management than for employees.

H9: There will be no significant difference between the three stakeholder groups on issues of privacy and information security by using social media.

H10: Data quality and integrity will be significantly more important for government senior management than for citizens and employees.

H10a: Data quality and integrity will be significantly more important for government senior management than for citizens

H10b: Data quality and integrity will be significantly more important for government senior management than for employees

- The relative importance of different social media for stakeholder groups

As mentioned in Table 2 (section 2.2), Cook classified social media according to the way in which they perform four distinct functions: (1) communication, (2) cooperation, (3) collaboration, and (4) connection. There is the potential for overlap among these categories. 
Depending on the tools or the purpose, a particular social media tool can perform more than one function (Cook, 2008). For example, in terms of collaboration, knowledge sharing and employee engagement from senior management and employees' perspectives, wikis are the primary collaborative tools for improving information sharing and distributing information across organizations (Chang \& Kannan, 2008; Mergel, 2011).

It has been suggested that social networking sites, especially Facebook and social presence applications such as Twitter could be a useful tool in the Canadian context for government to connect and communicate with citizens, particularly younger generations (Anonymous, 2009). Cooperation tools such as YouTube (image and video sharing) provide opportunities for information services and enables individuals and organizations to share content with others. At this stage the lack of reliable information does not allow the development of separate hypotheses for each of the four functions of different social media tools especially as these may vary across groups, but after I collect my data, I will discuss the relative importance of different social media tools and compare them with Cook's classification (2008). 


\section{Methodology}

In this section, I will explain the research methodology for this thesis. As mentioned above, there has been very little empirical research related to citizens' and employees' needs and expectations concerning government use of different social media tools. The current literature mainly focuses on organizational perspectives toward social media adoption. For example, Picazo-Vela et al. (2012) studied the risks and benefits of social media applications in Central Mexico. The information for this study was derived from a workshop that took place in Mexico City. A recent qualitative study by Mergel (2013) explored social media adoption in the U.S federal government by interviewing 15 social media directors to understand the factors that influence internal adoption decisions. The current study aims to provide a broader view of government social media use through considering the benefits of and barriers to social media adoption from the perspective of three stakeholder groups including citizens who are the consumers of services, government officials (called government senior management) as decision makers and government employees. After a comprehensive review of the literature in this area and a pretest (including both a qualitative and quantitative study) at a Canadian government agency, taking into consideration time and resource constraints and in order to have a wider empirical base, I chose to use a mixed method design combining quantitative and qualitative approaches for this study. I have collected additional qualitative data to enhance my understanding of attitudes held by each of the three groups. This section will explain the research design, sample, data collection and analytic methods employed for this study. 
This study used a mixed methods design for collecting, analyzing, interpreting and reporting data. The most common and well-known approach to using mixed methods is the Triangulation Design (Figure 7). The main objective of this design is "to obtain different but complementary data on the same topic" (Morse, 1991, p. 122) to clarify and understand the research problem. This design brings together quantitative and qualitative methods and provides an opportunity for the researcher to compare and contrast quantitative results with qualitative findings or to validate and expand quantitative results with qualitative data (Creswell \& Clark, 2007). The Triangulation Design has four variants, but for the purpose of this study I have used the Validating Qualitative Data Model (Creswell \& Clark, 2007) to complement the quantitative survey by including a number of open-ended qualitative questions. By following this model I was able to collect both types of data within one survey instrument. As shown in Figure 7, in a Triangulation Design data collection for quantitative and qualitative data occurs at the same time. In this approach the weighting (relative importance) of the quantitative and qualitative methods are usually equal (Creswell \& Clark, 2007). In this research the data has been considered simultaneously during the interpretation and analysis. 


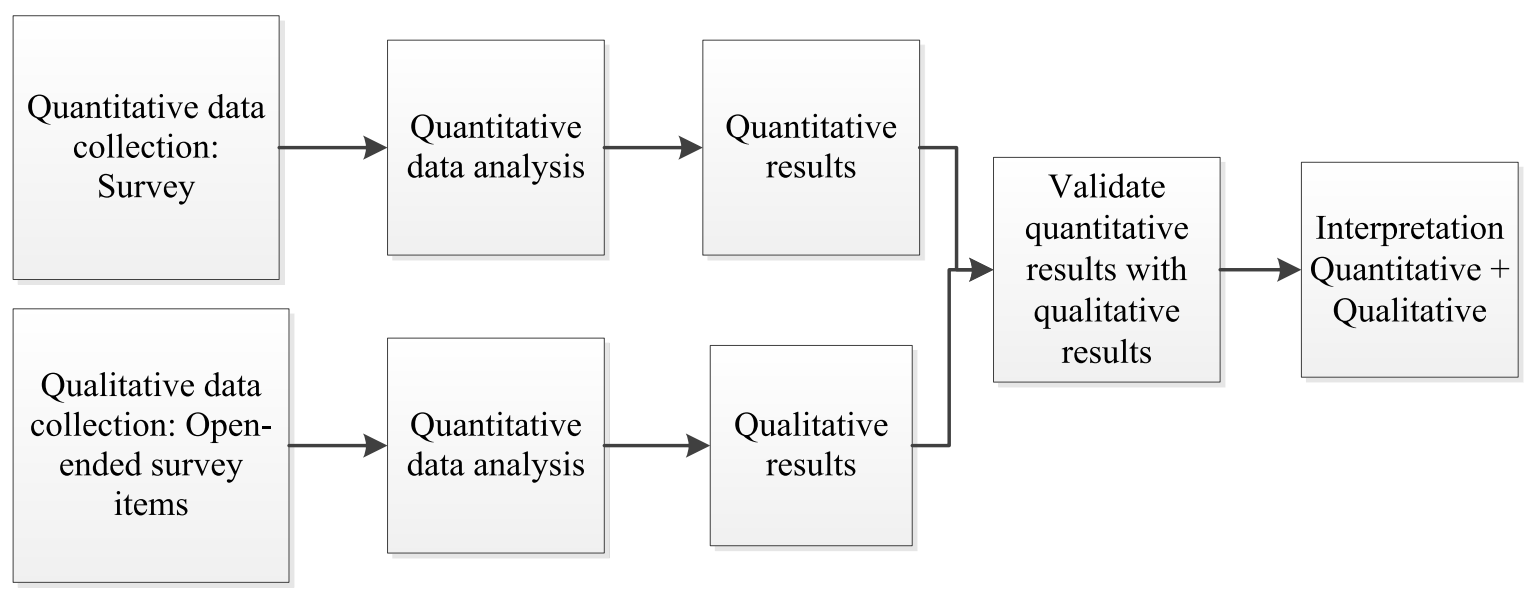

Figure 7 - Triangulation Design: Validating Qualitative Data Model

The empirical portion of this study begins with a quantitative survey instrument that included a number of open-ended qualitative questions designed to explore attitudes toward the government's use of social media tools. I gathered and analyzed data from individuals as representatives of each of the three groups of stakeholders, therefore, the level of analysis is the individual. I designed the questionnaire to gather respondents' evaluations of the various advantages and barriers that they perceive concerning the use of social media by government departments. The questions are partly drawn from the literature reviewed above and partly from my earlier work with a number of government departments. The earlier work was effective in discovering patterns in the use of social media by government departments. The parallel between the issues that I identified during my initial investigation and the variables suggested by the literature indicate that the items that I employed covered the most relevant factors indicating an acceptable level of face validity. The questionnaire is presented in Appendix A. For some questions, I employed a Likert scale for rating each of these items. These scales are divided in to 5 categories, with some ranging from strongly disagree to strongly agree and other from strongly 
helpful to not at all helpful. The second type also included an "I don't know" option. Like other methods the Likert type scale has several advantages and disadvantages. In terms of advantages the scale is highly recognizable, which makes it easy for most survey takers to complete. The data is also easy to analyze and allows for a wider range of answers compared to a simple yes-no questionnaire. However, the Likert Scale is uni-dimensional and only gives 5 options of choice, and intervals between choices on the scale do not necessarily present equal changes in attitude for all individuals. It may also fail to measure the true attitudes of respondents because sometimes individuals want to present a false impression of their attitudes, but this type of error is common to many forms of data collection (Bryman \& Bell, 2011).

The sample was drawn from an electronic group concerned with social media. The sample population for this study contains three different groups: 1) citizens, 2) employees and 3) government senior management from different government departments and agencies. Because it was difficult to discover those in the general population who have interactions with social media, I decided to use an electronic affinity group, LinkedIn, which has a social media focus for data collection. The members of this group include both government and non-governmental employees, providing samples of the groups necessary for the study. Using the Internet for survey research is similar to other methods in that it has some benefits as well as challenges. Via Internet we can efficiently recruit large and heterogeneous samples quickly, recruit specialized samples and easily replicate studies (Birnbaum, 2004). In terms of challenges, respondents to Internet-based surveys are most likely to be individuals who have access to computer networks, who have the skills to use the survey tools, and who accept and feel comfortable with Internet surveys. For web-based surveys there is always the danger that a participant can submit multiple 
responses (Zhang, 2000) although there seems little incentive for a respondent to do so in this case.

\subsection{The Survey Validity and Reliability}

In terms of the validity and reliability of the measurements, this study was concerned with construct validity, face validity and content validity. The instrument (survey questionnaire) was validated through the use of the majority of its items in a previous study and through a pilot test of the survey instrument. In developing the survey, the researcher reviewed the literature in this area, which contained references to all of the factors measured. Prior to this study the researcher had completed a similar study (including both a qualitative and quantitative component) at a Canadian government agency. In addition to this previous study, prior to data collection the researcher conducted a pilot test of the survey instrument using ten participants from the target population. Pilot test participants were asked to identify any confusing or offensive questions that would pose a threat to validity. The result found no substantial problems with the instrument though the pilot test participants did offer minor recommendations that impacted the current questionnaire. All suggestions from the pilot tests were used to refine and revise the questionnaire to ensure reliability and validity. Since no significant alterations were required, I proceeded with the data collection. The responses from the qualitative analysis indicate that respondents understood the questions clearly.

A high level of face validity is indicated by the fact that experts in the field believe that the items are relevant to the topic and the questions that were posed to an informed audience elicited appropriate responses. During the pilot test I also asked two social media communication 
advisors to review the questionnaire to determine whether or not the instrument reflected the concepts concerned; both approved the questionnaire. Concerning content validity, since there is no single construct being measured in this study, this form of validity has lower importance. The researcher did survey the literature and has constructed questions covering the most important dimensions of the topic. Therefore, the content-related evidence was checked by samples of participants during both the previous study and pilot test. The clarity and readability of the questions was tested through the pilot study. After analyzing qualitative data with a detailed description and interpretation of the current situation, the results of the current study and the previous work show similarities that indicate acceptable reliability in the survey instrument.

Since the hypotheses pose contrasts between the three groups, I used t-tests to evaluate the hypotheses and analyze the findings. More complex and sophisticated tests could be devised but since this was an exploratory study with little in the way of empirical work to guide my efforts and since the main concern was with the different goals of the stakeholders, t-tests were appropriate at this stage. Simple comparisons were seen as an important first step in determining both the degree and the direction of differences among the groups. Demographic data was also collected to examine possible differences based on age, education or other personal characteristics. The researcher believes that this input from participants will provide value for governments considering social media use as a means of contacting citizens and conducting official business as well as a guide to future research. 


\subsection{Sample}

I used an electronic group moderated through LinkedIn as the main source for respondents. There are several reasons for using LinkedIn including: 1) it contained people from all the relevant groups; 2) these people were at least familiar with the topic so could give reasonable answers; 3) they were easy to reach; 4) because there was already some connection, the problems with response rates would be lessened. I approached approximately 500 prospective participants who lived in Canada by email through LinkedIn. As with any sample this one posed certain issues of generalization, but it did have the advantage of including people who were likely to be informed and that were likely to respond. A larger sample of the entire Canadian population would have been very expensive and would have almost certainly produced a very low response rate. I also solicited participation of previous colleagues from different government departments where I had worked through direct email especially from those at the Director/DG levels. This was necessary partly because there were so few responses from this level and partly because some of them did not have a LinkedIn account. I also used the InMail feature in LinkedIn to target more government employees who are on LinkedIn but not part of the original group. With this feature I was able to send direct messages to more government employees although the response rate from this group appeared to be rather low. In order to broaden the scope of the research at the end of the data collection, I asked respondents to share the study with those who were interested in this area through their own social networks. It is therefore not possible to say what percentages of the respondents were included in the original network. Since individuals tend to cluster with those having similar profiles, whatever bias exists for those recruited in this way is probably similar to that found in the original group. 
This study similar to other studies in that it might suffer from three different types of bias in survey sampling: undercoverage bias, nonresponse bias, and voluntary response bias (Bryman \& Bell, 2011). Undercoverage bias occurs in survey sampling when some members of the population are inadequately represented in the sample, in this case those, who for some reason have never used social media services provided by a government. Nonresponse bias sometimes occurs when individuals chosen for the sample are unable or unwilling to do the survey. For example in the government senior management group the response rate was low, which may have been due to time pressures or reluctance to commit themselves on these issues. This study, as with any project depending on voluntary responses may be biased because certain segments of the potential pool are differentially represented. While I cannot rule out this type of bias, the fact that the original pool contained those who had expressed an interest in the topic, its effects are likely to be less severe than the other types.

Bias may also occur within the sample due to the operation of such factors as age or gender. For this study gender apparently had only a small effect with one benefit, building better relationships with citizens, exhibiting a significant relationship. There was also a significant correlation with one barrier, potential damage to intellectual property, but for the remainder gender had no large effect. When age was examined the outcome was quite different with regular patterns of bias emerging. Not surprisingly younger respondents perceived barriers to government's use of social media as less important than the older part of the sample. In contrast there was very little evidence of bias by age regarding potential benefits. Since the focus of this work lies in the potential differences among the three designated groups, this complication will not be pursued further although it may provide a fruitful area for future research. 


\subsubsection{Data Collection Process}

This study used an online survey instrument (attached as Appendix A) to explore the relative importance of the benefits and barriers for different stakeholder groups linked to social media use by governments. I used SurveyMonkey, an online survey service, to gather and categorize data from individuals as representatives of the three designated groups of stakeholders: government senior managers, employees below these levels from different government departments and agencies as well as citizens employed in the private sector, in educational institutions, in not for profit organizations, etc., i.e. those not engaged in government activities.

Having completed a study on this topic for a government department where I worked, constructing the current questionnaire was not difficult because I had already addressed some of these issues. For the pilot test I asked 10 individuals to complete the survey. These volunteers were from different organizations (employees from private and public organizations as well as students) with various backgrounds and levels of education to make sure the questions and instructions were clear. I also noted the time that each participant needed to fill out the survey. The results of the pilot test in terms of usability and clarity were acceptable indicating no need for major changes.

After receiving the initial responses, I realized that the number from the Director/DG level was quite low. As an alternative to communicating directly with those ranked Director/DG and above, I used the Government Electronic Directory Services (GEDS) which provides a listing of federal public servants for all regions across Canada to approach more high-level employees. 
Through this method I contacted 25 Director/DGs by email but not one of them completed the survey. I also contacted one Deputy Secretary to the Cabinet through my supervisor to see if I could arrange an interview with him in order to induce more cooperation from this group, but he only filled out the survey and declined to be interviewed or to assist me in contacting others at this level. To obtain a more even distribution I considered combining managers in the same category with the DGs/Directors and above together, but an examination of the data showed that managers more closely resembled the employees group so this redistribution was abandoned (See appendix B for more detail). In total, I received 206 responses of which 180 were complete. The initial survey took place in Canada in November 2013. The survey was available only in English.

\subsubsection{Demographics}

Table 10 shows that $60 \%$ of respondents were male and $40 \%$ female. This distribution is likely due to the fact that there is higher percentage of men in the IT area that was the basis of the LinkedIn connection employed to solicit participation. It may also be that males are more interested in joining a professional network such as LinkedIn. These biases might give rise to undercoverage bias in survey sampling. The table also shows that the majority of people in this sample have an undergraduate or postgraduate degree (85.42\%). The qualifications for a professional job in IT normally requires at a minimum an undergraduate degree which again is likely to be reflected in the LinkedIn membership. As one can see in Table 10, only 96 respondents indicated their level of education. Due to a clerical error this question was not added until almost $50 \%$ of the responses had been collected. There is little reason to believe that the overall distribution of this variable would be different if the additional data had been collected. 
Table 10 - Respondents' Profile: Demographic Features and Education Level

\begin{tabular}{|c|c|c|}
\hline Demographic Features & Frequency & Percent \\
\hline \multicolumn{3}{|l|}{ Gender } \\
\hline Male & 108 & $60.0 \%$ \\
\hline Female & 72 & $40.0 \%$ \\
\hline Total & 180 & \\
\hline Education Level & Frequency & Percent \\
\hline $\begin{array}{l}\text { Did not Graduate from high } \\
\text { school }\end{array}$ & 0 & 0 \\
\hline High School Graduate & 0 & 0 \\
\hline Some college & 14 & $14.58 \%$ \\
\hline Bachelor's degree & 41 & $42.71 \%$ \\
\hline Master's degree & 32 & $33.33 \%$ \\
\hline Ph.D. degree & 9 & $9.38 \%$ \\
\hline Total & 96 & \\
\hline
\end{tabular}

The respondents varied widely in terms of age (Table 11). The highest percentage of the respondents $(32.78 \%)$ were between 35 and 44 , followed by a relatively younger generation between 25 and $34(31.67 \%)$. 


\section{Table 11 - Age of the Respondents}

\begin{tabular}{|l|c|c|}
\hline Age of the Respondents & Frequency & Percent \\
\hline Under 18 years old & 0 & $0 \%$ \\
$18-24$ years old & 5 & $2.78 \%$ \\
$25-34$ years old & 57 & $31.67 \%$ \\
$35-44$ years old & 59 & $32.78 \%$ \\
$45-54$ years old & 37 & $20.56 \%$ \\
$55-64$ years old & 19 & $10.56 \%$ \\
Over 65 years old & 3 & $1.67 \%$ \\
Total & 180 & \\
\hline
\end{tabular}

Most of the respondents in this sample are currently employed (90\%). Those who are not employed tend to be students, retired, etc. (Table 12). In terms of respondents' employment sector, around half of them (51.11\%) work for the Government of Canada. This is mainly related to the Ottawa location as a significant proportion of the people from the primary LinkedIn site live in the region. In terms of the job positions of those respondents who work for the government, $56.04 \%$ are below managers. One quarter of the respondents are managers in the government $(26.37 \%)$. The $17.58 \%$ of respondents included in the DGs, directors and above category represent the main decision makers in the government. In this study all the remaining respondents are from the private sector, educational institutions, not-for-profit organizations or are unemployed, retired or students. These compose the citizens group (Table 12). 


\section{Table 12- Respondents' Employment Status}

\begin{tabular}{|l|c|c|}
\hline Employment Status & Frequency & Percent \\
\hline Employed & 162 & $90 \%$ \\
Unemployed & 3 & $1.67 \%$ \\
Retired & 2 & $1.11 \%$ \\
Student & 13 & $7.22 \%$ \\
Total & 180 & \\
\hline Sector & Frequency & Percent \\
\hline Government (all levels) & 92 & $51.11 \%$ \\
Private sector & 53 & $29.44 \%$ \\
Education & 17 & $9.4 \%$ \\
Not for profit & 4 & $2.22 \%$ \\
Not specified & 14 & $7.77 \%$ \\
Total & 180 & \\
& & \\
\hline
\end{tabular}




\section{Respondents' Employment Status (Cont.)}

\begin{tabular}{|c|c|c|c|c|c|}
\hline $\begin{array}{l}\text { Job title or } \\
\text { rank- } \\
\text { Government }\end{array}$ & Below manager & Manager & DG or Director & Above DG & Total \\
\hline & $\begin{array}{c}56.04 \% \\
51\end{array}$ & $\begin{array}{c}26.37 \% \\
24\end{array}$ & $\begin{array}{c}16.48 \% \\
15\end{array}$ & $\begin{array}{c}1.10 \% \\
1\end{array}$ & 91 \\
\hline \multirow[t]{2}{*}{$\begin{array}{l}\text { Job title or } \\
\text { rank-Private } \\
\text { sector }\end{array}$} & Below manager & Manager & $\begin{array}{l}\text { VP or } \\
\text { equivalent }\end{array}$ & $\begin{array}{l}\text { President or } \\
\text { CEO }\end{array}$ & Total \\
\hline & $\begin{array}{c}46.15 \% \\
24 \\
\end{array}$ & $\begin{array}{c}28.85 \% \\
15 \\
\end{array}$ & $\begin{array}{c}3.85 \% \\
2 \\
\end{array}$ & $\begin{array}{c}21.15 \% \\
11 \\
\end{array}$ & 52 \\
\hline \multirow[t]{2}{*}{$\begin{array}{l}\text { Job title or } \\
\text { rank-Education }\end{array}$} & Admin staff & Senior staff & $\begin{array}{l}\text { Professor (all } \\
\text { grades) }\end{array}$ & President or VP & Total \\
\hline & $\begin{array}{c}26.67 \% \\
4 \\
\end{array}$ & $\begin{array}{c}13.33 \% \\
2\end{array}$ & $\begin{array}{c}60 \% \\
9\end{array}$ & $\begin{array}{c}0 \% \\
0\end{array}$ & 15 \\
\hline \multirow[t]{2}{*}{$\begin{array}{l}\text { Job title or } \\
\text { rank-Not for } \\
\text { profit }\end{array}$} & Below manager & Manager & $\begin{array}{l}\text { VP or } \\
\text { equivalent }\end{array}$ & $\begin{array}{l}\text { President or } \\
\text { CEO }\end{array}$ & Total \\
\hline & $\begin{array}{c}42.86 \% \\
3\end{array}$ & $\begin{array}{c}28.57 \% \\
2\end{array}$ & $\begin{array}{c}14.29 \% \\
1\end{array}$ & $\begin{array}{c}14.29 \% \\
1\end{array}$ & 7 \\
\hline
\end{tabular}

\subsection{Results and Data Analysis}

In this section, I will examine in detail the results of the study. Both quantitative and qualitative methods were used to analyze the data. The SPSS V20 statistical package was employed for the main quantitative data analysis. For the qualitative work, the SurveyMonkey text analysis features were used to identify and categorize elements captured in the open-ended questions.

As presented in Tables 13 and Table 14, the overall, means are more heavily weighted by responses from employees and citizens due to the small number of responses from higher level government employees. In terms of the benefits of social media use for the sample as a whole almost all the respondents are above neutral which indicates that most of the respondents believe that the use of social media will increase the effectiveness of government services in different 
aspects such as providing timely and relevant information, improving two-way communication, improving service delivery, improving citizens' participation, engagement and collaboration and etc. Overall the means for all responses were located between 3 to 4 .

As shown in Table 13, "providing timely and relevant information" had the highest mean for the entire sample indicating that this element, as suggested by a number of authors, is one of the most important aspects of social media use by governments. At the other end "facilitating better recruitment" has the lowest mean in the table, which is a bit surprising given the large number of government employees in the sample. These results suggest that the three stakeholder groups consider social media tools as an appropriate way to convey and receive information from their government. From the perspective of government senior management (Director/DG and above) who are concerned with the dissemination of content, providing convenient, relevant and faster access to government information and improving two way communication are highly important. Moreover, in terms of an internal perspective, senior managers are mainly interested in improving work place collaboration and knowledge sharing for government employees. GCpedia is a good example of how social media are currently used in sharing information across Canadian government bodies. With two exceptions the means for all benefits are higher for senior managers than for the other two categories.

From the government employee perspective as service providers, besides allowing more convenient and faster access to government information, two-way communication and workplace collaboration are important factors. For citizens not only receiving timely and relevant 
information is important; they are also looking for participation and engagement with various levels of government. Social media tools promise to open the door for wider citizen participation.

Table 13- Benefits

\begin{tabular}{|c|c|c|c|c|}
\hline Variables & Overall Mean-180 & $\begin{array}{c}\text { Mean- } \\
\begin{array}{c}\text { Director/DG and } \\
\text { above (16) }\end{array}\end{array}$ & $\begin{array}{c}\text { Mean- Employees } \\
\text { (managers and } \\
\text { below-75) }\end{array}$ & Mean-Citizens (84) \\
\hline Improving service delivery & 3.7889 & 4.3125 & 3.9200 & 3.5476 \\
\hline $\begin{array}{l}\text { Improving two-way } \\
\text { communication }\end{array}$ & 3.9556 & 4.3750 & 4.0267 & 3.8095 \\
\hline \begin{tabular}{|l}
$\begin{array}{l}\text { Improving citizens' } \\
\text { participation and } \\
\text { engagement }\end{array}$ \\
\end{tabular} & 3.9832 & 4.2500 & 3.9333 & 3.9398 \\
\hline $\begin{array}{l}\text { Improving workplace } \\
\text { collaboration and } \\
\text { knowledge sharing } \\
\end{array}$ & 3.9833 & 4.3750 & 4.0267 & 3.8571 \\
\hline Reducing costs & 3.5222 & 3.7500 & 3.4400 & 3.5238 \\
\hline $\begin{array}{l}\text { Increasing government } \\
\text { transparency }\end{array}$ & 3.6517 & 3.8125 & 3.5811 & 3.6506 \\
\hline $\begin{array}{l}\text { Improving employee } \\
\text { engagement }\end{array}$ & 3.6271 & 4.0000 & 3.5753 & 3.5663 \\
\hline $\begin{array}{l}\text { Improving citizens' } \\
\text { collaboration and } \\
\text { knowledge sharing } \\
\end{array}$ & 3.8944 & 4.2500 & 3.7733 & 3.9048 \\
\hline Increasing public education & 3.9611 & 4.0625 & 3.9733 & 3.9048 \\
\hline $\begin{array}{l}\text { Building better } \\
\text { relationships with citizens }\end{array}$ & 3.8146 & 3.6875 & 3.7568 & 3.8675 \\
\hline $\begin{array}{l}\text { Providing timely and } \\
\text { relevant information }\end{array}$ & 4.1453 & 4.3750 & 4.2162 & 4.0119 \\
\hline $\begin{array}{l}\text { Providing convenient and } \\
\text { faster access to government } \\
\text { information }\end{array}$ & 3.9944 & 4.4375 & 4.0667 & 3.8313 \\
\hline $\begin{array}{l}\begin{array}{l}\text { Facilitating better } \\
\text { recruitment }\end{array} \\
\end{array}$ & 3.4972 & 3.2500 & 3.3784 & 3.6341 \\
\hline
\end{tabular}


Table 14 presents basic information for the whole sample concerning the possible challenges and barriers of social media adoption. In general the means reflect less concern for barriers and risks and a greater appreciation of benefits that might accrue. Privacy and information security is the main barrier for the three stakeholder groups although organizational culture is nearly as prominent. Privacy and information security are important challenges for social media adoption from the government senior management perspective. In addition to those concerns, organizational culture, data quality, creating and sustaining public engagement, official languages and lack of high level support are also important challenges for government decision makers. The risk of damage to intellectual property is not seen as an important challenge for any of the three stakeholder groups.

From an employees' perspective the main barrier is related to typical government culture. Although there have been some changes made recently, government culture can still be considered as hierarchical, top-down and most importantly a risk averse culture (Mergel, 2012; McNutt, 2014). As shown in Table 14, citizens believe that the use of social media has the potential to increase the risk that their personal information might be available to many people in an online community. Moreover, the quality of data content and lack of a coherent social media policy are other challenges that government needs to consider to ensure the accuracy, consistency, timeliness, usability and usefulness of data that they publish online. 
Table 14 - Barriers

\begin{tabular}{|l|c|c|c|c|}
\hline Variables & $\begin{array}{c}\text { Overall Mean } \\
\mathbf{( 1 8 0 )}\end{array}$ & $\begin{array}{c}\text { Mean- } \\
\text { Director/DG and } \\
\text { above (16) }\end{array}$ & $\begin{array}{c}\text { Mean- Employees } \\
\text { (managers and below) } \\
\text { (75) }\end{array}$ & Mean-Citizens (84) \\
\hline Organizational culture & 3.9659 & 4.4375 & 4.2703 & 3.6543 \\
\hline $\begin{array}{l}\text { Creating and sustaining } \\
\text { public engagement }\end{array}$ & 3.3657 & 4.2143 & 3.4459 & 3.1951 \\
\hline $\begin{array}{l}\text { Privacy and } \\
\text { information security }\end{array}$ & 4.0904 & 4.7500 & 4.0270 & 4.0366 \\
\hline $\begin{array}{l}\text { Data quality and } \\
\text { integrity (reliability of } \\
\text { content) }\end{array}$ & 3.7784 & 4.3333 & 3.7297 & 3.7561 \\
\hline Official languages & 3.3239 & 4.3750 & 3.3562 & 3.1220 \\
\hline Departmental access & 3.4091 & 3.9333 & 3.5811 & 3.2073 \\
\hline $\begin{array}{l}\text { Lack of social media } \\
\text { policy }\end{array}$ & 3.5920 & 3.4000 & 3.4865 & 3.7375 \\
\hline $\begin{array}{l}\text { Perception that social } \\
\text { media tools are for } \\
\text { entertainment only }\end{array}$ & 3.2857 & 2.8571 & 3.4730 & 3.1707 \\
\hline $\begin{array}{l}\text { Potential for } \\
\text { defamatory comments }\end{array}$ & 3.5029 & 3.5714 & 3.3784 & 3.5625 \\
\hline $\begin{array}{l}\text { Misinterpretation of } \\
\text { original context }\end{array}$ & 3.4277 & 3.9286 & 3.2432 & 3.4875 \\
\hline $\begin{array}{l}\text { Risk of damage to } \\
\text { intellectual property }\end{array}$ & 3.0347 & 3.4615 & 2.7432 & 3.1975 \\
\hline $\begin{array}{l}\text { Possibility of a chaotic } \\
\text { relationship between } \\
\text { government and } \\
\text { citizens }\end{array}$ & 3.1329 & 3.2857 & & \\
\hline $\begin{array}{l}\text { Lack of high level } \\
\text { support }\end{array}$ & 3.7209 & 4.0714 & & \\
\hline
\end{tabular}




\section{Hypothesis Testing}

To answer the research question proposed for this study, 10 hypotheses were developed in Chapter 5, with some having multiple components. This section presents the implications of the data analysis for the 10 hypotheses. Tables 15 and 16 present the results of the first group of hypotheses that deal with the possible benefits of social media for government use. The second group of hypotheses (Tables 17 and 18) are related to challenges and barriers in the use of social media. Some of these barriers concern organizational aspects (e.g. organizational culture), policy, and legislative issues (e.g. privacy and information security). One-tailed t-tests were used where the hypotheses indicated a directional difference between two groups. Two-tailed t-tests were used when the hypothesis posited no significant difference between the groups. A .05 alpha level of significance or $95 \%$ confidence level was established to reject the null hypothesis for this study. 
Table 15 - Two-Tailed Test: Benefits

\begin{tabular}{|c|c|c|c|c|c|}
\hline & \multicolumn{3}{|c|}{ Groups } & \multirow{2}{*}{$\begin{array}{l}\text { 2-Tailed Test } \\
\text { Hypothesis }\end{array}$} & \multirow[b]{2}{*}{ Sig. (2-tailed) } \\
\hline Variable & $\begin{array}{l}\text { Mean- } \\
\text { Director/DG } \\
\text { and above: } \\
\text { (D) }\end{array}$ & $\begin{array}{l}\text { Mean- } \\
\text { Employees } \\
\text { (managers } \\
\text { and below): } \\
\text { (E) }\end{array}$ & $\begin{array}{l}\text { Mean- } \\
\text { Citizens: (C) }\end{array}$ & & \\
\hline $\begin{array}{l}\text { Improving } \\
\text { service delivery }\end{array}$ & 4.3125 & 3.9200 & 3.5476 & $\begin{array}{c}\text { H1a: } D=C \text { not } \\
\text { supported }\end{array}$ & 0.001 \\
\hline $\begin{array}{l}\text { Improving two- } \\
\text { way } \\
\text { communication }\end{array}$ & 4.375 & 4.0267 & 3.8095 & $\begin{array}{c}\text { H2a: } C=D \text { not } \\
\text { supported }\end{array}$ & 0.021 \\
\hline \multirow{3}{*}{$\begin{array}{l}\text { Improving } \\
\text { citizens' } \\
\text { participation and } \\
\text { engagement }\end{array}$} & \multirow{3}{*}{4.25} & \multirow{3}{*}{3.9333} & \multirow{3}{*}{3.9398} & $\begin{array}{l}\mathrm{H} 3: \mathrm{D}=\mathrm{E} \\
\text { supported }\end{array}$ & 0.18 \\
\hline & & & & $\begin{array}{l}\mathrm{H} 3: \mathrm{C}=\mathrm{D} \\
\text { supported }\end{array}$ & 0.16 \\
\hline & & & & $\begin{array}{l}\mathrm{H} 3: \mathrm{E}=\mathrm{C} \\
\text { supported }\end{array}$ & 0.97 \\
\hline $\begin{array}{l}\text { Improving } \\
\text { workplace } \\
\text { collaboration } \\
\text { and knowledge } \\
\text { sharing }\end{array}$ & 4.375 & 4.0267 & 3.8571 & $\begin{array}{l}\mathrm{H} 4 \mathrm{a}: \mathrm{D}=\mathrm{E} \\
\text { supported }\end{array}$ & 0.078 \\
\hline $\begin{array}{l}\text { Increasing } \\
\text { government } \\
\text { transparency }\end{array}$ & 3.8125 & 3.5811 & 3.6506 & $\begin{array}{l}\mathrm{H} 5: \mathrm{D}=\mathrm{C} \\
\text { Supported }\end{array}$ & 0.38 \\
\hline
\end{tabular}


Table 16 - One-Tailed Test: Benefits

\begin{tabular}{|c|c|c|c|c|c|c|c|}
\hline & \multicolumn{3}{|c|}{ Groups } & \multirow{2}{*}{ 1-Tailed Test } & \multirow[b]{2}{*}{ Results } & \multirow[b]{2}{*}{$\begin{array}{l}\text { Sig. (2- } \\
\text { tailed) }\end{array}$} & \multirow[b]{2}{*}{$\begin{array}{l}\text { Sig. } \\
\text { (one- } \\
\text { tailed) }\end{array}$} \\
\hline Variable & $\begin{array}{c}\text { Mean- } \\
\text { Director/DG } \\
\text { and above } \\
\text { (D) }\end{array}$ & $\begin{array}{c}\text { Mean- } \\
\text { Employees } \\
\text { (managers } \\
\text { and below) } \\
\text { (E) } \\
\end{array}$ & $\begin{array}{c}\text { Mean- } \\
\text { Citizens (C) }\end{array}$ & & & & \\
\hline \multirow{2}{*}{$\begin{array}{l}\text { Improving } \\
\text { service } \\
\text { delivery }\end{array}$} & \multirow[t]{2}{*}{4.3125} & \multirow[t]{2}{*}{3.9200} & \multirow[t]{2}{*}{3.5476} & $\begin{array}{c}\text { H1b1: D }>E \\
\text { not supported }\end{array}$ & $\begin{array}{c}\mathrm{D}>\mathrm{E} \text { is in the } \\
\text { right direction } \\
\text { but not } \\
\text { significant }\end{array}$ & 0.057 & 0.0285 \\
\hline & & & & $\begin{array}{c}\text { H1b2:C }>\text { E not } \\
\text { supported }\end{array}$ & $\begin{array}{c}\mathrm{C}>\mathrm{E} \text { not } \\
\text { supported and } \\
\text { is in the wrong } \\
\text { direction }\end{array}$ & 0.010 & 0.005 \\
\hline \multirow{2}{*}{$\begin{array}{l}\text { Improving } \\
\text { two-way } \\
\text { communication }\end{array}$} & \multirow{2}{*}{4.375} & \multirow{2}{*}{4.0267} & \multirow{2}{*}{3.8095} & $\begin{array}{c}\mathrm{H} 2 \mathrm{~b} 1: \mathrm{C}>\mathrm{E} \\
\text { not supported }\end{array}$ & $\begin{array}{c}\mathrm{C}>\mathrm{E} \text { is not } \\
\text { supported and } \\
\text { is in the wrong } \\
\text { direction }\end{array}$ & 0.162 & 0.081 \\
\hline & & & & $\begin{array}{c}\mathrm{H} 2 \mathrm{~b} 2: \mathrm{D}>\mathrm{E} \\
\text { not supported }\end{array}$ & $\begin{array}{c}\mathrm{D}>\mathrm{E} \text { is in the } \\
\text { right direction } \\
\text { but not } \\
\text { significant }\end{array}$ & 0.144 & 0.072 \\
\hline \multirow{2}{*}{$\begin{array}{l}\text { Improving } \\
\text { workplace } \\
\text { collaboration } \\
\text { and knowledge } \\
\text { sharing }\end{array}$} & \multirow{2}{*}{4.375} & \multirow{2}{*}{4.0267} & \multirow{2}{*}{3.8571} & $\begin{array}{c}\mathrm{H} 4 \mathrm{~b} 1: \mathrm{E}>\mathrm{C} \\
\text { not supported }\end{array}$ & $\begin{array}{l}\mathrm{E}>\mathrm{C} \mathrm{E} \text { is in the } \\
\text { right direction } \\
\text { but not } \\
\text { significant }\end{array}$ & 0.179 & 0.089 \\
\hline & & & & $\begin{array}{c}\text { H4b2: } D>C \\
\text { supported }\end{array}$ & $\begin{array}{c}\mathrm{D}>\mathrm{C} \text { is in the } \\
\text { right direction } \\
\text { and is } \\
\text { significant }\end{array}$ & 0.008 & 0.004 \\
\hline \multirow{3}{*}{ Reducing costs } & \multirow{3}{*}{3.75} & \multirow{3}{*}{3.4400} & \multirow{3}{*}{3.5238} & $\begin{array}{c}\text { H6a: } \mathrm{D}>\mathrm{C} \text { not } \\
\text { supported }\end{array}$ & \multirow{2}{*}{$\begin{array}{c}\mathrm{D}>\mathrm{C} \text { is in the } \\
\text { right direction } \\
\text { but not } \\
\text { significant }\end{array}$} & \multirow[t]{2}{*}{0.318} & \multirow[t]{2}{*}{0.159} \\
\hline & & & & & & & \\
\hline & & & & $\begin{array}{c}\text { H6b: D }>\text { E not } \\
\text { supported }\end{array}$ & $\begin{array}{l}\mathrm{D}>\mathrm{E} \text { is in the } \\
\text { right direction } \\
\text { but not } \\
\text { significant }\end{array}$ & 0.200 & 0.1 \\
\hline
\end{tabular}


Hla: For government senior management vs. citizens there will be no significant differences in terms of improved service delivery through social media.

The results shows that hypothesis H1a is not supported; as the findings of a two-tailed ttest reported in Table 15 indicates that improved service delivery is considerably more important for government senior management than citizens. Hypothesis H1a proposed that improved service delivery would have equal importance for government senior management and citizens although for different reasons. The literature suggests that government officials hope to leverage social media tools to improve service delivery to their clients (Bertot et al., 2012). In contrast, citizens were expected to value these tools for their ability to provide timely and relevant services (Kavanaugh et al., 2012).

The results indicate that having an accurate picture of citizens' needs and expectations for better service delivery is an essential criterion for government senior management in order to deploy social media tools appropriately. The responses of the two groups suggest that while the desire for improved service delivery occurs among citizens, high-level managers may overestimate this demand just as some e-government commentators have done. The higher level of importance for senior officials may reflect a general interest in the potential of social media or it may be a mistaken projection of citizens' needs based on other benefits such as cost-saving that might derive from greater government use of these tools. Thus, from a decision-making perspective, it is important to focus on the specific instances where government can meet the needs of citizens and improve the provision of services (Jeager \& Bertot, 2010). 
H1b: Improved service delivery will be more important for government senior management and citizens than for employees

H1b1: Improved service delivery will be more important for government senior management than for employees

The results indicate that the mean for government senior management is higher than that for employees but does not achieve the .05 level of significance. The finding of the one-tailed ttest in Table 16 shows that hypothesis H1b1 is in the right direction but not significant $(0.057)$ although the p-value is very close to significance at the .05 level. Picazo-Vela et al. (2012) mentioned that social media tools provide opportunities for direct as well as two-way communication between citizens and government officials. This will lead government senior management to understand citizens' needs and expectations and improve service delivery in ways that meets citizens' expectations. It is always important for a service provider to deliver better services for their clients and improve their services by listening to them. Since the burden of providing those services falls more heavily on lower level employees once the policy has been initiated, it is not surprising that employees show a lower score on this issue even though the result is marginal.

H1b2: Improved service delivery will be more important for citizens than for employees

The result of the one-tailed t-test in Table 16 shows that the supposition that improved service delivery will be more important for citizens than employees is not supported and in fact the result is in the opposite direction. It appears that government employees, similar to their 
senior managers, are concerned with providing better services. It may be that senior management's concern with this issue has communicated itself to lower level employees. Equally employees below the senior level may see the use of social media as a means to make their tasks easier to handle.

H2a: There will be no significant difference between citizens and government senior management in the importance of two-way communication by using social media

As shown in Table 15, hypothesis H2a is not supported based on the findings of a twotailed t-test. The mean of government senior management is higher than the mean of citizens for two-way communications. The literature suggested that social media could act as important communication channels to improve two-way communication between citizens and government (Picazo-Vela et al., 2012). The following two definitions are from government senior managers who when asked to define social media saw it as a tool for two-way communication:

“....a form of media that allows for two way discussion" (Respondent 4)

"A way to electronically communicate and interact with individual and groups. A two ways communication" (Respondent 10)

However one citizen also mentioned that social media is "any medium that provides social features, such as one-way or two-way interactions, broadcasting, enabling communication. Web 2.0 is a great enabler for it (Respondent 14)". The relative means indicate that this issue is important for citizens, but that senior managers perceive it as even more so. 
H2b: Two-way communication will be significantly more important for citizens and senior management than for employees

H2b1: Two-way communication will be significantly more important for citizens than for employees

The result of the one-tailed t-test in Table 16 shows that hypothesis H2b1 is not supported and it is in the wrong direction. Mainly the result indicates that two-way communication is not significantly more important for citizens than employees. Hypothesis $\mathrm{H} 2 \mathrm{~b} 1$ proposed that two-way communication would be significantly more important for citizens than employees. Lavender (2013) mentioned that social media tools change the earlier model of e-government that only provides static information by expanding to two-way communication, which provides direct communication channels between citizens and government so that citizens can easily provide feedback and conduct discussions with government officials. It is perhaps understandable that senior managers would be more convinced of the benefits of increased use of social media by government bodies, but it is somewhat surprising that there is no significant difference between attitudes of employees and citizens. It may be that since the sample was drawn from those interested in this area that their technical interest erases any concerns over increased workload or greater complexity.

In general the results of phrase analysis through SurveyMonkey for the word "communication" in social media definitions shows that all three groups are talking about communication through social media tools. The word communication was used by citizens 15 times out of 67, by employees 22 times out of 70 , and 7 times out of 14 at the government senior 
management level in their definitions of social media. This result has two implications: communication is among the most prominent functions for all three stakeholder groups; communication seems more important from government senior management perspective.

H2b2: Two-way communication will be significantly more important for senior management than employees

The result shows that hypothesis $\mathrm{H} 2 \mathrm{~b} 2$ is in the right direction but not significant. Hypothesis $\mathrm{H} 2 \mathrm{~b} 2$ proposed that two-way communication would be more important for government senior management than employees. The literature suggested that social media tools enable government senior management to engage in direct conversation with different stakeholder groups including citizens, but from an employee's perspective that might create an extra communication channel that involves an increased workload and a decreased level of job satisfaction. The result indicates no significant difference between the two groups for two-way communication. That might be related to employees' dual role as a citizen who expect to have two way communications with government and as an employee in government who provides service for citizens.

H3: There will be no significant difference between the three stakeholder groups for the importance of participation and engagement in using social media

Hypothesis $\mathrm{H} 3$ is supported. The results indicate that participation and engagement in using social media is important for all three stakeholder groups. The mean for senior management (4.25) is higher than that for employees (3.93) and citizens (3.94) although not 
significantly so. Nam (2012) mentioned that from the government senior management perspective, participation and engagement of citizens are important because it allows the integration of citizens' interests to create better policies, programs and services. Organizations are using social media to engage in conversations with clients to understand their needs and expectations. On the other hand employees and citizens can provide feedback and engage with government as well. All three groups of stakeholders value this function of increased social media use by government albeit from somewhat different perspectives.

H4a: There will be no significant difference between government senior management and employees for the importance of collaboration and knowledge sharing through using social media

The results shows that Hypothesis H4a is supported as the findings of a two-tailed t-test indicate that collaboration and knowledge sharing through using social media is important for government senior management and employees. The means show it is important for both groups although this may stem from different concerns. From the employees' perspective, the internal use of social media tools provides opportunities for collaboration, knowledge sharing with peers, and engagement with their organization. Since government bureaucracies tend to operate in silos, greater internal use of social media could help to make these barriers more permeable. Public managers can use wikis as collaborative tools to facilitate knowledge sharing between employees and to distribute information across organizational boundaries (e.g. GCpedia) thus leading to greater efficiency and less duplication of effort. Senior managers apparently also see the utility of this cross-fertilization. 
H4b: Collaboration and knowledge sharing will be significantly more important for employees and senior management than it is for citizens

H4b1: Collaboration and knowledge sharing will be significantly more important for employees than it will be for citizens

As presented in Table 16, hypothesis $\mathrm{H} 4 \mathrm{~b} 1$ is in the right direction but not significant (0.179). Hypothesis H4b1 proposed that collaboration and knowledge sharing would be significantly more important for employee than it is for citizens. Cook (2008) suggested that social media tools can enhance productivity by providing workplace collaboration opportunities for employees. Citizens also can share their experience with government services through social media tools and find what others think about government services. The level of interest for knowledge sharing is pretty much the same, although the reasons for this estimate are probably not identical or at least the type of knowledge sharing the two groups have in mind is different.

H4b2: Collaboration and knowledge sharing will be significantly more important for senior management than it will be for citizens

Hypothesis $\mathrm{H} 4 \mathrm{~b} 2$ is in the right direction and it is significant (0.008). The result shows that workplace collaboration and knowledge sharing is significantly more important for senior management than it is for citizens. For example, one of the respondents from the government senior management level defined social media as “...a collaborative platform” (Respondent 13). Similarly another respondent mentioned that social media “... is a platform on Internet and provides opportunity to communicate, cooperate and collaborate with your community" 
(Respondent 6). The literature suggests that government officials hope to leverage these collaborative tools to engage their employees and share knowledge across organization (Chang \& Kannan, 2008). Citizens are unlikely to concern themselves with the internal allocation of information as long as it does not affect them directly.

H5: There will be no significant difference between government senior management and citizens for increased transparency by using social media

The result of a 2-tailed t-test shows that there is no significant difference between government senior management and citizens for increasing transparency by using social media. As suggested by the literature the use of social media promises to increase transparency in government through providing access to information and engaging citizens in program and policy development (Picazo-Vela et al., 2012). Citizens want a greater role in policy development and they want more openness and transparency from their institutions (Nineteenth Annual Report to the Prime Minister on the Public Service of Canada, 2012). One of the respondents from the citizens' group specifically said that: "I would like to have transparency of the policies and privacy regulations" (Respondent 5). It seems that as proposed by hypothesis $\mathrm{H} 5$, increased transparency is equally important for government senior management and citizens.

H6: Cost saving will be significantly more important for government senior management than it is for either citizens or employees

H6a: Cost saving will be significantly more important for government senior management than it will be for citizens 
Hypothesis H6a is in a right direction but does not approach significance (0.318). While cost saving is a concern for senior managers, the mean is the lowest among the nine benefits included in the study. Although potential savings are often mentioned in the literature apparently senior management does not see this as highly important or, perhaps, does not believe that these savings will eventuate. Lavender (2013) mentioned that social media could contribute to cost saving by educating customers and employees, reaching customers in remote areas and promoting easier access to customers' feedback. At least some of these considerations are seen as positive by both groups, but not as much as other potential benefits.

H6b: Cost saving will be significantly more important for government senior management than it will be for employees

The result of the one-tailed t-test shows that hypothesis $\mathrm{H} 6 \mathrm{~b}$ is in a right direction but not significant $(0.200)$. Costs are usually not a consideration for employees unless they are impacted directly. Among other benefits recognized by literature, social media allows organizations to engage with their customer at relatively low cost in comparison with more traditional communication tools (Kuzma, 2010; Gillin, 2010). The fact that those at the managers' level are included in the employee group may have some effect on this result.

H7a: Organizational culture will be a more important barrier for government senior management than citizens

The result shows that hypothesis $\mathrm{H} 7 \mathrm{a}$ is in the right direction and is significant $(0.000)$. The findings of the one-tailed t-test reported in Table 17 show that organizational culture is a 
more important barrier for government senior management than citizens. Government culture plays a key role in social media implementation (Lavender, 2013; McNutt, 2014). The results show that $93 \%$ of government senior managers in the sample believe (strongly agree and agree) that government organizational culture is one of the important barriers for social media use. Clearly this is either not perceived by citizens or not seen as important.

\section{H7b: Organizational culture will be more important barrier for employees than for citizens}

Hypothesis $\mathrm{H} 7 \mathrm{~b}$ is also in the right direction and is significant $(0.000)$. The finding indicates that the government's hierarchical, command-and-control, top-down and risk averse culture could have more impact on employees than citizens. Due to the command-and-control culture, employees at some government departments and agencies do not have access to different social media tools, which is one of the employees' main concerns. For example, employees believe that having access to YouTube can provide learning opportunities for them, but some of the Government of Canada's departments and agencies do not provide access to all social media tools. This limitation is either not perceived by citizens or not seen as important. Taken together these two results indicate that government employees at whatever level are more cognizant of cultural issues in the effective use of social media by governments than are citizens despite the public image of government agencies as being highly bureaucratic. It is encouraging that both employees and managers recognize the problem, but it is not clear whether they interpret it in the same way. This could be an issue for future research. 
Table 17 - One-Tailed Test: Barriers

\begin{tabular}{|c|c|c|c|c|c|c|c|}
\hline & \multicolumn{3}{|c|}{ Groups } & \multirow{2}{*}{$\begin{array}{l}\text { 1-Tailed } \\
\text { test } \\
\\
\text { Hypothesis }\end{array}$} & \multirow[b]{2}{*}{$\begin{array}{l}\text { In the } \\
\text { Direction } \\
\text { Predicted }\end{array}$} & \multirow[b]{2}{*}{$\begin{array}{l}\text { Sig. (2- } \\
\text { Tailed) }\end{array}$} & \multirow[b]{2}{*}{$\begin{array}{l}\text { Sig. (1- } \\
\text { Tailed) }\end{array}$} \\
\hline Variable & $\begin{array}{l}\text { Mean- } \\
\text { Director/DG } \\
\text { and above-D }\end{array}$ & $\begin{array}{l}\text { Mean- } \\
\text { employees } \\
\text { (managers } \\
\text { and below)- } \\
\text { E }\end{array}$ & $\begin{array}{l}\text { Mean- } \\
\text { Citizens } \\
\text {-C } \\
\end{array}$ & & & & \\
\hline \multirow{2}{*}{$\begin{array}{l}\text { Organizational } \\
\text { culture }\end{array}$} & \multirow{2}{*}{4.4375} & \multirow{2}{*}{4.2703} & \multirow{2}{*}{3.6543} & $\begin{array}{l}\mathrm{H} 7 \mathrm{a}: \mathrm{D}>\mathrm{C} \\
\text { supported }\end{array}$ & $\begin{array}{c}\mathrm{D}>\mathrm{C} \text { is in the } \\
\text { right direction } \\
\text { and its } \\
\text { significant }\end{array}$ & 0.000 & 0.000 \\
\hline & & & & $\begin{array}{l}\mathrm{H} 7 \mathrm{~b}: \mathrm{E}>\mathrm{C} \\
\text { supported }\end{array}$ & $\begin{array}{c}\mathrm{E}>\mathrm{C} \text { is in the } \\
\text { right direction } \\
\text { and its } \\
\text { significant }\end{array}$ & 0.000 & 0.000 \\
\hline \multirow{2}{*}{$\begin{array}{l}\text { Creating and } \\
\text { sustaining } \\
\text { public } \\
\text { engagement }\end{array}$} & \multirow{2}{*}{4.2143} & \multirow{2}{*}{3.4459} & \multirow{2}{*}{3.1951} & $\begin{array}{l}\text { H8a:D }>C \\
\text { supported }\end{array}$ & $\begin{array}{c}\mathrm{D}>\mathrm{C} \text { is in the } \\
\text { right direction } \\
\text { and its } \\
\text { significant }\end{array}$ & 0.001 & 0.000 \\
\hline & & & & $\begin{array}{l}\mathrm{H} 8 \mathrm{~b}: \mathrm{D}>\mathrm{E} \\
\text { supported }\end{array}$ & $\begin{array}{c}\mathrm{D}>\mathrm{E} \mathrm{C} \text { is in } \\
\text { the right } \\
\text { direction and } \\
\text { its significant }\end{array}$ & 0.008 & 0.004 \\
\hline \multirow{2}{*}{$\begin{array}{l}\text { Data quality and } \\
\text { integrity } \\
\text { (reliability of } \\
\text { content) }\end{array}$} & \multirow{2}{*}{4.3333} & \multirow{2}{*}{3.7297} & \multirow{2}{*}{3.7561} & $\begin{array}{c}\text { H10a: } D>C \\
\text { supported }\end{array}$ & $\begin{array}{c}\mathrm{D}>\mathrm{C} \text { is in the } \\
\text { right direction } \\
\text { and its } \\
\text { significant }\end{array}$ & 0.035 & 0.017 \\
\hline & & & & $\begin{array}{l}\text { H10b:D }>E \\
\text { supported }\end{array}$ & $\begin{array}{l}\mathrm{D}>\mathrm{E} \text { is in the } \\
\text { right direction } \\
\text { and its } \\
\text { significant }\end{array}$ & 0.044 & 0.022 \\
\hline
\end{tabular}

H8a: Creating and sustaining public engagement will be significantly more important for government senior management than for citizens

The results show that hypothesis H8a is in the right direction and is significant $(0.001)$. As suggested in the literature, creating and sustaining public interest and engagement in terms of interacting through social media is one of the main concerns of government senior management. 
Mergel (2013) suggested that the second most commonly stated objective for having social media tools from government officials is engagement with citizens. Tools in themselves cannot be helpful if citizens do not engage and participate in discussions (Lee \& Kwak, 2012). This result indicates that while citizens are positive about using social media for engagement, they seem more concerned with the instrumental uses of social media. This attitude might be related to their fear that their comments and feedback might be used in a negative way.

H8b: Creating and sustaining public engagement will be significantly more important for government senior management than for employees

Hypothesis $\mathrm{H} 8 \mathrm{~b}$ is in the right direction and is significant (0.008). As I mentioned in the previous section for $\mathrm{H} 8 \mathrm{a}$, creating and sustaining public engagement is significantly more important for government senior management. Similar to citizens, employees do not seem to care as much as government officials regarding building and sustaining relationships with citizens since their concerns are more with the execution of immediate tasks than with broad mandates. However, the result shows that employees seem to be more engaged than citizens with government through social media, but they do not see maintaining engagement as their job. It is government's responsibility to motivate and provide open discussions for employees and citizens to build and maintain their engagement. Employees might even fear engagement because it would tie them too closely to the government or, as with citizens, they might fear that their comments and feedback might be used against them.

H9: There will be no significant difference between the three stakeholder groups on issues of privacy and information security by using social media 
The results show that hypothesis H9a is not supported. As the findings of a two-tailed ttest reported in Table 18 indicate there are important differences between the three stakeholder groups on issues of privacy and information security caused by using social media. Security and privacy are important barriers for social media use especially for government (Lee \& Kwak, 2012). The results show that privacy and information security is more important for government senior management than the other two groups. This might be due to that fact that they are the ones who are seen to be responsible for safeguarding confidential information. A leak of information thought to be secure would require explanations from senior managers rather than those at lower echelons in the government apparatus. Senior managers may also be more aware of the long-term consequences of such leaks on the confidence that citizens place in social media enabled services. However, the means for citizens and employees were located between 4 to 5 (Table 18) which indicates that these two groups also consider privacy and information security as one of the challenges they might face when dealing with government through social media. Interestingly the level is comparatively low for citizens who one would expect to be more highly concerned about this issue. It seems that they are more willing to rely on the government to handle these problems. 
Table 18 - Two-Tailed Test: Barriers

\begin{tabular}{|c|c|c|c|c|c|}
\hline & \multicolumn{3}{|c|}{ Groups } & \multirow{2}{*}{$\begin{array}{r}\text { 2-Tailed Test } \\
\text { Hypothesis }\end{array}$} & \\
\hline Variable & $\begin{array}{c}\text { Mean- } \\
\text { Director/ } \\
\text { DG and } \\
\text { above (D) }\end{array}$ & $\begin{array}{c}\text { Mean- employees } \\
\text { (managers and } \\
\text { below) (E) }\end{array}$ & $\begin{array}{c}\text { Mean- } \\
\text { Citizens (C) }\end{array}$ & & Sig. (2-Tailed) \\
\hline \multirow{3}{*}{$\begin{array}{l}\text { Privacy and } \\
\text { information } \\
\text { security }\end{array}$} & \multirow{3}{*}{4.75} & \multirow{3}{*}{4.0270} & \multirow{3}{*}{4.0366} & $\begin{array}{l}\text { H9: } D=E \text { not } \\
\text { supported }\end{array}$ & \\
\hline & & & & $\begin{array}{l}\text { H9: } C=D \text { not } \\
\text { supported }\end{array}$ & \\
\hline & & & & H9: $E=C$ supported & 0.00 \\
\hline
\end{tabular}

H10: Data quality and integrity will be significantly more important for government senior management than citizens and employees

H10a: Data quality and integrity will be significantly more important for government senior management than citizens

Hypothesis $\mathrm{H} 10 \mathrm{a}$ is in the correct direction and is significant. In parallel with issues around keeping data secure, senior government officials are concerned with the quality of this data quite possibly because it becomes the basis for policy decisions. Often sentiment data in social media suffer from low quality and a lack of reliability. Identifying the salient data points and filtering this information for decision-making is a continuing issue for government departments and agencies (Chun \& Luna Reyes, 2012). This analysis must also contend with the well-known problem that social media can be utilized by groups to indicate opinions that are only held by a few. 
Some of the other challenges that government senior management needs to consider are the accuracy, usability and usefulness of the data that they provide online. Making decisions on the basis of faulty data can cause severe repercussions in the short or long term. Taking advantage of different social media tools is desirable, but trying to manage them in an appropriate way can cause difficulties for senior management. Government needs to develop and adopt data models and strategies to manage and mine the important data in a timely manner and share this information with citizens. On the other hand citizens expect to receive accurate and useful data, but do not see its provision as their responsibility. In their eyes they are service/data consumers not providers.

H10b: Data quality and integrity will be significantly more important for government senior management than employees

As the results displayed show, hypothesis $\mathrm{H} 10 \mathrm{~b}$ is in the right direction and is significant. Hypothesis $\mathrm{H} 10 \mathrm{~b}$ proposed that data quality and integrity is significantly more important for government senior management than employees. $\mathrm{H} 10 \mathrm{~b}$ is similar to $\mathrm{H} 10 \mathrm{a}$, because it is mainly government senior management who are tasked with responsibility for overall data quality and integrity although employees may be concerned about specific cases. Those at higher levels have a responsibility to provide resources to enable their employees to do their jobs in providing timely, useful and consistent data for different social media tools.

This section presented the results and initial implications of the quantitative data analysis for the 10 hypotheses developed in Chapter 5. The analysis of quantitative data helps shed light on the fundamental research question posed in this study, which focused on the relative 
importance for different stakeholder groups of the benefits and barriers linked to social media use by governments. The results show that most of the hypotheses related to benefits of social media use were in the right direction but not significant. However, all the hypotheses related to barriers are significant and in the right direction with one exception (H9). In general the hypotheses concerning benefits were less likely to be supported than those concerning barriers. Since the hypotheses in this study were derived from work on social media use by government the results would seem to imply that the literature related to benefits is less accurate concerning benefits and barriers are much easier to perceive. As there were no earlier empirical studies to contrast benefits and barriers between different stakeholder groups, it is not surprising that not all of the results are significant. The existing theoretical literature is mainly from an organizational perspective emphasizing a government perspective, which may have focused more on potential benefits than perceived barriers. The low number of respondents from the senior management level diminishes the power of tests involving that group, but, of course, one cannot assume that simply adding cases would automatically lead to more significant comparisons.

The findings related to the hypotheses show that for government senior management vs. citizens improved service delivery and improved two-way communication do not have equal importance. Although the literature suggests that these potential benefits would have equal prominence for the two stakeholder groups although for different reasons. For both these items the means for government senior management are higher than those for citizens.

The results indicate that improving citizens' participation and engagement and increasing government transparency in using social media are important for government senior management 
and citizens. Participation and engagement are central concerns for the two groups but for different reasons. Governments want to use social media to engage in conversations with citizens to understand their needs and expectations and citizens want to participate to provide feedback and engage in policy making. Collaboration and knowledge sharing is significantly more important for senior management than it is for citizens. The literature also suggested that from an internal perspective government senior management consider social media as a collaborative platform for knowledge sharing across organization (Lavender, 2013; Mergel, 2011). Although cost saving (H6a) is not significantly more important for government senior manager vs. citizens it is in a right direction. Cost saving is an important concerns for government officials, but surprisingly it has the lowest mean for senior level managers of any of the potential benefits of adopting social media.

In terms of comparing government senior management vs. employees the results of onetailed tests show that the means for improved service delivery, improved two-way communication and cost saving for government senior management is higher than that for employees but none of these differences is significant for these three hypotheses (H1b1, H2b2, H6b). Improving citizens' participation and engagement as well as work place collaboration and knowledge sharing through using social media are important for government senior management and employees.

The means for improving citizens' participation and engagement for both employees and citizens group are very close. This might be related to employees' dual role as a citizen (service user) and as an employee in government who provides service for citizens. 
As the results displayed in Table 17 show, organizational culture, creating and sustaining public engagement and data quality and integrity are significantly more important for government senior management than citizens. Government senior management and employees mentioned organizational culture as an important challenge for social media use. All the four barriers including creating and sustaining public engagement, organizational culture, privacy and information security, and data quality and integrity have higher means for government senior management than the other two groups. It seems that for all three groups, senior government officials are seen as having the main responsibility for handling these challenges. The next section will present the result of qualitative data analysis. 


\section{Qualitative Analysis: Data Discussion and Findings}

This section presents the results of a qualitative analysis of certain open-ended questions included in the survey to gain a deeper understanding of attitudes toward government use of social media (Creswell \& Clark, 2007). The analysis in this section is based on eight questions from the survey answered by the three stakeholder groups. In order to maintain the anonymity of participants, the researcher will employ pseudonyms, e.g., Respondent 1 . This pseudonym will be used to label specific comments from each individual. The percentages referred to below are the percentage of those from that specific category responding to the question. The analysis of qualitative data and the findings from each question are presented below. In this section I found it useful in examining some questions to distinguish two groups within the employees category, those at the mangers' level and those below. Even though the numeric profiles of the responses from these two groups were similar, the comments they offered often reflected different viewpoints. These differences may stem from the managers' intermediate position between government senior managers and lower level employees.

\section{Q2: What does the term "social media" mean to you?}

There are several methods of examining written responses such as text analysis, a close reading of written work, that allows the researcher to explore levels of usage and meaning, but this method requires extensive sentence-based text (Rockwell, 2003). After reviewing all the social media definitions from the 180 respondents (157 answered and 23 skipped), the researcher decided that given the small sample size and the types of analysis available to use a straightforward corpus-based analysis in order to locate frequently used words and phrases. A 
utility available through the SurveyMonkey collection site made this type of analysis possible. Corpus analysis is a more contemporary approach to the examination of language in written form. This type of analysis involves using software to locate and characterize words, phrases or other syntactic units (Moon, 2010).

Basically they mentioned that social media provides a platform for communication, sharing information between actors (organization, individuals, etc.), connecting and interacting easily with other users (Table 19). Some respondents simply defined social media as a tool for social networking such as Twitter, Facebook, and LinkedIn. Others suggested that social media tools are essentially designed to create and exchange user-generated content, information and ideas in virtual communities and networks. These tools, by using the Web 2.0 environment, provide opportunities for user engagement and facilitate two-way conversation.

Table 19- Social Media Definition: Text Analysis

\begin{tabular}{|c|c|c|c|c|}
\hline $\begin{array}{l}\text { Text Analysis-Social Media } \\
\text { Definition }\end{array}$ & $\begin{array}{l}\text { Director/DG and } \\
\text { above (16) }\end{array}$ & $\begin{array}{l}\text { Government Employees } \\
\text { (Managers and below } \\
\text { Managers) (75) }\end{array}$ & $\begin{array}{l}\text { Citizens } \\
(84)\end{array}$ & $\begin{array}{l}\text { Overall } \\
(\mathbf{1 8 0})\end{array}$ \\
\hline Communication & 7 & 22 & 12 & 41 \\
\hline Share & 3 & 20 & 20 & 43 \\
\hline Interact & 3 & 14 & 18 & 35 \\
\hline Collaboration & 2 & 5 & 1 & 8 \\
\hline Connect & 0 & 9 & 15 & 24 \\
\hline Engage & 0 & 5 & 1 & 6 \\
\hline Easy access & 0 & 3 & 1 & 4 \\
\hline Create (or co-create) & 0 & 7 & 6 & 13 \\
\hline Exchange & 1 & 6 & 6 & 13 \\
\hline Networking & 0 & 4 & 5 & 9 \\
\hline User-generated & 0 & 2 & 1 & 3 \\
\hline Social networking & 0 & 4 & 1 & 5 \\
\hline
\end{tabular}


Government senior management mainly defined social media tools as a communication vehicle to share information and to interact with different audiences. For example, Respondent 5 said, "In a GC or work context I see social media as an electronic forum that allows public servants to easily interact with each other and citizens". Respondent 9 supported this view by saying that, "Social Media sites allow users to interact with each other, form communities and contribute content online directly, with few intermediaries. The value of social media sites is usually found in the communities that cluster around the site rather than the sophistication of the tools which they provide”. Overall, government senior management appeared to be focused on the communication possibilities and knowledge sharing ability of social media tools to support collaboration among people. It is interesting to note that at least some of the senior managers see social media as important for internal communication, a function that is not often mentioned in the e-government literature.

Government employees at the manager level, similarly defined social media as a new type of communication medium between individuals and groups. Social media provide opportunities to connect, collaborate, and share information and social interactions between people with similar interests. This is more about the social aspect than the operation of the technology itself. As suggested by Respondent 24, "It's social, involves other people, communication, exchanging ideas, collaboration, 2-way communication, technology, online. It's a buzz term that means, being social while using interactive technologies". The theme of social connections was echoed by Manager 7 who saw in social media, "the ability to connect with like-minded individuals. As 
the word 'social' [implies a] way of meeting or connecting with people, friends and family. Used more and more by business as a way of increasing or providing information about their company or themselves to achieve a wider audience for their product." This evidence suggests that lower level managers have slightly different opinions from government senior management about the communication functions of social media tools. They seem to favour two-way communication and exchange ideas instead of one-way communication that pushes information to the client, a view that seems more prominent in the vision of government senior management. The idea underlying these definitions is that social media is a term for different applications that enable users to participate and connect with people in a collaborative fashion (Cook, 2008). The collaborative idea was also emphasized by Respondent 15 who defined social media as any online collaborative platform that allows people to co-create and/or share information with each other, "often in a decentralized way with 'user profiles' as a key central feature". The emphasis on the interactive aspect of social media may indicate that managers also view the use of these tools as important for internal government communication.

Lower level employees mainly defined social media as sharing and communication tools being used in a modern way that is open and transparent in comparison with traditional communication channels. This perspective is very similar to managers and citizens who define social media tools as appropriate for two-way conversation. Table 20 presents some examples of employees' definitions of social media tools. Employees as a service user of government services expect to use these tools to help them communicate with government in an open, less controlled environment. 
Table 20- Employee's Definition of Social Media

\begin{tabular}{|c|c|}
\hline $\begin{array}{l}\text { Respondent- } \\
\text { Government employees } \\
\text { (below managers) }\end{array}$ & What does the term "social media" mean to you? \\
\hline Respondent 43 & $\begin{array}{l}\text { "Social media is a modern way of internet-based communication, } \\
\text { instant information sharing/distribution and creation of a new form of } \\
\text { association by "virtual" community". }\end{array}$ \\
\hline Respondent 23 & $\begin{array}{l}\text { "The media that is more open and connected with less control and } \\
\text { censorship; its basis are the nodes or people who take part in it". }\end{array}$ \\
\hline Respondent 19 & $\begin{array}{l}\text { "Social media refers to interaction among people in which they } \\
\text { create, share, and/or exchange information and ideas in virtual } \\
\text { communities and networks. Andreas Kaplan and Michael Haenlein } \\
\text { define social media as 'a group of Internet-based applications that } \\
\text { build on the ideological and technological foundations of Web 2.0, } \\
\text { and that allow the creation and exchange of user-generated content'. } \\
\text { Furthermore, social media depends on mobile and web-based } \\
\text { technologies to create highly interactive platforms through which } \\
\text { individuals and communities share, co-create, discuss, and modify } \\
\text { user-generated content. It introduces substantial and pervasive } \\
\text { changes to communication between organizations, communities, and } \\
\text { individuals". }\end{array}$ \\
\hline Respondent 15 & $\begin{array}{l}\text { "Communications tools that allow for a two-way conversation } \\
\text { between the "speaker" (whether an individual or organization) and } \\
\text { the "audience"". }\end{array}$ \\
\hline
\end{tabular}

The results suggest that citizens have similar degrees of knowledge regarding social media tools as the two groups discussed above although, as mentioned before, the sample may be somewhat biased in that direction. From their perspective social media tools are more for communication, sharing information, interacting and connecting with other individuals and organizations. Citizen 5 stated that, "Social media is any medium that let people interact and communicate with each other in virtual worlds of internet and networking. It started with introduction of Internet with chat rooms, Web-loggers and extended to much richer experience 
with mobile devices and services such as Facebook, Twitter and etc.”. Another citizen defined social media from a different angle. He suggested that social media has two perspectives as both a noun and a verb and mentioned that, “...to me social media is essentially synonymous with the 'modern internet'. Hence why I like to contextualize all discussions relating to social media and separate the noun from the verb. Social Media (noun)--> Internet based tools and applications that build on the ideological and technical foundations of Web 2.0. --> I like to refer to this as 'social media tools'. Social Media (verb)--> The creation and exchange of user-generated content. --> I like to refer to this as 'social media engagement"'. Moreover the social features are also supported in citizens' group in much the same way as in the other groups. These quotations show that citizens perceive social media as a tool to share information with friends, families and society and to connect with them. This virtual community offers the possibility of interaction with governments in an open and transparent environment. Appendix $\mathrm{C}$ includes more examples of social media definitions from all three stakeholder groups.

Overall, the responses from all the different stakeholder groups indicated that they believed social media tools enhanced communication, collaboration and knowledge sharing through interactions and connections enabled by the open and collaborative platforms offered by Web 2.0. This is underlined by the fact that "share", "communication", and "interact" are the top three words included in the definitions offered by government senior management and employees. Even though employees used communication, share and interact in their definitions, their responses show that their definition of communication and interaction goes beyond communication itself and is more related to two-way conversations. This might be related to the perceptions that employees consider themselves as a service users as well as service providers, 
an example of the multiple roles experienced by users (Rowley, 2011). For citizens the "connect" word occurs more frequently than "communication". Citizens' understanding of social media might be shaped by their experience with social network tools such as Facebook for connection and two-way conversation rather than other functions. The results indicate that all three stakeholder groups have a similar degree of knowledge regarding social media tools but citizens' expectations differ from those inside government structures. This implies that a thorough knowledge of stakeholders' expectations of social media and their functionality is a necessary first step in allowing governments to employ these tools appropriately.

\section{Q10: Do you have any general concerns about using social media?}

Almost one third of government senior management $(36.36 \%)$ responding mentioned that privacy is their most important concern about using social media. Respondent 3 said that, "the only concern that I have is that you always have someone watching you; therefore nothing is private anymore". This is interesting as it seems to indicate that higher government officials are not only worried about the security of others' information, but that of their own communications as well. Not only is privacy a major concern, but possible misinterpretation of the original context could be important too. As stated by Respondent 5 that, "there is always a concern that information will be shared that has not been approved or messages will be misinterpreted or out of context. There is very little tolerance for mistakes by public servants these days".

Similar to government senior management, government employees at the manager level believe that privacy is one of their most common concerns about using social media (25.49\%). Respondent 17 said, "In my view, the main concern of using social media is an individual's 
privacy breach as well as misinterpretation or even increasing misappropriation of personal information. Mainly for this reason, I do not use Facebook which imposes too many requirements to disclose very personal information which then becomes available to anyone in the world with Internet access". This individual seems to be more concerned about the potential misuse of their own information than that collected by governments from citizens.

Employees below the manager level also indicated that government has a strong culture of information control with several layers of approval required. Respondent 14 said, "...to interact with the public, it seems like you've either got to train your spokespeople to use Social Media or train your Social Media team to be spokespeople, both of which are barriers". Moreover, having a consistent internal policy is very important for enabling government employee to feel comfortable and secure when using social media and sharing their personal information. As stated by Respondent 26, "as a public servant, the line between freedom of self-expression as a Canadian on social media and not seeming to be representing views or opinions on behalf of the Government of Canada is blurry. Some internal policies exist in government departments, but they are not widely endorsed, communicated or followed. This needs to be resolved before public servants can feel safe using social media". Here the idea of potential negative consequences for the individual emerges again. At least some employees wish to have an open conversation with government, but want to be assured that they can do so without fear of prosecution or other negative consequences.

Similar to other stakeholder groups, citizens indicate that privacy and information security are their biggest concern (47.72\%). Respondent 48 said that, "privacy is the biggest 
issue and how government and other agencies collect our personal data". This seems similar to employees' perception that not only are they concerned about privacy, but also knowing how government collects and evaluates their personal information is important as well. Some government departments and agencies such as the Royal Canadian Mounted Police (RCMP) before hiring employees, review the candidate's social media profile to evaluate his/her character and personality. This scrutiny accompanies more traditional evaluation practices.

As suggested by the literature, security and privacy are not new issues for social media implementation; these barriers were identified over a decade ago when the e-government concept first emerged (Lavender, 2013; Gil-Gracia et al., 2009). The interesting finding from an examination of the data is that each stakeholder group has its own solution to managing and overcoming these barriers. Some respondents from the citizens group believe that education and training play an important role. Respondent 75 argued that to obtain more trust among users, government could offer training, “...In order to ensure that social media is used effectively and safely, perhaps the government could offer 'social media training' sessions to those who do not feel confident with the process and thus their participation in the platform of social media." Similarly, Respondent 28 said, "there is always the risk of losing intellectual property, someone steeling your idea/ photos, and using them as their own. However, in a world where people open their newsfeed on Facebook instead of reading the daily newspaper, you must evolve. Education is key on using social media, because not everything you read may be what it seems". Additionally, Respondent 49 supported a training solution and said that this is more about people than tools, "Not about using social media but rather the people using the tools. $99 \%$ of issues boil down to human behaviour. What is needed is education, training, guidelines, strategy, 
governance and human resources". These sentiments indicate a belief in the need for education in general to promote a critical approach to social media as well as specific training for those who are tasked with using social media for government purposes.

Q11: Do you have any specific concerns about using social media when dealing with the government?

Similar to general concerns about the use of social media when dealing with government, privacy is the main specific issue that arises for the three stakeholder groups. There are some concerns from the government senior management perspective that relate to using social media including: how social media are being internally managed, lack of action on social media use, leaking confidential files, and privacy itself. Respondent 16 suggested a risk awareness solution for government use of social media instead of restricting their use and mentioning that, "Social media has positive and negative implications for making government more effective. We need to be conscious of risks (e.g., social media creation of narrowcast echo chambers where individuals reinforce their views and are unwilling to address and engage wider challenges leading to it being harder to develop effective policies or gain widespread support for them)“. It appears that this individual is at least aware of the problem arising from a few motivated individuals dominating social media channels.

In terms of specific concerns about using social media when dealing with the government, government employees at the manger level had more concerns and suggestions than government senior management. From their perspective, besides privacy, a lengthy approval process, lack of standards and ethics, lack of awareness among the public, official languages, and being slow 
with social media adoption are all major issues. For example, Respondent 12 said that, "the approval process is contrary to the nature of what social media should be. It makes things slow and cumbersome and prevents us from going at the required speed. Official languages are also often a barrier in being able to use these tools effectively". Manager 6 mentioned that a lack of awareness of government programs and services is not a new issue. This issue existed for many years even before social media were available. Knowing what kind of services government can provide for their citizens is a very important concept for service users. There is a need for greater awareness, while government is becoming more involved with social media there is a lot of work to do in increasing awareness among the public. Overall, the managers mainly suggested the importance of having internal standards, ethics and protocols to implement social media use. Moreover, standards are not only necessary for implementation; they also provide structure and protocols for disseminating information to and collecting information from citizens through social media. As such clear standards are an important factor for successful implementation and use. This concern reflects managers' functions in having to turn policies generated at higher levels into action.

Employees' concerns are around information security, privacy, being watched and monitored for use and comments, many layers of approval, and insufficient engagement. For example, regarding security concerns, Respondent 10 said that, "I would think the main concern of using social media for government would be potential security breach and wrongful use or misinterpretation of information posted by government sources. Government generates an enormous amount of information and another related concern would be deciding what, when, in what form and degree to disclose it, as well as who will make such decisions and on what 
legislative basis". Due to the open and autonomous nature of social media tools, citizens, government employees and government officials are concerned about the risk of accidentally disclosing confidential information and security breaches that result in unauthorized access to data (Lee \& Kwak, 2012). Another concern from the employees' perspective is related to the bureaucratic culture and resulting levels of approval inside government which contrast strongly with the nature of social media. By the time a message passes through many levels of approval it is likely out-dated. As stated by Respondent 4, “... One of the largest benefits of social media is timely distribution of information. If the social media policy is inefficient or holds up information for 'approval' for too long, the information may become irrelevant or be heard/seen too late for it to be effective in any way". It appears that the government senior management is less concerned about the approvals process than lower levels employees.

From the citizens' perspective privacy and security of information delivered through social media tools are also very important. As stated by Respondent 48, "It is not easy to ensure our personal data will be secured”. This concern was echoed by Respondent 11 who said that, “... most communication with the government is personal, and not something I would want made public. If I were to use social media, I assume it would be more to research something, rather than a two -way communication". If this attitude is widespread among citizens, it may pose a serious barrier to some of the more interactive uses posited by social media advocates. Those citizens who expected to have an open conversation with government wanted to do so without fear of prosecution, profiling or being watched. As suggested by the literature, social media relies primarily on open participation leading to citizen engagement. Open participation provides opportunities for collaboration to include citizen engagement in government policy development 
(Lee \& Kwak, 2012). Another concern expressed by citizens is the lack of access to government services through social media for specific populations (e.g. the elderly or the poor or disabled communities). Respondent 78 mentioned that, "my only concern is lack of access for certain segments of the population (ex. disability community, 'the poor', etc.) who may otherwise benefit from this avenue of communication but would be either less able or unable to do so due to barriers to technology". Since social media would be one of the communication channels between citizens and government, this issue could be addressed by having other more accessible communication channels for specific target audiences.

For this question the findings indicate that employees at the manager level, tend to consider a wider variety of organizational implications in their suggestions. They cited a lack of standards, privacy issues, official languages, lack of awareness regarding government services through social media, and slow adoption processes as internal issues that government officials need to consider in their policy development. Employees are more concerned about the effects of a bureaucratic, silo-based culture of government for the social media adoption process. As mentioned earlier, privacy is an issue for all three stakeholder groups regarding the use of social media when dealing with government.

Q 12: When you contact government through social media, what are you trying to accomplish?

At the government senior management level, more than half of those responding to this question (5 out of 9) mentioned that they want to obtain information by contacting government including access to information and sharing information. For example, Respondent 14 said that 
"obtain and share information regarding a government service, participate in an interactive broadcast, assist in recruitment" are his primary goals. There was one senior manager who mentioned that besides obtaining information, improving communication was important while contacting government. This again emphasizes that internal uses of social media are important to government senior managers.

From a government employee's perspective at the manager level, getting information $(41.18 \%)$ as well as quick responses $(17.65 \%)$ from government officials are their most important concerns. Basically they suggested seeking information about particular products and services, real-time conversation, fast and accurate information and quick responses are the main items to accomplish. Manager 1 answered this question by saying that, "real-time conversations with higher/faster response rate from the government". A few managers said that they don't use social media to contact government, have no experience in this or they haven't done this yet which indicates that a general movement by government to more use of social media will involve some level of internal education.

Like the previous groups, employees below the manager level have a parallel perspective. Almost 40\% (39.39\%) said that they usually try to get information quickly through social media. One of the respondents mentioned that the main reason for him to use social media to contact government is to acquire timely information instead of searching government websites. Some employees mentioned that they used social media to provide feedback for government, an example of an individual playing multiple roles. For example respondent 48 said that, “...I would use social media to provide negative or positive feedback about a service or I would 
request information about a particular program". A few employees admitted that they have not yet attempted to use social media, but as respondent 4 said, "...If I saw more presence of government over social media I may be inclined to ask questions about services and/or other subjects". It seems that one of the key problems that citizens and employees currently face is a lack of awareness regarding social media use by government.

From the citizens' perspective, seeking information, asking questions about government services, educating users, gaining quicker access to information and giving feedback about a particular topic are the main goals they see in increased social media use. For example, Respondent 59 said that, "I think the government can use social media to better educate its citizens with regards to its policies, etc. and to broadcast information that needs to be provided to its citizens, but to request information from its citizens will need to be carefully considered due to privacy and information security, unless the information requested is of the nature of general survey, feedback etc.”. For example, Lavender (2013) indicated that YouTube is the best social media to educate and train individuals. Some users could better learn via a visual presentation rather than by reading. Not only can external users employ the training features of YouTube, but using this type of technology could also educate and train employees without incurring any cost (Lavender, 2013). The same idea was further supported by Respondent 1 who said, “... I imagine social media like YouTube can be helpful in providing education and information regarding government services to the users".

The results indicate that, as stated by all three stakeholder groups, obtaining timely and relevant information is a central concern. It is interesting that government senior managers on 
one hand want to improve communication with the public to enhance decision-making, but on the other hand they expect to obtain information from the government in their role as citizens. This is a further example of an individual playing multiple roles vis-à-vis social media. Citizens want to accomplish two-way communication and interaction with governments. They want to obtain information, ask questions, get a quick response and provide feedback to the relevant departments and agencies. It appears that for this question employees and citizens see themselves as service users who are looking for a more open environment conducive to two way conversation.

Q 13: Do you feel you are currently accomplishing what you intended by contacting the government through social media?

There are three types of answers to this question at the government senior management level. Only 5 respondents answered this question with the rest simply replying either "no" or "N/A". Another mentioned that government makes very limited (or inconsistent) use of social media (Respondent 5). Respondent 16 suggested a useful solution when he said, "As these tools evolve, we need to stop thinking about them as ways of 'contacting' government (like writing a letter). We'll need to consider how to dynamically develop policies and programs in ways that continually interact with and benefit from wider input". Thus it seems that recently government officials acknowledged the benefits of using social media tools to contact with citizens and receive feedback regarding their policies and programs.

At the employee level, mangers were mainly concerned that they don't have any relevant experience because they haven't contacted government through social media. Employees below 
the managers' level also had a similar reaction to this question. One third answered "no" to this question because they rarely use social media to contact the government while another third returned an "N/A" response. As mentioned by Respondent 20, "If I have to contact the government about something that is personal, I would contact them through the telephone or in person. However, I do retweet government content that is interesting or notable. In that way, I have a limited 'social' interaction with government social media accounts". Another employee suggested the reason to contact government through social media is mainly to get more public answers/opinions than general information from government. As indicated by Respondent 42, "normally when contacting the government through normal channels (e-mail, phone, postal mail), you have to go through a bureaucratic mess in order to get to someone to answer your question. Through social media your question is accessible to everyone and because of that increases the chances of having the question answered". This view contrasts with the perception cited above which cites the numerous levels of approval required for social media.

From the citizens' perspective, $46.66 \%$ said that they felt that they didn't accomplish what they intended by contacting the government through social media because there is not enough engagement from the government. One of the citizens had a different perspective and said that, "I am not sure if the comments are read by the right officials" (Citizen 13). This poses an interesting problem for establishing social media connections. Many citizens will want to address high public officials who clearly will not have time to read or respond to more than a fraction of messages. At a lower level citizens may be unsure what department or unit they should be contacting. 
Overall, the results show that from the three stakeholder groups' perspectives, they feel that either they haven't had enough interaction with the government to judge the effectiveness of social media or they haven't accomplished what they intended to do by contacting the government in this way. This is interesting in itself since conversations about the use of social media by governments have been under way for some time.

Q14: If you feel you are NOT currently accomplishing what you intended by contacting the government through social media, please explain why you feel this way.

Overall, there were few responses to this question, which may stem from three causes. First, respondents may feel that they are accomplishing their aims through social media although there is little evidence from other responses to support this view. Second, the respondents may believe that they have already addressed this issue through their earlier comments. Third, some respondents clearly do not use social media to communicate with government agencies and so would have no experience that would allow them to evaluate responses. At the government senior management level, Respondent 10 mentioned that because of multiple barriers it is difficult to accomplish what we expect. A further point by Respondent 5 was related to receiving information instead of contacting government by using social media. His use of social media connections with the government tended to be unidirectional, "I do not use social media to contact the government - I think that would be ineffective. I use social media to keep informed on what is going on in the GC."

Mangers listed some problems related to not accomplishing what they intended by contacting government such as: lack of social awareness about availability, slow answers, the 
government of Canada isn't there yet, there isn't a lot of room for conversation, and it is very one-way communication. In his study Lavender (2013) mentioned that awareness of the respondents regarding government services through social media could affect their use and engagement. Respondent 16 suggested that, "I think a lot more could be done by government on social media. For example, more interactive consultations, crowdsourcing government or public policy problems, developing policies that work both for government objectives and citizens' needs". The findings indicate that in answering this question managers mainly saw their role as an individual who wants to use government services.

From the perspective of the employees below manager they feel that any change in government is painfully slow, government is behind ever-evolving social media tools, government social media policy is not advanced enough, there is not enough online presence, the multi-stage approval process slows responses and when the government does reply it is usually standard text. Employee 43 mentioned three challenges regarding contacting government saying:

"... citizens who contact the government through the social media still experience delays in government responses unacceptable for the fast pace of the social media. The social media way of instant flow of information, that can be sometimes untrue or imprecise, is in conflict with the government strive to provide correct and precise information at the expense of the speed at which the information is supplied. Another obstacle for the government in utilizing social media is the multi-stage approval process of any type of communication. The biggest challenge is to attribute responsibility for the correctness of information to a specific public servant or to a Department/Minister, or the government as a whole. A mistake one public servant can make may be too costly for the 
government. Therefore, the speed of information is traded for its precision, appropriateness and correctness".

From a citizen's perspective government online information is mostly out of date. Some citizens also felt that the government does not have not enough online presence. There is also a feeling that government is not actively engaged with social media. For example, Respondent 49 didn't feel that he accomplished what he intended to do and said that, "when a social media account is only used to push out messages then nothing is accomplished".

The results indicate that all three stakeholder groups feel that they have not accomplished what they intended by contacting government through social media. Similar to the previous question, this might be related to the fact that they have not had enough interaction with the government to judge the effectiveness of social media or to a lack of awareness of services that governments provide. The paucity of visible government online presence and the multi-stage approval process that slows responses when people actually make contact are also issues. One of the most interesting outcomes for this question is the number of respondents, many of whom are interested in social media, who have not used these tools to contact government.

\section{Q 16: What information would you like to have about how social media is being used in} your government?

There are different suggestions from government senior managers in terms of information that they would like to have about how social media is being used such as: what tools are available, significant changes in legislation, more action than fear, data quality and integrity of content, the implications of the privacy act and job posting. For example Respondent 14 
suggested that he would like to know, "1. How is government ensuring that the social media platform(s) being used are in line with the government organization's mission? 2. Management of the social media content; 3. Review of the social media content for appropriateness". Furthermore regarding the privacy act, Respondent 3 said, "I would like to know exactly how it [social media] would be used in accordance with the Privacy Act". It is obvious that government senior managers are concerned with how the use of social media fits into and is consistent with the overarching rules and regulations.

At the employee level, managers have valuable suggestions for government. They see two roles for themselves: service provider and service user. Managers as a service user would like to see a list of services that are available through social media as well as internal job postings that may assist them in their careers. In contrast, as service providers they suggest a campaign for increased public awareness, including advertisements directing people to government social media pages. They would also like more information on how and why social media are being used, what kind of social media tools are available to them and how they may be used. Table 21 presents some examples of responses to this question from different stakeholder groups.

Employees want to know if the information is reliable and accurate, to what extent social media is being used, what policies have been developed for its utilization by government units, future plans of social media use, clear information about privacy concerns and how sensitive information is being protected. It seems that employees are more interested in knowing about policy, the current situation and future plans about social media use inside their departments and 
agencies. However, the social media policy in each department and agency might be different based on internal culture, department services and their current contacts with their clients.

From the citizens' perspective, it is important to know how social media is being used, what services are currently provided through social media, knowledge about the collection, use and disclosure of data, any kind of news about government such as government policies, information about privacy rules and regulations, as well as the overall social media policy. Like the other groups there appears to be an appetite for considerably more information among the citizens although their concerns seem less policy oriented and more toward practical issues of availability and accessibility.

Overall, the results indicate that there is a high level of uncertainty about many aspects of social media use by governments and that the three groups of respondents share many of the same concerns. Many respondents were unclear about basic questions such as which services government provides through social media, policies regulating the government's use of social media, the level of government engagement, and to what extent social media tools are being used. 
Table 21 - Some Examples of What Information You Would Like to Have Regarding

\author{
Social Media Being Used in the Government
}

\begin{tabular}{|c|c|}
\hline $\begin{array}{l}\text { Government employee- } \\
\text { Director/DG and above }\end{array}$ & $\begin{array}{l}\text { Q 16: What information would you like to have about how } \\
\text { social media is being used in your government? }\end{array}$ \\
\hline Respondent 3 & $\begin{array}{l}\text { "I would like to know exactly how it would be used in accordance } \\
\text { with the Privacy Act." }\end{array}$ \\
\hline \multicolumn{2}{|l|}{$\begin{array}{l}\text { Government Employee- } \\
\text { manager level }\end{array}$} \\
\hline Respondent 24 & $\begin{array}{l}\text { "Depends on what I am looking for, each tool mentioned above has } \\
\text { its advantages and could be used to leverage some information, all } \\
\text { depending on what you wanted to focus on and what your target } \\
\text { audience is looking for. Each one can be used in the proper time, } \\
\text { messaging and info sharing" }\end{array}$ \\
\hline Respondent 6 & $\begin{array}{l}\text { "How services are being delivered through social media - there is a } \\
\text { perception that it is mainly for people to complain or informally } \\
\text { chat - there is still a barrier of getting people to recognize these tool } \\
\text { as a real means for delivering professional services". }\end{array}$ \\
\hline Respondent 1 & $\begin{array}{l}\text { "The media/tools being used and the level of engagement of the } \\
\text { government body. Also the authority/accuracy of the information } \\
\text { provided on the social media. In other words, whether there is a } \\
\text { direct link between policy/decision makers and the government } \\
\text { employees running the social media platform". }\end{array}$ \\
\hline \multicolumn{2}{|l|}{$\begin{array}{l}\text { Government Employee- } \\
\text { below manager level }\end{array}$} \\
\hline Respondent 45 & $\begin{array}{l}\text { "To what extent it's being used as a tool for outreach and keeping } \\
\text { citizens informed". }\end{array}$ \\
\hline Respondent 20 & $\begin{array}{l}\text { "It would be good to have one place where all the social media sites } \\
\text { of the government are listed." }\end{array}$ \\
\hline Respondent 15 & $\begin{array}{l}\text { "Would like to know how government (not politicians) will use } \\
\text { social media to improve service delivery and responsiveness to } \\
\text { citizen concerns". }\end{array}$ \\
\hline Respondent 1 & $\begin{array}{l}\text { "How sensitive information is being protected. How the information } \\
\text { is collected, used and published". }\end{array}$ \\
\hline Citizens & \\
\hline
\end{tabular}




\begin{tabular}{|l|l|}
\hline Respondent 59 & $\begin{array}{l}\text { "I would like to know how social media is being used by my } \\
\text { government and if services are provided through social media what } \\
\text { are those services. Some services may be of concern if provided } \\
\text { through social media". }\end{array}$ \\
\hline Respondent 44 & $\begin{array}{l}\text { "I would like to know how my personal information, comments and } \\
\text { other means of communication are being used and for what } \\
\text { purposes and if being analyzed and monitored". }\end{array}$ \\
\hline Respondent 4 & $\begin{array}{l}\text { "How they guarantee the accuracy of the information. What's the } \\
\text { purpose of using social media and who's the main target receiver". }\end{array}$ \\
\hline
\end{tabular}

Q 26: Do you have any suggestions on how government could better use social media?

From the government senior management perspective, social media tools are useful for more than simply pushing information out to clients. It is also for gathering information, input and feedback. Those who commented mentioned that government officials need to understand social media tools, how to use them and what their impact will be. Respondent 6 said, "Make it mandatory for your department. We can have all the projects on internal Wiki or each project/program could have their own blogs. Let people say whatever they want to say. Minimize approval process". Respondents suggested that government could use social media tools for internal use to provide collaboration and knowledge sharing between employees.

Any new technology tends to be driven by early adopters who appreciate the newness of the technology but may not be able to show business value (Mergel, 2013a). If the business value becomes self-obvious, then the new technology gets picked up by a larger segment of the population that "just wants it to work". Due to a number of factors built into the government environment (pressures to accomplish operational goals, organizational culture, lack of innovative spirit, etc.) it remains unclear whether government has been able to convert early 
enthusiasm into sustainable use. Respondent 9 described his personal experience with his department which utilizes three social media tools: wikis, Twitter, and blogs. The use of wikis in his department has two benefits for the average government employee. Wikis provide barrierfree online collaboration (in drafting documents) and enable low-priority web publishing without recourse to specialized web publishers. They also use Twitter to provide an early broadcast mechanism for a large number of users who have already adopted Twitter in their routines. Moving forward, social media also allows easy interaction with engaged individuals and communities, although it remains to be seen if the organization is interested in interacting more freely. Blogging platforms in his department allow for a somewhat controlled way to enable government to interact with larger communities. Blogs also speed up publishing for certain kind of content, and allow easier solutions to interactivity problems (Respondent 9).

As this paper mentioned before, knowing different tools, understanding their implications and having a comprehensive strategy are very important for senior management. As stated by Respondent 2, "Create an integrated social media strategy and develop expertise in social media planning, campaign management, and analysis to craft an authentic and effective communication within each governmental organizations and the external communities. Change the perception that social media distracts employees, wasting their time and reducing efficiency while posing additional risks to emphasize that social media tools can improve the way in which employees use resources, perform their jobs and make decisions". This insight is valuable in that it indicates government officials have noticed the benefit of using social media tools although in the current environment there is little evidence of government adopting this attitude. 
At the employee level, managers suggested government needs to be less risk averse, encouraging more conversation and interaction with citizens, utilizing more advertising regarding social media services. Moreover, these respondents mentioned that government needs to find ways to have a real conversation with citizens. The employees also feel that these tools could find more internal use for government employees. Respondent 1 stated that, "Social media is about having fast and transparent access to information and engaging in two-way discussions. Any social media policy adopted by the government should respect the above and not be overly restrictive. For instance, if the information has to go through a lengthy approval process before being published on social media, it may lose its timeliness and value to the public".

Employees below the manager level suggested faster and more open reactions to public opinion, two-way communication, minimizing the level of approval, citizens' participation in policy development and changes to government organizational culture. For example, Respondent 44 said that, "It would be interesting to try to develop policy papers in collaboration with stakeholders". Another respondent suggested, "Be more open to get messages out there faster and be more open to react to public opinion equally quickly" (Respondent 46). In terms of providing information for citizens, Respondent 10 mentioned that, "government information should be neutral, free from politics, religion and other contentious issues, presented in a simple, easily readable and understood format". Employees suggested that some social media tools could be beneficial for specific purposes. For example, Twitter could be used for public broadcasts, warnings, announcements, etc.; Facebook for two-way communication and feedback; Linked In for job postings and recruitment/scouting; YouTube and Vimeo for public education. 
Citizens expect to use social media to engage and have conversations with government officials. Governments could use social media to provide information to their citizens and to conduct surveys and receive other types of feedback with regards to public policy. Having different social media tools as a communication channel might encourage more involvement by young people, which could be beneficial for government. However, as suggested by Respondent 44, "Government needs to build trust by being open about how they protecting public information and the use of private information of its citizens and an assurance to the citizens that their information and opinions are not being used against them in any sort". Citizens mentioned that having social media pages is not an issue, but making the page up to date and interactive is very important for government to consider. For example, elected officials should be using Twitter to keep in touch with their constituents; the government itself should be pushing RSS feeds or have a blog to keep citizens up to date on what is happening in the country, province and city. Mayor Jim Watson (Ottawa) is an excellent example of a government official who interacts with people on social media as opposed to just providing information (Respondent 4).

In conclusion, there are some similarities and differences across the three stakeholder groups that are potentially related to their role(s) in the organization. As suggested by Rowley (2011) for e-government an important aspect of classifying stakeholders is to consider roles instead of groups. For example, at the same time an individual can be service user, a citizen, and a senior manager who is responsible for decision-making. Since there is potential overlap among these three stakeholder groups, there may also be tensions concerning how they evaluate the benefits from and barriers to social media use. One of the interesting elaborations of the quantitative data through the qualitative analysis was the differentiation of the managers from 
other employees below the DG level. While there statistical profile was similar, some of their specific concerns were quite different.

As I mentioned before, understanding stakeholder needs and expectations is important for governments as they attempt to craft appropriate strategies. Thus organizations including governments need to identify stakeholder groups and their relationships in order to analyze their preferences, goals and expectations. The next section presents an overview of the findings of this study as well as a discussion of similarities and differences among the three stakeholder groups (See appendix C for more detail). 


\section{Discussions, Conclusions, and Recommendations}

Different types of social media tools are being deployed by governments to a greater or lesser degree. For example, government departments and agencies have used wikis to internally share information, Twitter to provide an early broadcast mechanism for a large number of users, and blogs to interact with and communicate information to their audiences. The potential of social media tools creates a public sector paradox. On the one hand, social media tools provide opportunities for collaboration, two-way communication, citizens' engagement and transparency. On the other hand, information flow within government, across government agencies and between government and public is often highly restricted through regulation, slowed by a rigorously specified reporting structure and therefore delayed by a pervasive bureaucratic government culture. The emergence of social media tools shows that there is an apparent need within government to create, distribute and collect information outside the traditional, hierarchical government information flow. Clearly, Web 2.0 technology is creating dramatic changes in the way people communicate and collaborate over the Internet. Therefore, this potentially has an impact on the way governments work and communicate with employees and citizens. At the same time such deployments also create difficulties and challenges for organizations including governments in deciding if and how these technologies will be deployed. As mentioned above, it is not technology that prevents government from embracing this transformation and innovation; it is organizational barriers that need to be overcome (Mergel, 2013a). 
This study reviewed the relative importance of the benefits and barriers linked to social media use by government as seen by three stakeholder groups including government senior management, employees and citizens. Although a few studies have discussed the impact of social media adoption by government (Mergel, 2013a; Mergel 2013b; Bertot et al., 2012; Kavanaugh et al., 2012; Lavender, 2013; Picazo-Vela et al., 2012), this study aimed to link the benefits and barriers of social media use with specific stakeholders' needs and interests regarding government. The results strongly suggest that successful social media initiatives involves more than utilizing different tools; they require the engagement of different stakeholders, understanding their interests, needs and expectations and bringing them into alignment.

The results indicate that the three stakeholder groups envision different uses for social media tools (i.e. Facebook, Twitter, wikis and YouTube), but they exhibit a similar degree of knowledge regarding the tools. More than half of the employees and citizens report using Facebook daily. Twitter seems less popular among the three stakeholder groups with less than $20 \%$ daily use for all three groups. Wiki is more popular for government officials for daily use, which is related to the popularity of GCpedia inside the government. Employees use GCpedia for knowledge and experience sharing, and building communities of practice among those with similar interests in a particular domain or area. It also provides opportunities for the members to develop themselves personally and professionally. YouTube seems more popular for daily use by citizens than any other group (Table 22). 
Table 22 - Social Media Use

\begin{tabular}{|c|c|c|c|c|c|c|}
\hline \multicolumn{7}{|c|}{ Approximately how often do you use Facebook? } \\
\hline Answer Options & $\begin{array}{c}\text { Response } \\
\text { Percent- } \\
\text { Director/DG and } \\
\text { above }\end{array}$ & $\begin{array}{c}\text { Response } \\
\text { Count }\end{array}$ & $\begin{array}{c}\text { Response } \\
\text { Percent- } \\
\text { Employee }\end{array}$ & $\begin{array}{c}\text { Response } \\
\text { Count }\end{array}$ & $\begin{array}{c}\text { Response } \\
\text { Percent- } \\
\text { Citizens }\end{array}$ & $\begin{array}{c}\text { Response } \\
\text { Count }\end{array}$ \\
\hline Never & $18.8 \%$ & 3 & $5.4 \%$ & 4 & $10.7 \%$ & 9 \\
\hline Rarely & $43.8 \%$ & 7 & $9.5 \%$ & 7 & $14.3 \%$ & 12 \\
\hline A few times a month & $18.8 \%$ & 3 & $8.1 \%$ & 6 & $3.6 \%$ & 3 \\
\hline Weekly & $6.3 \%$ & 1 & $13.5 \%$ & 10 & $13.1 \%$ & 11 \\
\hline \multirow[t]{3}{*}{ Daily } & $12.5 \%$ & 2 & $63.5 \%$ & 47 & $58.3 \%$ & 49 \\
\hline & Answered question & 16 & & 74 & & 84 \\
\hline & Skipped question & 0 & & 1 & & 0 \\
\hline \multicolumn{7}{|c|}{ Approximately how often do you use Twitter? } \\
\hline Answer Options & Response Percent & $\begin{array}{c}\text { Response } \\
\text { Count }\end{array}$ & $\begin{array}{c}\text { Response } \\
\text { Percent }\end{array}$ & $\begin{array}{c}\text { Response } \\
\text { Count }\end{array}$ & $\begin{array}{c}\text { Response } \\
\text { Percent }\end{array}$ & $\begin{array}{c}\text { Response } \\
\text { Count }\end{array}$ \\
\hline Never & $18.8 \%$ & 3 & $36.0 \%$ & 27 & $45.2 \%$ & 38 \\
\hline Rarely & $6.3 \%$ & 1 & $17.3 \%$ & 13 & $20.2 \%$ & 17 \\
\hline A few times a month & $25.0 \%$ & 4 & $10.7 \%$ & 8 & $7.1 \%$ & 6 \\
\hline Weekly & $31.3 \%$ & 5 & $16.0 \%$ & 12 & $9.5 \%$ & 8 \\
\hline \multirow[t]{3}{*}{ Daily } & $18.8 \%$ & 3 & $20.0 \%$ & 15 & $17.9 \%$ & 15 \\
\hline & Answered question & 16 & & 75 & & 84 \\
\hline & Skipped question & 0 & & 0 & & 0 \\
\hline \multicolumn{7}{|c|}{ Approximately how often do you use any kind of wiki (Wikipedia, GCpedia, etc.)? } \\
\hline Answer Options & Response Percent & $\begin{array}{c}\text { Response } \\
\text { Count }\end{array}$ & $\begin{array}{c}\text { Response } \\
\text { Percent }\end{array}$ & $\begin{array}{c}\text { Response } \\
\text { Count }\end{array}$ & $\begin{array}{c}\text { Response } \\
\text { Percent }\end{array}$ & $\begin{array}{c}\text { Response } \\
\text { Count }\end{array}$ \\
\hline Never & $0.0 \%$ & 0 & $1.3 \%$ & 1 & $2.4 \%$ & 2 \\
\hline Rarely & $6.3 \%$ & 1 & $6.7 \%$ & 5 & $8.3 \%$ & 7 \\
\hline A few times a month & $25.0 \%$ & 4 & $26.7 \%$ & 20 & $25.0 \%$ & 21 \\
\hline Weekly & $31.3 \%$ & 5 & $38.7 \%$ & 29 & $38.1 \%$ & 32 \\
\hline \multirow[t]{3}{*}{ Daily } & $37.5 \%$ & 6 & $26.7 \%$ & 20 & $26.2 \%$ & 22 \\
\hline & Answered question & 16 & & 75 & & 84 \\
\hline & Skipped question & 0 & & 0 & & 0 \\
\hline \multicolumn{7}{|c|}{ Approximately how often do you use YouTube? } \\
\hline Answer Options & Response Percent & $\begin{array}{c}\text { Response } \\
\text { Count }\end{array}$ & $\begin{array}{c}\text { Response } \\
\text { Percent }\end{array}$ & $\begin{array}{c}\text { Response } \\
\text { Count }\end{array}$ & $\begin{array}{c}\text { Response } \\
\text { Percent }\end{array}$ & $\begin{array}{c}\text { Response } \\
\text { Count }\end{array}$ \\
\hline Never & $6.3 \%$ & 1 & $1.3 \%$ & 1 & $1.2 \%$ & 1 \\
\hline Rarely & $0.0 \%$ & 0 & $10.7 \%$ & 8 & $8.3 \%$ & 7 \\
\hline A few times a month & $31.3 \%$ & 5 & $18.7 \%$ & 14 & $16.7 \%$ & 14 \\
\hline Weekly & $50.0 \%$ & 8 & $38.7 \%$ & 29 & $34.5 \%$ & 29 \\
\hline \multirow[t]{3}{*}{ Daily } & $12.5 \%$ & 2 & $30.7 \%$ & 23 & $39.3 \%$ & 33 \\
\hline & Answered question & 16 & & 75 & & 84 \\
\hline & Skipped question & 0 & & 0 & & 0 \\
\hline
\end{tabular}


Similarly, the results show that the top five most helpful social media tools for the three stakeholder groups are, wikis, YouTube, Blogs, Twitter and Facebook (See appendix C for more detail). It is interesting to see that all three groups have similar ideas regarding how helpful they think each of the social media tools would be in delivering government services. Overall the means for these five social media tools were located between 2 to 3 , which means respondent perceived them either as very helpful or somewhat helpful. The result of a quantitative study by Bonson et al. (2012) in the European Union at the local level of government arrived at a similar conclusion, i.e. that Twitter, YouTube, Facebook, blogs, Flickr, and LinkedIn are the most widespread social media technologies employed by governments. Similarly, Sneed (2013), who studied social media use in the U.S. government, mentioned that the seven most common types of social media in his sample are: Twitter, Facebook, YouTube, and Flickr as external-based third-party hosted social media and RSS feeds, blogs, podcasts, and videos as agency produced and administrated tools that are the most popular in the U.S. government. However, the current study shows that Facebook in Canada is fifth, which is not as popular as in Europe or in the U.S. government. The results of the study by Snead (2013) in the U.S. and Bonson et al. (2012) in Europe placed Facebook as the number two social media after Twitter.

The level of engagement with government through social media is different among the three groups. Employees seem to be more moderately and heavily engaged than the other two groups. This might be related to their awareness of the social media tools being used by their department as well as a more precise knowledge of the services that government now offers through social media. The findings show that government senior management is less engaged than government employees, which might be related to their busy schedule leading to a lack of 
time for higher levels of engagement or it might also be connected to their fear that their words might be used in a negative way. Half of the citizens mentioned that they are not at all engaged with government through social media (Figure 7). As indicated by results reported above this low level of engagement is most likely related to a lack of awareness regarding services that government provides through social media, lack of trust and concerns about privacy and security of information. It is suggested that government needs to do more advertising regarding services and information available through social media. It is also government's responsibility to build a trust relationship with their users instead of having several online presences with different social media tools and using them mainly to push information rather than promoting interaction. As mentioned in the literature, due to the open nature of social media tools, citizens, government employees and senior management are concerned about the risk of disclosing confidential information (Lee \& Kwak, 2012; McNutt, 2014). Having said that, these issues shouldn't prevent government from using these tools although officials need to manage the attendant risks. This would require a change in the internal culture of government departments with policy makers and managers becoming less risk averse, more proactive, more open to ownership of information, and less bureaucratic in their insistence on multiple levels of approval. This would imply a less hierarchical structure inside government structures. These changes would require parallel changes in users' perspectives as they may be accustomed to viewing government as closed and inflexible.. 
Figure 8- Level of Engagement

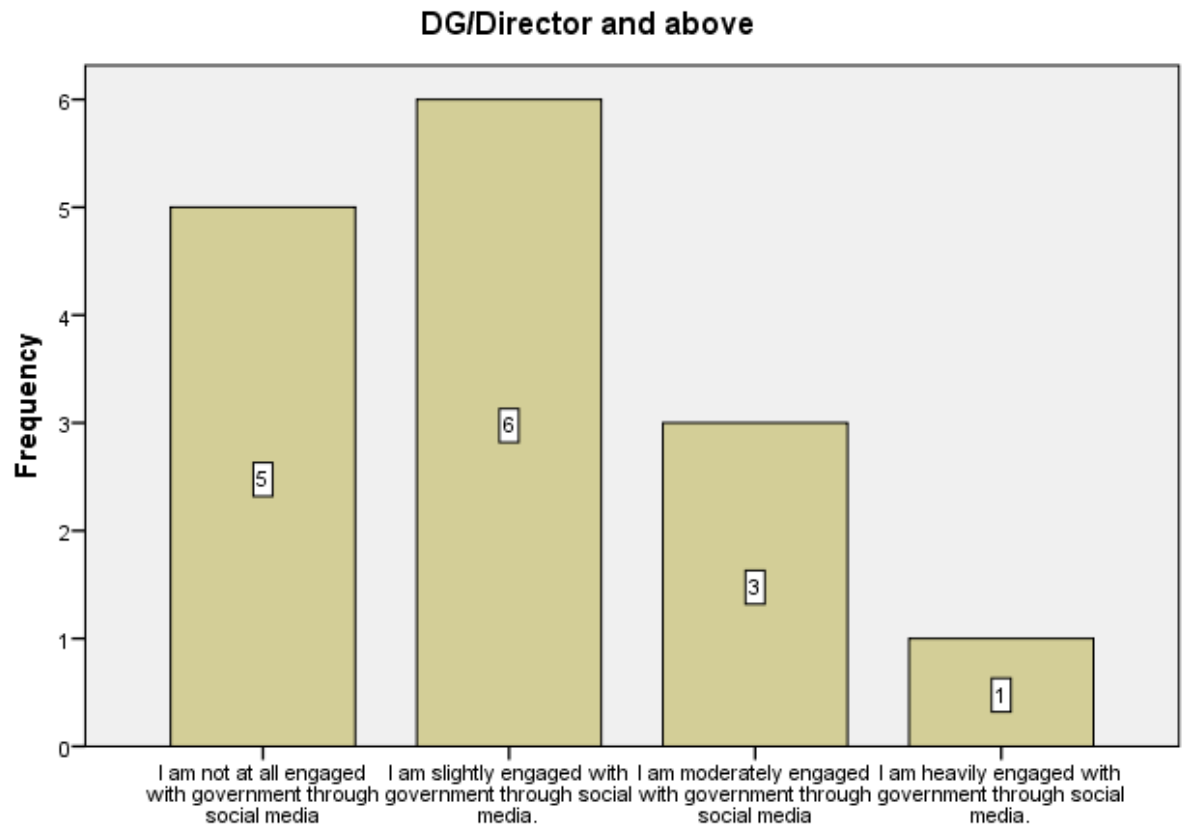

Please rate your level of engagement with government through social media such as Twitter, YouTube, Facebook and Wikis.

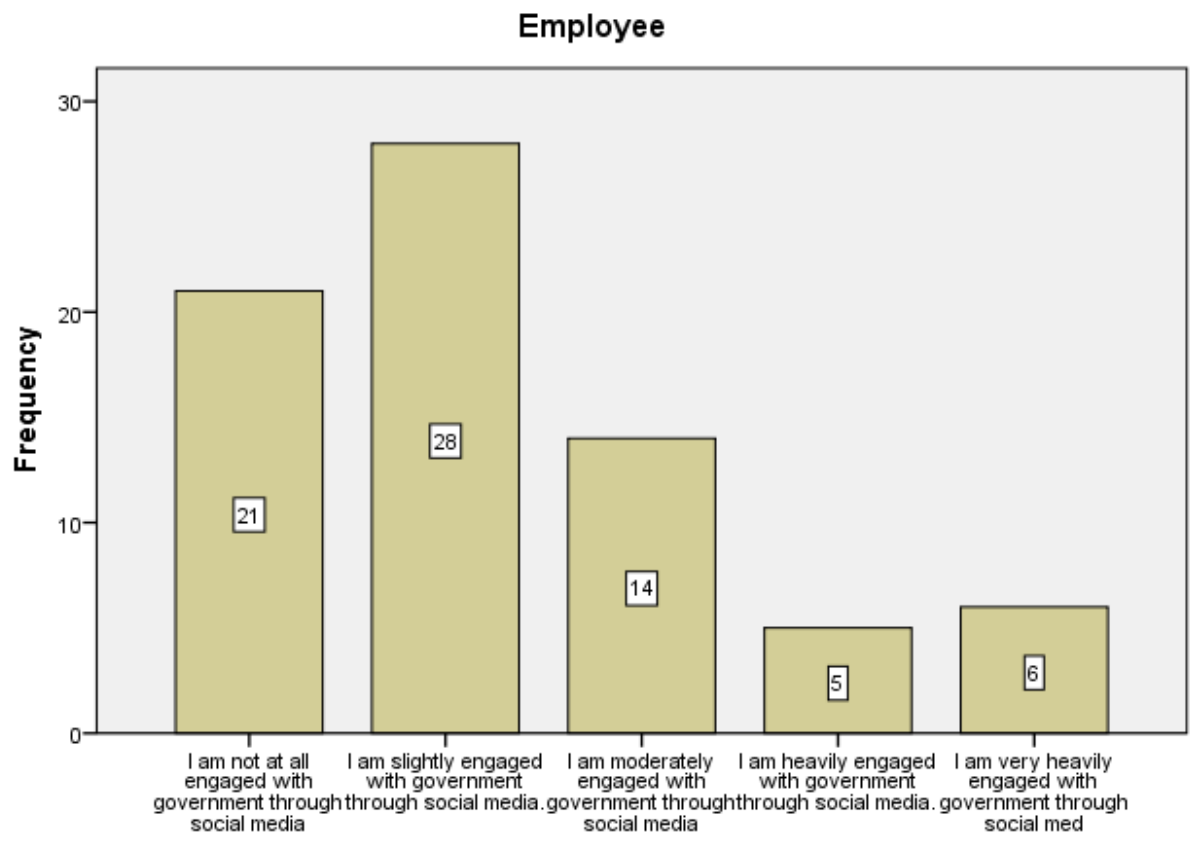

Please rate your level of engagement with government through social media such as Twitter, YouTube, Facebook and Wikis. 


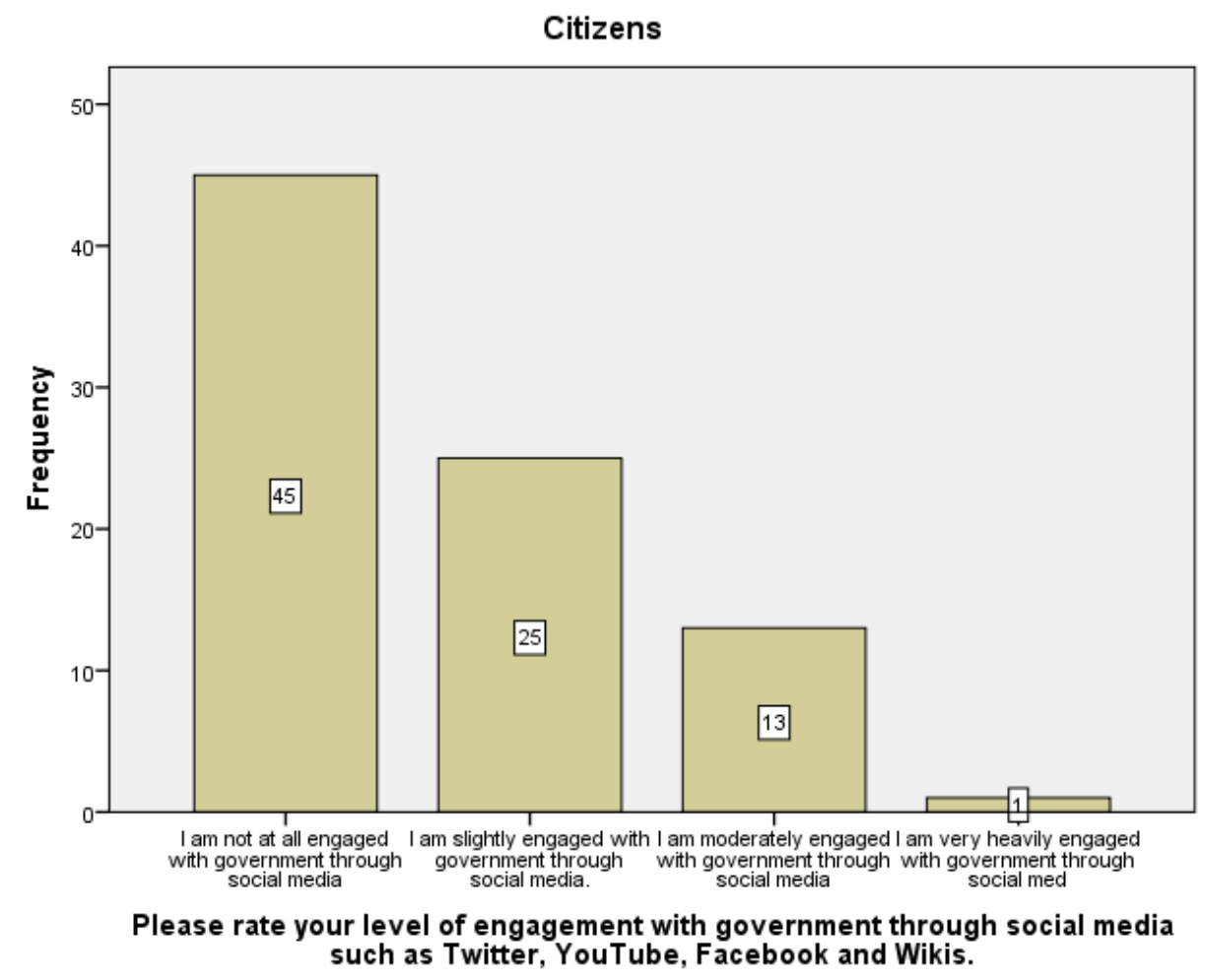

There are some similarities and differences across the three stakeholder groups in terms of perceived benefits and barriers which are mainly related to their role(s) in the organization. As mentioned earlier, there is a potential overlap among these three stakeholder groups regarding how they evaluate the benefits and barriers of social media based on their roles. Each benefit and barrier might be dependent on individual role(s). For example, an individual employee might considers the benefits and barriers of social media use based on his/her role at that moment, as someone who provides a service for citizens or as a service receiver. The qualitative data shows that senior managers were concerned about privacy in the role as citizens, while at the same time 
they would presumably be engaged with the effectiveness of the system in conveying information to clients.

Overall, the results of the qualitative data were very similar to those derived from the quantitative data which suggested that "providing timely and relevant information", "improving citizens' participation and engagement", and “improving workplace collaboration and knowledge sharing" are the top three benefits that the three stakeholders believe the use of social media will bring for government. On the other hand, "privacy and information security" and "organizational culture" are the top two concerns of the three stakeholder groups. According to stakeholder theory each of the stakeholder groups has a stake in the organization and recognizing stakeholders' stakes/interests as well as challenges are very important for the organization.

The results of qualitative analysis of open-ended questions show that citizens as service users mainly want timely and relevant information, participation and engagement, collaboration, transparency, and two-way communication with their government. Citizens are mainly suffering from lack of engagement from government, lack of awareness regarding government services through social media, lack of transparency regarding individual monitoring, privacy and slow responses due to multiple levels of approval. From a government senior management perspective as a decision-maker for social media use privacy, and security issue, data quality and integrity, governing and governance, participation and engagement and cost saving are important factors. Government employees as individuals who work for government are limited by a bureaucratic culture, multiple levels of approval, lack of clear policies, and lack of access to different social 
media tools. They are interested in using social media tools for internal collaboration and knowledge sharing as well as two-way communication with higher levels.

This study attempted to differentiate between three stakeholder groups using the concept of salience developed by Mitchell et al. (1997) who suggested that an organization needs to know how to prioritize competing stakeholders' claims. As mentioned earlier in the study, understanding primary stakeholders' needs, stakes and expectations provides an opportunity for government to integrate their information and opinions into the policy making process in innovative ways. This requires increasing transparency by sharing information and improving client satisfaction by providing better services and collaborating with clients to create solutions for government problems.

As indicated by the entire sample, providing timely and relevant resources from the government senior management for citizens who expect to receive information quickly from government are important aspects of successfully utilizing social media tools. This finding supports claims derived from the literature (Bertot et al., 2012; Kavanaugh et al., 2012; Lavender, 2013; Picazo-Vela et al., 2012) that from a citizens' perspective, receiving quick and appropriate responses/information from the government is very important. The main objective of having social media is to deliver information and services effectively and efficiently to the client.

Furthermore, engaging citizens in co-producing services is one of the key opportunities that social media can offer government. Co-production in which government and citizens jointly develop, design and deliver government services can improve their quality and delivery (Bertot et al., 2012). The results suggest that government official needs to engage citizens in their 
program and policy making, but most of the government departments and agencies still rely mainly on a push strategy to provide information for citizens without seeking their reactions to policies and procedures. Current research (Snead, 2013; Chun \& Luna Reyes, 2012; Picazo-Vela et al., 2012; Lavender, 2013) supports the observation that governments use social media as a tool to provide information to the public and attract individuals to government websites instead of soliciting feedback and comments from citizens. The results of this study offer further evidence that generally governments use social media as a tool to push information to the public. Recognizing that a listening or a pull strategy is very important in terms of engaging citizens and receiving and considering information from the public. Such a pull strategy is also supported in Mergel's (2013) study which included interviews with 15 social media directors in the U.S. to evaluate the diffusion of social media tools among federal government departments and agencies. She found that public organizations use three strategies for social media adoption: push to broadcast information, pull to receive input and a networking strategy that includes both push and pull activities for open exchanges.

Picazo-Vela et al. (2012) suggested that one important benefit of social media tools such as wikis is related to the development of inter-organizational networks among employees for knowledge sharing. As indicated by this study, from an internal perspective, senior management is mainly interested in improving work place collaboration and knowledge sharing for government employees. The result indicates that using internal wikis is the good example of sharing knowledge across government organizations. Internal wikis not only provide opportunities for employees to share best practices and learn from each other but also build communities of practice among those with similar interests in a particular domain. In this 
situation employees easily can learn from each other and share their understanding and experience on the same topic.

The study found that an important aspect of government senior management responsibility and concern is dealing with the issues of privacy and information security generated by utilizing different social media tools inside their organization. Taking advantage of different social media tools is desirable, but managing them in an inappropriate way can cause difficulties for senior management. From the citizens' perspective it is important to know that their privacy will be maintained and their information is safe and secure. Recent losses of data stored in what were thought to be secure servers only heighten this concern. Citizens expect to receive accurate and useful data but it is not their responsibility to deal with privacy issues when they contact government through social media. The results of this study show that privacy and information security is an important concern for all three stakeholder groups. There is an indication that the employees are also worried that their information and messages might be appropriated and judged by government officials. That means they have privacy concerns both as citizens and as employees.

The results that point to the risk averse nature of its organizational culture pose an important challenge for social media use by government. Although there have been some changes made recently, the typical government culture remains bureaucratic, employs lengthy approval processes, relies on a command-and-control structure build around departmental silos. This finding coincides with observations in the literature that without shifting the organizational culture towards more open and transparent processes, successful implementation of social media 
initiatives seems unachievable (McNutt, 2014; Lee \& Kwak, 2012; Bertot et al., 2010). As any change in the government is painfully slow, most departments have yet to take advantage of the ever-evolving social media tools. Many of the respondents believe that government social media policy is not advanced enough and risks falling even further behind the expectations of citizens. Even though all government senior management in this study acknowledge the need to use social media, there are still some major changes in both policy and culture that must be implemented before these tools can be fully deployed.

The results further indicate that even though all government senior management in this study acknowledge the need to increase use of social media, some suggested that adoption is driven by citizens' needs and expectations; eventually government officials want to be where the citizens currently are. This study suggested that governments need to be good listeners, providing more conversation with citizens and offering more advertising of the social media services now available. This would be an important first step in responding to citizens' expectations that social media should facilitate two-way interactions with government and leading to higher levels of engagement with program and policy development.

Overall, the results of the qualitative data enhanced the conclusions derived from the quantitative results by providing more insights and practical examples from individuals at different levels who are actually central stakeholders and are involved with government social media services either as users, providers or policy makers. Following Mitchel et al.'s admonition that an organization's managers must understand the needs of its key stakeholders to form policy, the results of the qualitative and quantitative data analyses have some implications for 
government officials. The following recommendations are based on response analysis from citizens and employees on how government could better use social media tools, including but not limited to:

1. Government needs to have an internal policy for professional and personal use of social media tools. Having clear policy guidelines would help employees to engage more with their organization without fear that their comments and feedback might be used against them.

2. Government needs to provide some internal and external training for privacy and security issues (i.e. similar to security awareness training for employees handling government classified information) keeping in mind that the three stakeholder groups, based on their needs and interests in the organizations, have varied concerns on this topic.

3. Government could generate awareness through advertising the availability of services offered via social media tools to achieve more citizen engagement. As the results indicate, employees seem to be more engaged than the other two groups. This might be related to their awareness of the social media tools being used by government as well as knowledge of service that government offers through social media.

4. Having clear objectives before adoption and knowing the target audience based on their needs and expectations are very important (e.g. the Department of Foreign Affairs, Trades and Development (DFATD) recently created Facebook and Twitter accounts for Canadian offices abroad using the local language). It is essential to 
differentiate between target audiences that have the ability to influence the organization.

5. Social media should be constantly monitored and evaluated to ensure the efficiency of that particular tool. Each application needs to solve certain social problems for the stakeholders.

6. Government needs to have a dedicated and trained team for social media to regularly measure, monitor and evaluate audience use, engagement and feedback. Audiences won't be engaged until they recognize that their stakes are being addressed.

7. Government needs to show more transparency in social monitoring to eliminate fears of being watched. If these types of suspicions are prevalent, the goal of increasing engagement of citizens and employees is unlikely to be met.

8. Government officials need to take into account feedback and comments in their drive to improve services for their various stakeholders.

The next chapter will present the contributions and implications of this study for the field as well as a discussion of its limitations. Finally, I will suggest some of the implications of this work for possible future studies in the area. 


\section{Contributions, Limitations, and Future Research}

\subsection{Contribution of the Research}

Social media have the potential to radically transform government in terms of how it operates internally and interacts with citizens and employees (Mergel, 2013a; Mergel, 2013b; Bertot et al., 2012). Social media use by government can be expected to have a positive impact in many areas, including citizen engagement, increased transparency, collaboration, knowledge sharing, improvement of service delivery, etc. (Bertot et al., 2012; Kavanaugh et al., 2012; Lavender, 2013; McNutt, 2014 ; Picazo-Vela et al., 2012). The possibilities of social media tools also bring challenges for governments including organizational and technical issues, policy and legislative barriers, as well as privacy and security risks associated with online interaction. It is government's responsibility to understand their potential stakeholders (i.e. citizens and employees) and differentiate between the stakeholder groups that have the ability to exert influence on the organization. While governments around the world have been slower than the private sector to take advantage of Web 2.0's interactive platform and collaborative tools, a number of current governments have begun employing different social media tools.

Turning to the Canadian context, the population has largely used the Internet, is starting to use social media, and believes that government should employ these tools. Having said that, and with the potential benefits of social media in mind, governments in Canada should consider integrating these technologies and applications in their business plans as well as developing policies and procedures in federal departments and agencies (Nineteenth Annual Report to the Prime Minister on the Public Service of Canada, 2012). This should have positive consequences 
in many arenas, from global economics to international competitiveness, from citizen engagement to international relations, from employee skills development to knowledge sharing. Moving forward with the use of different social media tools requires understanding stakeholders' claims and addressing them with an appropriate strategic plan.

As mentioned earlier, there has been very little empirical research related to citizens' and employees' needs and expectations for government use of social media tools. The current study mainly focuses on organizational perspectives toward social media use through the lens of stakeholder theory. A recent qualitative study by Mergel (2013) explored social media adoption in the U.S federal government by interviewing social media directors to recognize the factors that influence internal adoption decisions. Similarly, Snead (2013) studied social media use and public participation with social media in the U.S. The results show that individuals do interact with government websites and use social media to stay informed about government activities (Snead, 2013). Participants in a study by Picazo-Vela et al. (2012) from central Mexico, agreed on some benefits deriving from social media use and mentioned that social media provide better communication between the government and its citizens, improved citizens' participation as well as enhancing trust and democracy. While some work recognizes the benefits of social media use by government, a gap still exists between different stakeholders and their needs and expectations from social media use by government. The current study aims to provide a broader view of government social media use through considering the benefits and barriers of social media from the perspective of three distinct stakeholder groups all of whom have the ability to influence government organizations. 
The results of this study indicate that each stakeholder group has its own perspective and expectations in terms of having and using social media tools, however, there are some similarities between the three groups. From a government senior management perspective (i.e. organizational perspective), increased external use of social media might stem from three main reasons including representation of the department or agency to provide faster access to government information, engagement of citizens, improved service delivery and networking with citizens and listening to them. Due to the success of some social media tools such as Facebook with about a billion users and Twitter with 500 million users in 2012, government wants to have a presence there with their citizens. A positive representation of government on varied social media tools which can serve as interaction channels that augment static websites is one of the reasons for governments to adopt these tools.

Another frequently mentioned objective for having social media tools from government senior management is engagement with citizens. As I mentioned earlier, the results of this study suggest that government officials need to engage citizens in their program development and policy-making to collaborate with the public in addressing government problems. The engagement could lead government to understand citizens better, increase transparency, provide two-way communication and improve service delivery to them. It is important for government to know their target audiences and employ appropriate tool to serve their purposes and engage them. However, social media tools are still very new to most governments and therefore best practices in the public sector are rare, but government can learn from citizens and apply their comments to provide better services through these channels. Having tools by itself does not bring engagement; government needs to be more active to motivate citizens for engagement. At the 
moment there appears to be little actual engagement with the government of Canada due to factors such as bureaucratic culture, issues of privacy, lack of policies for personal and official use and the lack access to certain social media tools among other reasons.

Increased networking with the public and more listening to citizens and receiving feedback from them are other possible implications of social media use by government officials to facilitate conversations among its stakeholders. Social media can help governments monitor the public environment and provide insight about what kinds of conversations are taking place regarding government programs and services. This work leads to the conclusion that the next step could be analyzing conversation data, identifying emerging issues and employing them in government decisions. Knowing this helps government to co-write strategic plans and policies with help of a knowledgeable audience. The qualitative results indicate that by choosing the right language to get the message across and listening to the public, government could better understand their stakeholders. Social media monitoring provides opportunities for government to identify issues, interests, and information gaps related to their policies and programs. For example the Canadian Immigration and Citizenship (CIC) Facebook page has 45,633 likes as of April 2014, but the last post in this page was 5 November 2013. This cannot be interpreted as citizens' engagement. If governments are really looking for feedback and information from the public, this is not the right way to maintain a social media channel. A similar page called Quebec Friends with 11,283 members as of April, 2014 with all the information related to CIC Quebec skilled worker category is a very interactive page. It provides a very good example of a dynamic page run by citizens that has a large amount of information and feedback related to CIC. Now it is time for government officials to focus more on social media tools and to consider the 
importance of these tools for government services as well as social media monitoring in policy making and external communication. This finding is supported by Bekkers at al., (2013), who studied the implications of monitoring individuals via social media in four Dutch public organizations. They suggested that policy departments are more interested in monitoring to utilize the results in policy making. Social media monitoring is one of the emerging topics in social media studies that need further consideration.

Internal use of social media might have some implications for government such as collaboration, knowledge sharing and employee engagement (Picazo-Vela et al., 2012; Nam, 2012; Snead, 2013). The study found that government senior management could use the collaboration and knowledge sharing ability of social media tools to support collaboration among employees. This might decrease the cost of staff training by sharing knowledge and best practices. For example, tools like wikis and blogs have been used internally with some government departments and agencies to share information, encourage two-way communication and receive feedback from employees. The results from this study show that even though government employees acknowledge the benefit of having tools such as blogs for internal use, some suggested that because of lack of a clear policy governing professional use they worry that their feedback/comments might be used in a negative way. This might lead employees to less rather than more engagement. Crafting and promulgating internal social media policies for official, professional and personal use by employees is a necessary step in encouraging internal usage.

The results of this study aim to provide empirical research related to citizens' and employees' needs and expectations in terms of social media use. The findings provide support 
for the notion that positive perceptions of using social media tools to receive government information and services exist among most Canadians. Citizens are using these tools with different purposes such as receiving timely and relevant services, faster access to government information, two-way communication, participation and engagement and increased government transparency. Having enumerated these benefits there is the question of why government utilization of social media tools is happening so slowly in the government. Based on the literature (Mergel, 2013a; Picazo-Vela et al., 2012; Bertot, et al, 2010; Lavender, 2013) and the results of this study, the slow emergence of these benefits might be related to challenges such as government organizational culture, lack of awareness about social media tools, issues of privacy and information security and fear of the consequences. The existing bureaucratic control structures and the top-down orientation of government cause communication delays that both citizens and employees see as an important barrier. A risk averse culture might prevent government from adopting different tools for external use. For example, the Public Service Commission (PSC) which runs jobs.gc.ca has only a Twitter account for external communications even though most of their audience is composed of recent graduates aged 18-24 who are also active on Facebook. If the PSC wants to talk to them, understand their needs and hire talented students, then they need to use these channels to communicate with them. Shifting the organizational culture towards being more open and transparent is not easy, but is necessary for the successful implementation of social media tools (Lee \& Kwak, 2012; Bertot et al., 2010). Overall, I found that citizens expect to have an open conversation with government through social media without fear of prosecution, profiling or being watched. As mentioned before, social 
media relies primarily on open participation that provides opportunities for citizens' collaboration and engagement.

This study attempted to fill a gap that exists in the literature regarding what citizens and employees want/need from government through social media tools. In the course of this project I have examined a number of potential benefits and barriers to government use of social media suggested in the literature from the point of view of three separate stakeholder groups. My results indicate that, while there are commonalities in their perspectives, the three groups have distinct views of these issues that need to be managed and coordinated to increase the effective use of these new communication technologies.

To summarize the results, the primary contributions of this research are:

- The literature on government use of social media has not, to this point, considered separate classes of stakeholders. This study shows there are important similarities and differences in the attitudes of the three stakeholder groups toward proposed benefits and barriers.

- The results of the study underline the utility of stakeholder theory for framing research analysing social media for government use.

- The results strongly suggest that there are differences in salience among suggested benefits and barriers and that these differ by group. 
- The study also identified organizational culture as one of the most important barriers to governments' effective use of social media

- Given the prior lack of systematic data this study will provide an empirical base for future research.

\subsection{Limitations}

As with any kind of research, the proposed study has some limitations. The findings from this study are limited in how far they can be generalized. This stems partly from the fact that the sample is drawn from a virtual group contacted through a particular site, LinkedIn. Although such a site attracts those from all over the world, the respondents are mainly from Canada, specifically the Ottawa area. Given the nature of the list respondents may be more informed about social media than the general population. This may impact the research findings since many of the respondents indicated, for example, that they did not engage with the government on social media. A more random sample of the population would almost certainly show even less experience in this direction. The fact is that since most of the respondents were from around Ottawa also means that they probably used the Government of Canada as their reference when responding to questions. Despite these limitations, I believe that sampling people from a virtual group provides an opportunity to have respondents from diverse government departments and agencies.

There are also some limitations regarding the scope of this study. This study presented different aspects of benefits and barriers related to social media use by governments, but based on the literature review and resource constraints, I only examined those that the appeared to be 
the most important. The number of different aspects of benefits and barriers could be expanded in future studies. For example, future research could consider normative issues related to social media monitoring from a privacy and transparency perspective. Future research is also needed to evaluate how government could increase public education and improve recruitment through social media.

A third limitation involves focusing on three key stakeholder groups, citizens, employees, and government senior management. This restriction was due partly to time and resource constraints. It also stemmed from the fact that relatively little empirical work had been done on the needs of stakeholders in government use of social media. I believe the three groups addressed are among the most important for this set of issues, each having a quite specific set of needs. Adding more groups would have added considerable to the complexity of the research and the difficulty of data collection. Now that we have some baseline information concerning the relative needs of these key groups, further research can add other stakeholders to the model.

The fourth limitation is related to the small number of respondents from the Director/DG level. Having only sixteen respondents in this group lowers the predictive power of the relevant statistical tests and makes their interpretation problematic. Having said that, there is no obvious reason to believe that those that did not reply were significantly different from those that did with the possible exception of their participation in the original LinkedIn group. In the future cooperation from a government body such as the Treasury Board may facilitate greater coverage across multiple levels. 


\subsection{Recommendations for Future Research}

The findings of this study suggest that future research could measure audience engagement with different social media tools. Government needs to know the level of engagement of their audiences by monitoring different social media channels as this is one of their stated goals. The next step is to find ways to increase engagement with the audiences and start conversations to generate interest in using social media tools. As suggested by Mergel (2012) many agencies in the U.S. are reluctant to actively measure their social media interactions beyond the number of comments on Facebook or like the Facebook page as an indicator for engagement. Government needs to measure and monitor the level of engagement and understand to what extent they are reaching the right audiences by applying different criteria for different social media tools. They need to go beyond the descriptive data. Instead they need to understand how they can analyze conversation data, identify emerging issues and embed citizens' needs and expectations in program and policy development. Future research is needed to design and test social media metrics to compare the data with agency missions and social media strategies.

Future research could also help academics and practitioners to determine what factors influence the effectiveness of governments in using social media to reach their target audiences. At this stage, I suggest stakeholder theory as a theoretical foundation for this research to understand different audiences' needs, interests and expectations. I hope the result of this study will help government organizations to increase the quality of government services through understanding citizens' and employees' needs and expectations. Additional research is necessary 
to understand the implications and main objectives of social media tools for different target audiences.

Future research is needed to develop reliable and valid metrics to measure and demonstrate the return on investment and to evaluate the success of using social media tools. Additional research should be undertaken to determine how social media tools contribute to cost saving to ensure the government receives its return on investment from the use of social media tools. For example, could call centers could be replaced by such a tools like Twitter to respond to citizens' inquiries thus reducing organizational cost? Even though the aim of governments in using social media are wider than cost reduction, indeed this research seems to indicate that this is not a high priority, lowering expenditures is often used as an argument for increased social media utilization.

Future research should specifically address young individuals (age 18-24) and evaluate their needs and expectations to help construct an appropriate strategy for using social media tools when contacting them. This research received only 5 responses from the 18-24 age group. A future study might consider another data collection method to obtain more responses from this age cohort, as adoption of social media tools tends to be greatest among younger Canadians. Understanding how their concerns coincide with or deviate from those of the subjects of this study would be important in crafting new policies and implementing current ones.

In this study, all the respondents had to be able to access social media tools or email either at work or at home in order to answer the questionnaire. However future research could consider specific samples drawn from groups that have limited or no access to social media. 
Future research could also employ Mergel`s typology (Mergel, 2013a) of social media strategies (push, pull and networking) to understand government strategies when contacting young individuals via different tools (e.g., Facebook, Twitter, YouTube and Blog) with the aim of improving participation and feedback from young individuals.

As I mentioned earlier in the limitation section, this study only focused on three key stakeholder groups: citizens, employees, and government senior management. Future research could add more stakeholder groups based on this study in order to situate their attitudes alongside these results. Additional groups could include politicians, local communities, nongovernment agencies and platform providers among others.

In this study the analysis benefited from Rowley's (2011) framework for examining stakeholders in terms of roles rather than as groups or individuals. As I mentioned before, both organization and individuals can play several roles. Future research could evaluate the effect of multiple roles for social media adoption and use by governments. As was hinted in some of the discussion, different roles may lead to conflicting preferences among groups and individuals. An employee may desire more complete information from a client group, but be reluctant as a citizen to provide personal details because of privacy concerns. The extent and consequences of multiple roles would form an intriguing and important topic for future research.

This study presents different examples of social media initiatives adopted by public sector organizations in Canada and by national governments around the world. Further research is needed to understand whether the diffusion across all departments and agencies of the federal government are equal or not, especially the factors that drive the adoption initiatives in the 
governments at different levels in Canada. Future studies could evaluate different strategies, implementation processes, uses and results of the same social media tools in different public sector organizations. Not only that but also each government department and agency could evaluate their social media tools with the public and receive feedback on usability and value of such a tools and applications.

The results of this study indicate that the three stakeholder groups believe that using social media tools have the potential to improve government service delivery although there are some distinct differences in how each group views the advantages of and barriers to government use of social media. What is now needed is an appropriate strategy for analyzing data from different social media channels and utilizing the results to improve the quality of government services by considering stakeholders' opinions and feedback. Future research could develop a baseline or framework to examine the quality of government services after employing stakeholders' opinions through social media use. 


\section{Appendices}

\subsection{Appendix A: Questionnaire}

1. Do you agree to the consent information listed on this page?

I agree to participate in a study of social media for government use being conducted by Ms. Narges Shahsavarani and supervised by Dr. David Cray of the Sprott School of Business at Carleton University. This study is designed to understand the implications of social media for government.

I understand that the data for this study will be gathered through an electronic questionnaire that will take approximately 15 minutes to complete.

I further understand that my replies will remain anonymous and that I will not be identified in any publications that result from this study. Written data will be retained in a locked file cabinet in Professor Cray's office. Only Professor Cray and I will have access to the data.

Canadian governments at various levels and the citizens of Canada could benefit from this study in two ways. As governments prepare to make greater use of social media it is important to know the opinion of those who may be affected by these changes. Since most of those consulted for this study already use social media tools and will continue to do so, knowing their interests and expectations may provide new perspectives for governments in terms of social media use. Second, this information might helpful for governments to understand citizens' needs and how to address them in future policy development.

It has been made clear that my participation in this study is strictly voluntary. I may also decline to answer any of the questions that the researchers may pose. I may stop the survey at any time and not submit it. If I submit the survey it is not possible to withdraw the information I have provided. The researchers will provide a summary of the results of the study when it is completed. I will also have access to any further papers that may result from this project.

Please note that the online survey tool used in this study (SurveyMonkey) is hosted by a server located in the USA. The United States Patriot Act permits U.S. law enforcement officials, for the purpose of an anti-terrorism investigation, to seek a court order that allows access to the personal records of any person without that person's knowledge. In view of this I cannot absolutely guarantee the full confidentiality and anonymity of your data. With your consent to participate in this study you acknowledge this.

Finally, I understand that this project has been approved by the Carleton University Research Ethics Board, if I have any concerns about this research I may contact: Professor Andy Adler, Chair, Research Ethics Board, Carleton University(ethics@carleton.ca) 
Having read and understood this letter, I agree to participate in this study of social media for government use. By completing this survey, I indicate my understanding of the project and its aims.

Please do not hesitate to contact me if you have any question.

Thanks,

Narges Shahsavarani (nshahsav@connect.carleton.ca)

David Cray(David.Cray@carleton.ca)

2. What does the term "social media" mean to you?

3. Approximately how often do you use Facebook?
a. Never
b. Rarely
c. Few times a month
d. Weekly
e. Daily

4. Approximately how often do you use Twitter?
a. Never
b. Rarely
c. Few times a month
d. Weekly
e. Daily

5. Approximately how often do you use any kind of wiki (Wikipedia, GCpedia, etc.)?

a. Never 

b. Rarely
c. Few times a month
d. Weekly
e. Daily

6. Approximately how often do you use YouTube?
a. Never
b. Rarely
c. Few times a month
d. Weekly
e. Daily

7. Please rate your level of engagement with government through social media such as Twitter, YouTube, Facebook, Wiki

a. I am not at all engaged with government through social media.

b. I am slightly engaged with government through social media.

c. I am moderately engaged with government through social media.

d. I am heavily engaged with government through social media.

e. I am very heavily engaged with government through social media.

8. Indicate the degree to which you believe that the use of social media will increase the effectiveness of government services by:

\begin{tabular}{|l|l|l|l|l|l|}
\hline Benefits & Strongly agree & Agree & Neutral & Disagree & Strongly Disagree \\
\hline $\begin{array}{l}\text { Improve service } \\
\text { delivery }\end{array}$ & & & & & \\
\hline $\begin{array}{l}\text { Improve two-way } \\
\text { communication }\end{array}$ & & & & & \\
\hline $\begin{array}{l}\text { Improve citizens } \\
\text { participation and } \\
\text { engagement }\end{array}$ & & & & & \\
\hline Improve workplace & & & & & \\
\hline
\end{tabular}




\begin{tabular}{|l|l|l|l|l|l|}
\hline Benefits & Strongly agree & Agree & Neutral & Disagree & Strongly Disagree \\
\hline $\begin{array}{l}\text { collaboration and } \\
\text { knowledge sharing }\end{array}$ & & & & & \\
\hline Cost saving & & & & & \\
\hline $\begin{array}{l}\text { Increase government } \\
\text { transparency }\end{array}$ & & & & & \\
\hline $\begin{array}{l}\text { Improve employee } \\
\text { engagement }\end{array}$ & & & & & \\
\hline $\begin{array}{l}\text { Improve citizens } \\
\text { collaboration and } \\
\text { knowledge sharing }\end{array}$ & & & & & \\
\hline Public education & & & & & \\
\hline $\begin{array}{l}\text { Build better relationship } \\
\text { with citizens }\end{array}$ & & & & & \\
\hline $\begin{array}{l}\text { Provide timely and } \\
\text { relevant new }\end{array}$ & & & & & \\
\hline $\begin{array}{l}\text { Provide convenient and } \\
\text { faster access to } \\
\text { government information }\end{array}$ & & & & & \\
\hline Better recruitment & & & & & \\
\hline $\begin{array}{l}\text { Other benefits? (please } \\
\text { specify) }\end{array}$ & & & & & \\
\hline
\end{tabular}

9. Listed below are some concerns that may impede the effective use of social media by governments. Please indicate the degree to which you believe each of the following will pose important barriers.

\begin{tabular}{|l|l|l|l|l|l|}
\hline Barriers/Challenges & Strongly agree & Agree & Neutral & Disagree & Strongly Disagree \\
\hline Organizational Culture & & & & & \\
\hline $\begin{array}{l}\text { Creating and sustaining } \\
\text { public engagement }\end{array}$ & & & & & \\
\hline $\begin{array}{l}\text { Privacy and } \\
\text { information security }\end{array}$ & & & & & \\
\hline $\begin{array}{l}\text { Data quality and } \\
\text { integrity (reliability of } \\
\text { content) }\end{array}$ & & & & & \\
\hline Official languages & & & & & \\
\hline Departmental access & & & & & \\
\hline $\begin{array}{l}\text { Lack of social media } \\
\text { policy }\end{array}$ & & & & & \\
\hline
\end{tabular}




\begin{tabular}{|l|l|l|l|l|l|}
\hline Barriers/Challenges & Strongly agree & Agree & Neutral & Disagree & Strongly Disagree \\
\hline $\begin{array}{l}\text { Perception that social } \\
\text { media tools are for } \\
\text { entertainments only }\end{array}$ & & & & & \\
\hline $\begin{array}{l}\text { Potential for } \\
\text { defamatory comments }\end{array}$ & & & & & \\
\hline $\begin{array}{l}\text { Misinterpretation of } \\
\text { original context }\end{array}$ & & & & & \\
\hline $\begin{array}{l}\text { Risk of damage to } \\
\text { intellectual property }\end{array}$ & & & & & \\
\hline $\begin{array}{l}\text { Possibility of chaotic } \\
\text { relationship between } \\
\text { government and } \\
\text { citizens }\end{array}$ & & & & & \\
\hline $\begin{array}{l}\text { Lack of high level } \\
\text { support }\end{array}$ & & & & & \\
\hline $\begin{array}{l}\text { Other barriers? (please } \\
\text { specify) }\end{array}$ & & & & & \\
\hline
\end{tabular}

10. Do you have any general concerns about using social media? If yes, could you explain them.

11. Do you have any specific concerns about using social media when dealing with the government? If yes, could you explain them.

12. When you contact government through social media, what are you trying to accomplish?

13. Do you feel you are currently accomplishing what you intended by contacting the government through social media? If yes, explain why you feel this way.

14. If you feel you are NOT currently accomplishing what you intended by contacting the government through social media, please explain why you feel this way.

15. How helpful do you think each of the following social media tools would be in delivering government services?

\begin{tabular}{|l|l|l|l|l|l|l|}
\hline $\begin{array}{l}\text { Social Media } \\
\text { Tools }\end{array}$ & $\begin{array}{l}\text { Extremely } \\
\text { helpful }\end{array}$ & $\begin{array}{l}\text { Very } \\
\text { helpful }\end{array}$ & $\begin{array}{l}\text { Somewhat } \\
\text { helpful }\end{array}$ & $\begin{array}{l}\text { Slightly } \\
\text { helpful }\end{array}$ & $\begin{array}{l}\text { Not at all } \\
\text { helpful }\end{array}$ & $\begin{array}{l}\text { Don't } \\
\text { know }\end{array}$ \\
\hline Facebook & & & & & & \\
\hline Twitter & & & & & & \\
\hline Wiki & & & & & & \\
\hline
\end{tabular}




\begin{tabular}{|l|l|l|l|l|l|l|}
\hline YouTube & & & & & & \\
\hline Blogs & & & & & & \\
\hline RSS feeds & & & & & & \\
\hline LinkedIn & & & & & & \\
\hline Pinterest & & & & & & \\
\hline Google+ & & & & & & \\
\hline Flickr & & & & & & \\
\hline Delicious & & & & & & \\
\hline Vimeo & & & & & & \\
\hline
\end{tabular}

16. What information would you like to have about how social media is being used in your government?

17. Please indicate your age group
a. Under 18 years old
b. 18-24 years old
c. 25-34 years old
d. $35-44$ years old
e. $45-54$ years old
f. $55-64$ years old
g. Over 65 years old

18. What is the highest level of education you have completed?
a. Did not graduate from high school
b. High school graduate
c. Some college
d. Bachelor's degree
e. Master's degree
f. Ph.D. degree

19 . What is your gender? 

a. Female
b. Male

20. Are you Canadian citizen?
a. Yes
b. No

21. In what country do you currently reside?

22. What is your present employment status?
a. Employed
b. Unemployed
c. Retired
d. Student

23. In what sector are you employed?
a. Government (all levels)
b. Private sector
c. Education
d. Not for profit
e. Other (please specify)

24. What is your job title or rank?

\begin{tabular}{|l|l|l|l|}
\hline Government & Private sector & Education & Not for profit \\
\hline Below manager & Below manager & Admin staff & Below manager \\
\hline Manager & Manager & Senior staff & Manager \\
\hline DG or Director & VP or equivalent & Professor (all grades) & VP or equivalent \\
\hline Above DG & President or CEO & President or VP & President or CEO \\
\hline
\end{tabular}

25. What is your marital status?
a. Married 

b. Single
c. Divorced
d. Separated
e. widowed

26. Do you have any suggestions on how government could better use social media? 


\subsection{Appendix B: Quantitative Data - Descriptive Statistics}

Descriptive Statistics: All Three Groups

\begin{tabular}{|c|c|c|c|c|c|}
\hline & $\mathrm{N}$ & Minimum & Maximum & Mean & Std. Deviation \\
\hline Improving service delivery & 180 & 1.00 & 5.00 & 3.7889 & .92143 \\
\hline $\begin{array}{l}\text { Improving two-way } \\
\text { communication }\end{array}$ & 180 & 1.00 & 5.00 & 3.9556 & .96776 \\
\hline $\begin{array}{l}\text { Improving citizens' participation } \\
\text { and engagement }\end{array}$ & 179 & 1.00 & 5.00 & 3.9832 & .92089 \\
\hline $\begin{array}{l}\text { Improving workplace } \\
\text { collaboration and knowledge } \\
\text { sharing }\end{array}$ & 180 & 1.00 & 5.00 & 3.9833 & .86828 \\
\hline Reducing costs & 180 & 1.00 & 5.00 & 3.5222 & 1.02186 \\
\hline $\begin{array}{l}\text { Increasing government } \\
\text { transparency }\end{array}$ & 178 & 1.00 & 5.00 & 3.6517 & 1.05874 \\
\hline $\begin{array}{l}\text { Improving employee } \\
\text { engagement }\end{array}$ & 177 & 1.00 & 5.00 & 3.6271 & .90889 \\
\hline $\begin{array}{l}\text { Improving citizens' } \\
\text { collaboration and knowledge } \\
\text { sharing }\end{array}$ & 180 & 1.00 & 5.00 & 3.8944 & .78745 \\
\hline Increasing public education & 180 & 1.00 & 5.00 & 3.9611 & .88035 \\
\hline $\begin{array}{l}\text { Building better relationships } \\
\text { with citizens }\end{array}$ & 178 & 1.00 & 5.00 & 3.8146 & .90473 \\
\hline $\begin{array}{l}\text { Providing timely and relevant } \\
\text { information }\end{array}$ & 179 & 1.00 & 5.00 & 4.1453 & .83539 \\
\hline $\begin{array}{l}\text { Providing convenient and faster } \\
\text { access to government } \\
\text { information }\end{array}$ & 179 & 1.00 & 5.00 & 3.9944 & .92710 \\
\hline Facilitating better recruitment & 177 & 1.00 & 5.00 & 3.4972 & .93617 \\
\hline Valid N (listwise) & 167 & & & & \\
\hline
\end{tabular}


Descriptive Statistics: All Three Groups

\begin{tabular}{|l|c|c|c|c|c|}
\hline & $\mathrm{N}$ & Minimum & Maximum & Mean & Std. Deviation \\
\hline Organizational culture & 176 & 1.00 & 5.00 & 3.9659 & .89377 \\
Creating and sustaining public & 175 & 1.00 & 5.00 & 3.3657 & 1.00171 \\
engagement & 177 & 1.00 & 5.00 & 4.0904 & 1.04597 \\
$\begin{array}{l}\text { Privacy and information security } \\
\text { Data quality and integrity }\end{array}$ & 176 & 2.00 & 5.00 & 3.7784 & .99816 \\
(reliability of content) & 176 & 1.00 & 5.00 & 3.3239 & 1.08638 \\
$\begin{array}{l}\text { Official languages } \\
\text { Departmental access }\end{array}$ & 176 & 1.00 & 5.00 & 3.4091 & 1.02691 \\
$\begin{array}{l}\text { Lack of social media policy } \\
\text { Perception that social media } \\
\text { tools are for entertainment only }\end{array}$ & 174 & 1.00 & 5.00 & 3.5920 & 1.04253 \\
$\begin{array}{l}\text { Potential for defamatory } \\
\text { comments }\end{array}$ & 173 & 1.00 & 5.00 & 3.2857 & 1.23110 \\
$\begin{array}{l}\text { Misinterpretation of original } \\
\text { context }\end{array}$ & 173 & 1.00 & 5.00 & 3.4277 & 1.08998 \\
$\begin{array}{l}\text { Risk of damage to intellectual } \\
\text { property }\end{array}$ & 173 & 1.00 & 5.00 & 3.0347 & 1.19542 \\
$\begin{array}{l}\text { Possibility of a chaotic } \\
\text { relationship between government } \\
\text { and citizens }\end{array}$ & 173 & 1.00 & 5.00 & 3.1329 & 1.13081 \\
Lack of high level support & 1.00 & 5.00 & 3.7209 & .98706 \\
Valid N (listwise) & 163 & & & & \\
\hline
\end{tabular}


Descriptive Statistics: Director/DG and above

\begin{tabular}{|c|c|c|c|c|c|}
\hline & $\mathrm{N}$ & Minimum & Maximum & Mean & Std. Deviation \\
\hline Improving service delivery & 16 & 3.00 & 5.00 & 4.3125 & .70415 \\
\hline $\begin{array}{l}\text { Improving two-way } \\
\text { communication }\end{array}$ & 16 & 2.00 & 5.00 & 4.3750 & .80623 \\
\hline $\begin{array}{l}\text { Improving citizens' participation } \\
\text { and engagement }\end{array}$ & 16 & 3.00 & 5.00 & 4.2500 & .77460 \\
\hline $\begin{array}{l}\text { Improving workplace } \\
\text { collaboration and knowledge } \\
\text { sharing }\end{array}$ & 16 & 3.00 & 5.00 & 4.3750 & .61914 \\
\hline Reducing costs & 16 & 2.00 & 5.00 & 3.7500 & .77460 \\
\hline $\begin{array}{l}\text { Increasing government } \\
\text { transparency }\end{array}$ & 16 & 3.00 & 5.00 & 3.8125 & .54391 \\
\hline $\begin{array}{l}\text { Improving employee } \\
\text { engagement }\end{array}$ & 16 & 3.00 & 5.00 & 4.0000 & .63246 \\
\hline $\begin{array}{l}\text { Improving citizens' } \\
\text { collaboration and knowledge } \\
\text { sharing }\end{array}$ & 16 & 4.00 & 5.00 & 4.2500 & .44721 \\
\hline Increasing public education & 16 & 3.00 & 5.00 & 4.0625 & .57373 \\
\hline $\begin{array}{l}\text { Building better relationships } \\
\text { with citizens }\end{array}$ & 16 & 2.00 & 5.00 & 3.6875 & .70415 \\
\hline $\begin{array}{l}\text { Providing timely and relevant } \\
\text { information }\end{array}$ & 16 & 3.00 & 5.00 & 4.3750 & .71880 \\
\hline $\begin{array}{l}\text { Providing convenient and faster } \\
\text { access to government } \\
\text { information }\end{array}$ & 16 & 4.00 & 5.00 & 4.4375 & .51235 \\
\hline $\begin{array}{l}\text { Facilitating better recruitment } \\
\text { Valid N (listwise) }\end{array}$ & $\begin{array}{l}16 \\
16\end{array}$ & 2.00 & 4.00 & 3.2500 & .93095 \\
\hline
\end{tabular}


Descriptive Statistics: Director/DG and above

\begin{tabular}{|c|c|c|c|c|c|}
\hline & $\mathrm{N}$ & Minimum & Maximum & Mean & Std. Deviation \\
\hline Organizational culture & 16 & 3.00 & 5.00 & 4.4375 & .62915 \\
\hline $\begin{array}{l}\text { Creating and sustaining public } \\
\text { engagement }\end{array}$ & 14 & 2.00 & 5.00 & 4.2143 & .89258 \\
\hline Privacy and information security & 16 & 4.00 & 5.00 & 4.7500 & .44721 \\
\hline $\begin{array}{l}\text { Data quality and integrity } \\
\text { (reliability of content) }\end{array}$ & 15 & 2.00 & 5.00 & 4.3333 & .89974 \\
\hline Official languages & 16 & 4.00 & 5.00 & 4.3750 & .50000 \\
\hline Departmental access & 15 & 2.00 & 5.00 & 3.9333 & .96115 \\
\hline Lack of social media policy & 15 & 1.00 & 5.00 & 3.4000 & 1.18322 \\
\hline $\begin{array}{l}\text { Perception that social media } \\
\text { tools are for entertainment only }\end{array}$ & 14 & 2.00 & 5.00 & 2.8571 & 1.23146 \\
\hline $\begin{array}{l}\text { Potential for defamatory } \\
\text { comments }\end{array}$ & 14 & 2.00 & 5.00 & 3.5714 & 1.01635 \\
\hline $\begin{array}{l}\text { Misinterpretation of original } \\
\text { context }\end{array}$ & 14 & 2.00 & 5.00 & 3.9286 & .99725 \\
\hline $\begin{array}{l}\text { Risk of damage to intellectual } \\
\text { property }\end{array}$ & 13 & 2.00 & 5.00 & 3.4615 & 1.05003 \\
\hline $\begin{array}{l}\text { Possibility of a chaotic } \\
\text { relationship between government } \\
\text { and citizens }\end{array}$ & 14 & 2.00 & 5.00 & 3.2857 & .99449 \\
\hline Lack of high level support & 14 & 3.00 & 5.00 & 4.0714 & .47463 \\
\hline Valid N (listwise) & 12 & & & & \\
\hline
\end{tabular}


Descriptive Statistics: Government Employees (Managers and Below Managers)

\begin{tabular}{|c|c|c|c|c|c|}
\hline & $\mathrm{N}$ & Minimum & Maximum & Mean & Std. Deviation \\
\hline Improving service delivery & 75 & 2.00 & 5.00 & 3.9200 & .80135 \\
\hline $\begin{array}{l}\text { Improving two-way } \\
\text { communication }\end{array}$ & 75 & 1.00 & 5.00 & 4.0267 & .97223 \\
\hline $\begin{array}{l}\text { Improving citizens' participation } \\
\text { and engagement }\end{array}$ & 75 & 1.00 & 5.00 & 3.9333 & .96329 \\
\hline $\begin{array}{l}\text { Improving workplace } \\
\text { collaboration and knowledge } \\
\text { sharing }\end{array}$ & 75 & 1.00 & 5.00 & 4.0267 & .83784 \\
\hline Reducing costs & 75 & 1.00 & 5.00 & 3.4400 & 1.10576 \\
\hline $\begin{array}{l}\text { Increasing government } \\
\text { transparency }\end{array}$ & 74 & 1.00 & 5.00 & 3.5811 & 1.09803 \\
\hline $\begin{array}{l}\text { Improving employee } \\
\text { engagement }\end{array}$ & 73 & 1.00 & 5.00 & 3.5753 & .97065 \\
\hline $\begin{array}{l}\text { Improving citizens' } \\
\text { collaboration and knowledge } \\
\text { sharing }\end{array}$ & 75 & 2.00 & 5.00 & 3.7733 & .84747 \\
\hline Increasing public education & 75 & 1.00 & 5.00 & 3.9733 & .97223 \\
\hline $\begin{array}{l}\text { Building better relationships } \\
\text { with citizens }\end{array}$ & 74 & 1.00 & 5.00 & 3.7568 & .96246 \\
\hline $\begin{array}{l}\text { Providing timely and relevant } \\
\text { information }\end{array}$ & 74 & 1.00 & 5.00 & 4.2162 & .83207 \\
\hline $\begin{array}{l}\text { Providing convenient and faster } \\
\text { access to government } \\
\text { information }\end{array}$ & 75 & 1.00 & 5.00 & 4.0667 & .93481 \\
\hline Facilitating better recruitment & 74 & 1.00 & 5.00 & 3.3784 & 1.02973 \\
\hline Valid N (listwise) & 69 & & & & \\
\hline
\end{tabular}


Descriptive Statistics: Government Employees (Managers and Below Managers)

\begin{tabular}{|c|c|c|c|c|c|}
\hline & $\mathrm{N}$ & Minimum & Maximum & Mean & Std. Deviation \\
\hline Organizational culture & 74 & 2.00 & 5.00 & 4.2703 & .74571 \\
\hline $\begin{array}{l}\text { Creating and sustaining public } \\
\text { engagement }\end{array}$ & 74 & 1.00 & 5.00 & 3.4459 & .98122 \\
\hline Privacy and information security & 74 & 1.00 & 5.00 & 4.0270 & 1.05950 \\
\hline $\begin{array}{l}\text { Data quality and integrity } \\
\text { (reliability of content) }\end{array}$ & 74 & 2.00 & 5.00 & 3.7297 & 1.02432 \\
\hline Official languages & 73 & 1.00 & 5.00 & 3.3562 & 1.14710 \\
\hline Departmental access & 74 & 1.00 & 5.00 & 3.5811 & 1.08548 \\
\hline Lack of social media policy & 74 & 1.00 & 5.00 & 3.4865 & 1.13769 \\
\hline $\begin{array}{l}\text { Perception that social media } \\
\text { tools are for entertainment only }\end{array}$ & 74 & 1.00 & 5.00 & 3.4730 & 1.24111 \\
\hline $\begin{array}{l}\text { Potential for defamatory } \\
\text { comments }\end{array}$ & 74 & 1.00 & 5.00 & 3.3784 & 1.14321 \\
\hline $\begin{array}{l}\text { Misinterpretation of original } \\
\text { context }\end{array}$ & 74 & 1.00 & 5.00 & 3.2432 & 1.15641 \\
\hline $\begin{array}{l}\text { Risk of damage to intellectual } \\
\text { property }\end{array}$ & 74 & 1.00 & 5.00 & 2.7432 & 1.23932 \\
\hline $\begin{array}{l}\text { Possibility of a chaotic } \\
\text { relationship between government } \\
\text { and citizens }\end{array}$ & 74 & 1.00 & 5.00 & 3.1351 & 1.08948 \\
\hline Lack of high level support & 74 & 1.00 & 5.00 & 3.8108 & 1.06855 \\
\hline Valid N (listwise) & 73 & & & & \\
\hline
\end{tabular}


Descriptive Statistics: Citizens

\begin{tabular}{|c|c|c|c|c|c|}
\hline & $\mathrm{N}$ & Minimum & Maximum & Mean & Std. Deviation \\
\hline Improving service delivery & 84 & 1.00 & 5.00 & 3.5476 & .99885 \\
\hline $\begin{array}{l}\text { Improving two-way } \\
\text { communication }\end{array}$ & 84 & 1.00 & 5.00 & 3.8095 & .98759 \\
\hline $\begin{array}{l}\text { Improving citizens' participation } \\
\text { and engagement }\end{array}$ & 83 & 1.00 & 5.00 & 3.9398 & .91531 \\
\hline $\begin{array}{l}\text { Improving workplace } \\
\text { collaboration and knowledge } \\
\text { sharing }\end{array}$ & 84 & 1.00 & 5.00 & 3.8571 & .89366 \\
\hline Reducing costs & 84 & 1.00 & 5.00 & 3.5238 & .99971 \\
\hline $\begin{array}{l}\text { Increasing government } \\
\text { transparency }\end{array}$ & 83 & 1.00 & 5.00 & 3.6506 & 1.10909 \\
\hline Improving employee engagement & 83 & 1.00 & 5.00 & 3.5663 & .88611 \\
\hline $\begin{array}{l}\text { Improving citizens' collaboration } \\
\text { and knowledge sharing }\end{array}$ & 84 & 1.00 & 5.00 & 3.9048 & .77021 \\
\hline Increasing public education & 84 & 2.00 & 5.00 & 3.9048 & .85896 \\
\hline $\begin{array}{l}\text { Building better relationships with } \\
\text { citizens }\end{array}$ & 83 & 1.00 & 5.00 & 3.8675 & .86632 \\
\hline $\begin{array}{l}\text { Providing timely and relevant } \\
\text { information }\end{array}$ & 84 & 1.00 & 5.00 & 4.0119 & .85720 \\
\hline $\begin{array}{l}\text { Providing convenient and faster } \\
\text { access to government information }\end{array}$ & 83 & 1.00 & 5.00 & 3.8313 & .94765 \\
\hline Facilitating better recruitment & 82 & 1.00 & 5.00 & 3.6341 & .82420 \\
\hline Valid N (listwise) & 77 & & & & \\
\hline
\end{tabular}


Descriptive Statistics: Citizens

\begin{tabular}{|c|c|c|c|c|c|}
\hline & $\mathrm{N}$ & Minimum & Maximum & Mean & Std. Deviation \\
\hline Organizational culture & 81 & 1.00 & 5.00 & 3.6543 & .91050 \\
\hline $\begin{array}{l}\text { Creating and sustaining public } \\
\text { engagement }\end{array}$ & 82 & 1.00 & 5.00 & 3.1951 & .96147 \\
\hline Privacy and information security & 82 & 1.00 & 5.00 & 4.0366 & 1.07088 \\
\hline $\begin{array}{l}\text { Data quality and integrity } \\
\text { (reliability of content) }\end{array}$ & 82 & 2.00 & 5.00 & 3.7561 & .97577 \\
\hline Official languages & 82 & 1.00 & 5.00 & 3.1220 & .98620 \\
\hline Departmental access & 82 & 1.00 & 5.00 & 3.2073 & .91271 \\
\hline Lack of social media policy & 80 & 2.00 & 5.00 & 3.7375 & .91047 \\
\hline $\begin{array}{l}\text { Perception that social media tools } \\
\text { are for entertainment only }\end{array}$ & 82 & 1.00 & 5.00 & 3.1707 & 1.19469 \\
\hline $\begin{array}{l}\text { Potential for defamatory } \\
\text { comments }\end{array}$ & 80 & 2.00 & 5.00 & 3.5625 & .96579 \\
\hline $\begin{array}{l}\text { Misinterpretation of original } \\
\text { context }\end{array}$ & 80 & 2.00 & 5.00 & 3.4875 & .98075 \\
\hline $\begin{array}{l}\text { Risk of damage to intellectual } \\
\text { property }\end{array}$ & 81 & 1.00 & 5.00 & 3.1975 & 1.13380 \\
\hline $\begin{array}{l}\text { Possibility of a chaotic } \\
\text { relationship between government } \\
\text { and citizens }\end{array}$ & 80 & 1.00 & 5.00 & 3.1000 & 1.17570 \\
\hline Lack of high level support & 79 & 1.00 & 5.00 & 3.5823 & .95552 \\
\hline Valid N (listwise) & 73 & & & & \\
\hline
\end{tabular}




\subsection{Appendix C: Qualitative Data}

\section{Some examples of Q2: "What does the term "social media" mean to you?"}

\begin{tabular}{|c|c|}
\hline $\begin{array}{l}\text { Respondents - } \\
\text { Director/DG and above }\end{array}$ & What does the term "social media" mean to you? \\
\hline Respondent 5 & $\begin{array}{l}\text { "In a GC or work context I see social media as an electronic forum } \\
\text { that allows public servants to easily interact with each other and } \\
\text { citizens." }\end{array}$ \\
\hline Respondent 9 & $\begin{array}{l}\text { "Social Media sites allow users to interact with each other, form } \\
\text { communities and contribute content online directly, with few } \\
\text { intermediaries. The value of social media sites is usually found in the } \\
\text { communities that cluster around the site rather than the sophistication } \\
\text { of the tools which they provide." }\end{array}$ \\
\hline Respondent 12 & "It's a vehicle to communicate with audiences" \\
\hline Respondent 14 & $\begin{array}{l}\text { "The term "social media" refers to the tools and services that aid in } \\
\text { facilitating communication and knowledge sharing between people or } \\
\text { groups of people." }\end{array}$ \\
\hline \multicolumn{2}{|l|}{$\begin{array}{l}\text { Respondents - } \\
\text { Government } \\
\text { Employees (managers) }\end{array}$} \\
\hline Respondent 7 & $\begin{array}{l}\text { "The ability to connect with like minded individuals. As the word } \\
\text { "social" as way of meeting or connecting with people, friends and } \\
\text { family. Use more and more by business as a way of increasing or } \\
\text { providing information about their company or themselves to achieve } \\
\text { a wider audience for their product." }\end{array}$ \\
\hline Respondent 23 & $\begin{array}{l}\text { "Any communication medium where you can engage in a many to } \\
\text { many conversation." }\end{array}$ \\
\hline Respondents 24 & $\begin{array}{l}\text { "It's social, involves other people, communication, exchanging ideas, } \\
\text { collaboration, } 2 \text { way communication, technology, online. It's a buzz } \\
\text { term that means, being social while using interactive technologies." }\end{array}$ \\
\hline \multicolumn{2}{|l|}{$\begin{array}{l}\text { Respondents - } \\
\text { Government } \\
\text { Employees (below } \\
\text { managers) }\end{array}$} \\
\hline Respondent 43 & $\begin{array}{l}\text { "Social media is a modern way of internet-based communication, } \\
\text { instant information sharing/distribution and creation of a new form of } \\
\text { association by "virtual" community." }\end{array}$ \\
\hline Respondent 23 & $\begin{array}{l}\text { "The media that is more open and connected with less control and } \\
\text { censorship; it's basis are the nodes or people who take part in it." }\end{array}$ \\
\hline
\end{tabular}




\begin{tabular}{|c|c|}
\hline Respondent 19 & $\begin{array}{l}\text { "Social media refers to interaction among people in which they } \\
\text { create, share, and/or exchange information and ideas in virtual } \\
\text { communities and networks. Andreas Kaplan and Michael Haenlein } \\
\text { define social media as "a group of Internet-based applications that } \\
\text { build on the ideological and technological foundations of Web 2.0, } \\
\text { and that allow the creation and exchange of user-generated content. } \\
\text { "Furthermore, social media depends on mobile and web-based } \\
\text { technologies to create highly interactive platforms through which } \\
\text { individuals and communities share, co-create, discuss, and modify } \\
\text { user-generated content. It introduces substantial and pervasive } \\
\text { changes to communication between organizations, communities, and } \\
\text { individuals." }\end{array}$ \\
\hline Respondent 15 & $\begin{array}{l}\text { "Communications tools that allow for a two-way conversation } \\
\text { between the "speaker" (whether an individual or organization) and } \\
\text { the "audience"." }\end{array}$ \\
\hline \multicolumn{2}{|l|}{ Respondents- Citizens } \\
\hline Respondent 77 & $\begin{array}{l}\text { "Any medium that provides social features, such as one-way or two- } \\
\text { way interactions, broadcasting, enabling communication. Web } 2.0 \text { is } \\
\text { a great enabler for it." }\end{array}$ \\
\hline Respondent 73 & $\begin{array}{l}\text { "Essentially, a communications discipline enabled by open and } \\
\text { collaborative platforms that enable individuals to create, share, } \\
\text { comment on and borrow content from anywhere at any time. A term } \\
\text { that will soon be passé, as soon enough it will just be "media." " }\end{array}$ \\
\hline Respondent 69 & $\begin{array}{l}\text { "Social media is a new way to communicate and share information } \\
\text { among friends, family, and colleagues online, as well as meeting } \\
\text { people with similar interests." }\end{array}$ \\
\hline Respondent 49 & $\begin{array}{l}\text { I'm very happy you started with this question. Context is key. I } \\
\text { actually think the term has outgrown itself and is now far too broad. } \\
\text { To me social media is essentially synonymous with the "modern } \\
\text { internet". Hence why I like to contextualize all discussions relating to } \\
\text { social media and separate the noun from the verb. Social Media } \\
\text { (noun)--> Internet based tools and applications that build on the } \\
\text { ideological and technical foundations of web 2.0. --> I like to refer to } \\
\text { this as "social media tools". Social Media (verb)--> The creation and } \\
\text { exchange of user-generated content. --> I like to refer to this as } \\
\text { "social media engagement" }\end{array}$ \\
\hline Respondent 31 & $\begin{array}{l}\text { "Any of the websites that provides the mean for people to create their } \\
\text { own profiles there, and find links to other people and then share } \\
\text { information, pictures, etc." }\end{array}$ \\
\hline Respondent 24 & $\begin{array}{l}\text { "A web application which help to build up network of connections } \\
\text { (social), share or exchange ideas, files. It helps to develop a } \\
\text { community (small or big)." }\end{array}$ \\
\hline
\end{tabular}




\begin{tabular}{|l|l|}
\hline \multirow{3}{*}{ Respondent 5 } & $\begin{array}{l}\text { "Social media is any medium that let people interact and } \\
\text { communicate with each other in virtual worlds of internet and } \\
\text { networking. It started with introduction of Internet with chat rooms, } \\
\text { Web-loggers and extended to much richer experience with mobile } \\
\text { devices and services such as Facebook, Twitter and etc." }\end{array}$ \\
\hline
\end{tabular}


Text Analysis-Social media definition: Number of times each world used

\begin{tabular}{|l|c|c|c|}
\hline Text Analysis-Social Media Definition & $\begin{array}{l}\text { Director/DG } \\
\text { and above }\end{array}$ & $\begin{array}{l}\text { Government } \\
\text { Employees }\end{array}$ & Citizens \\
\hline Communication & 7 & 22 & 12 \\
\hline share & 3 & 20 & 19 \\
\hline Interact & 3 & 14 & 16 \\
\hline Collaboration & 2 & 5 & 1 \\
\hline Connect & 0 & 9 & 12 \\
\hline Engage & 0 & 5 & 1 \\
\hline Easy access & 0 & 3 & 1 \\
\hline Create(or co-create) & 0 & 7 & 6 \\
\hline exchange & 1 & 6 & 5 \\
\hline networking & 0 & 4 & 4 \\
\hline user-generated & 0 & 2 & 1 \\
\hline Social networking & 0 & 4 & 1 \\
\hline
\end{tabular}




\title{
Some examples of Q 26: "Do you have any suggestions on how government could
}

\author{
better use social media?"
}

\begin{tabular}{|c|c|}
\hline $\begin{array}{l}\text { Respondents - } \\
\text { Director/ DG and } \\
\text { above }\end{array}$ & $\begin{array}{l}\text { Do you have any suggestions on how government could better use } \\
\text { social media? }\end{array}$ \\
\hline Respondent 2 & $\begin{array}{l}\text { "Create an integrated social media strategy and to develop expertise } \\
\text { in social media planning, campaign management, and analysis to } \\
\text { craft an authentic and effective communication within each } \\
\text { governmental organizations and the external communities. Change } \\
\text { the perception that social media distracts employees, wasting their } \\
\text { time and reducing efficiency while posing additional risks to } \\
\text { emphasize that social media tools can improve the way in which } \\
\text { employees use resources, perform their jobs and make decisions." }\end{array}$ \\
\hline Respondent 4 & $\begin{array}{l}\text { "Government should be completely re-structured using social media. } \\
\text { The notion of MP's travelling to Ottawa to represent us is antiquated. } \\
\text { We are far more literate and connected than we were at the time of } \\
\text { Confederation. We should use social media for democratic reform } \\
\text { and totally transform programs and service delivery. Government } \\
\text { could use digital media to create service for individuals based on } \\
\text { their unique needs. Just as advances in genetic medicine make the } \\
\text { notion of one-pill-fits all seem ineffective and dated, so does } \\
\text { Employment Insurance operating in a isolation from tax and health. } \\
\text { With big data and social media, government, political and } \\
\text { bureaucratic, should be far nimble in understanding and meeting our } \\
\text { needs." }\end{array}$ \\
\hline Respondent 6 & $\begin{array}{l}\text { "Make it mandatory for your department We can have all the projects } \\
\text { on internal Wiki or each project/program could have their own blogs } \\
\text { Let people to say whatever they what to say Minimize approval } \\
\text { process" }\end{array}$ \\
\hline Respondent 10 & "Seek input from Citizens on proposed regulations and legislations" \\
\hline Respondent 11 & "Tearing down the silos between branches. Let’s keep going!" \\
\hline Respondent 12 & $\begin{array}{l}\text { "I think it's a hot topic and we don't understand all of them. We don't } \\
\text { know how to use them but we just want them. We need to take time } \\
\text { to understand them and their impact." }\end{array}$ \\
\hline Respondent 13 & $\begin{array}{l}\text { "It is not just pushing information out there, it's about getting } \\
\text { information and feedback." }\end{array}$ \\
\hline Respondent 14 & $\begin{array}{l}\text { "Governments need to ensure that a social media strategy is } \\
\text { implemented in order to ensure that the social media platforms being } \\
\text { utilized to promote interaction between individuals and information }\end{array}$ \\
\hline
\end{tabular}




\begin{tabular}{|c|c|}
\hline & $\begin{array}{l}\text { sharing is inline with the departmental goals and objectives. This will } \\
\text { help to guide employees who are responsible for the social media } \\
\text { accounts as well as mitigate the risks posed by using highly } \\
\text { interactive third-party platforms such as Facebook, YouTube and } \\
\text { LinkedIn." }\end{array}$ \\
\hline \multicolumn{2}{|l|}{$\begin{array}{l}\text { Respondents - } \\
\text { Government employees } \\
\text { (managers) }\end{array}$} \\
\hline Respondent 1 & $\begin{array}{l}\text { "Social media is about having fast and transparent access to } \\
\text { information and engaging in two-way discussions. Any social media } \\
\text { policy adopted by the government should respect the above and not } \\
\text { be overly restrictive. For instance, if the information has to go } \\
\text { through a lengthy approval process before being published on social } \\
\text { media, it may lose its timeliness and value to the public." }\end{array}$ \\
\hline Respondent 6 & $\begin{array}{l}\text { "Dedicate resources to it as a means of modernizing the public } \\
\text { service and promote its use among the public to increase awareness } \\
\text { of programming." }\end{array}$ \\
\hline Respondent 11 & $\begin{array}{l}\text { "I don't see any social media benefit for external use, I see it mainly } \\
\text { for internal use. End result of this study will help us to have more } \\
\text { internal collaboration" }\end{array}$ \\
\hline Respondent 22 & "Have conversations! Be SOCIAL!" \\
\hline Respondent 24 & $\begin{array}{l}\text { "Be less risk averse, find ways to have true conversations with } \\
\text { Canadians, find tools that can be more interactive." }\end{array}$ \\
\hline \multicolumn{2}{|l|}{$\begin{array}{l}\text { Respondents - } \\
\text { Government employees } \\
\text { (below managers) }\end{array}$} \\
\hline Respondent 51 & $\begin{array}{l}\text { "Just use it - Briefing books still use paper instead of tablets - Direct } \\
\text { to MP Briefing Notes using ICTs and social media" }\end{array}$ \\
\hline Respondent 48 & $\begin{array}{l}\text { "Standardized response times, more targeted social media channels } \\
\text { with info relevant to specific audiences." }\end{array}$ \\
\hline Respondent 43 & $\begin{array}{l}\text { "Put more emphasis on the speed of the information exchange and } \\
\text { less emphasis on the precision of the information provided. Ease the } \\
\text { restrictions imposed on the public servants in social media } \\
\text { utilization. Ease the control on the centralized messaging function of } \\
\text { the government senior management. Allow government subject } \\
\text { experts to communicate more freely with the public." }\end{array}$ \\
\hline Respondent 4 & $\begin{array}{l}\text { "Twitter for public broadcasts, warnings, announcements, etc. } \\
\text { Facebook for one on one contact as well as above uses for Twitter. } \\
\text { Linked In for Job postings and recruitment/scouting. Youtube and } \\
\text { Vimeo for public education." }\end{array}$ \\
\hline Respondents - Citizens & \\
\hline
\end{tabular}




\begin{tabular}{|l|l|}
\hline Respondent 74 & $\begin{array}{l}\text { "Really see it as a way to engage and have conversations - not just to } \\
\text { broadcast" }\end{array}$ \\
\hline Respondent 58 & $\begin{array}{l}\text { "There just needs to be less fear in using it. It's social media for a } \\
\text { reason. It is meant to be used by all to connect with all and not } \\
\text { locked down with several layers of security." }\end{array}$ \\
\hline Respondent 44 & $\begin{array}{l}\text { "Government needs to build trust by being open about how is } \\
\text { protecting public information and the use of private information of its } \\
\text { citizens and an assurance to the citizens that their information and } \\
\text { opinions are not being used against them in any sort." }\end{array}$ \\
\hline Respondent 20 & $\begin{array}{l}\text { "I think the government has to be sensitive to the audience it is trying } \\
\text { to reach. For example, how helpful is it to tell Veterans there is an } \\
\text { app to direct them to available services." }\end{array}$ \\
\hline
\end{tabular}


Q15: How helpful do you think each of the following social media tools would be in delivering government services?

Director/DG and above: How helpful do you think each of the following social media tools would be in delivering government services?

$\begin{array}{lcccccccc}\begin{array}{l}\text { Answer } \\ \text { Options }\end{array} & \begin{array}{c}\text { Extremely } \\ \text { helpful }\end{array} & \begin{array}{c}\text { Very } \\ \text { helpful }\end{array} & \begin{array}{c}\text { Somewhat } \\ \text { helpful }\end{array} & \begin{array}{c}\text { Slightly } \\ \text { helpful }\end{array} & \begin{array}{c}\text { Not at } \\ \text { all } \\ \text { helpful }\end{array} & \begin{array}{c}\text { Don't } \\ \text { know }\end{array} & \begin{array}{c}\text { Rating } \\ \text { Average }\end{array} & \begin{array}{c}\text { Response } \\ \text { Count }\end{array} \\ \text { Facebook } & 2 & 4 & 4 & 4 & 2 & 0 & 3.00 & 16 \\ \text { Twitter } & 4 & 3 & 7 & 0 & 0 & 2 & 2.69 & 16 \\ \text { Wiki } & 6 & 8 & 1 & 0 & 1 & 0 & 1.88 & 16 \\ \text { YouTube } & 4 & 8 & 3 & 0 & 1 & 0 & 2.13 & 16 \\ \text { Blogs } & 4 & 7 & 0 & 3 & 0 & 2 & 2.63 & 16 \\ \text { RSS feeds } & 3 & 7 & 2 & 0 & 0 & 3 & 2.73 & 15 \\ \text { LinkedIn } & 2 & 4 & 6 & 1 & 2 & 1 & 3.00 & 16 \\ \text { Pinterest } & 0 & 0 & 3 & 1 & 2 & 10 & 5.19 & 16 \\ \text { Google+ } & 1 & 3 & 4 & 5 & 0 & 3 & 3.56 & 16 \\ \text { Flickr } & 1 & 1 & 4 & 2 & 2 & 6 & 4.31 & 16 \\ \text { Delicious } & 1 & 1 & 2 & 1 & 2 & 9 & 4.81 & 16 \\ \text { Vimeo } & 1 & 1 & 2 & 2 & 10 & 5.19 & 16 \\ & & 1 & & & & & \text { answered question } & \text { skipped question }\end{array}$

Employees: How helpful do you think each of the following social media tools would be in delivering government services?

$\begin{array}{lccccccccc}\begin{array}{l}\text { Answer } \\ \text { Options }\end{array} & \begin{array}{c}\text { Extremely } \\ \text { helpful }\end{array} & \begin{array}{c}\text { Very } \\ \text { helpful }\end{array} & \begin{array}{c}\text { Somewhat } \\ \text { helpful }\end{array} & \begin{array}{c}\text { Slightly } \\ \text { helpful }\end{array} & \begin{array}{c}\text { Not at } \\ \text { all } \\ \text { helpful }\end{array} & \begin{array}{c}\text { Don't } \\ \text { know }\end{array} & \begin{array}{c}\text { Rating } \\ \text { Average }\end{array} & \begin{array}{c}\text { Response } \\ \text { Count }\end{array} \\ \text { Facebook } & 6 & 20 & 26 & 3 & 14 & 4 & 3.15 & 73 \\ \text { Twitter } & 12 & 30 & 11 & 9 & 7 & 4 & 2.74 & 73 \\ \text { Wiki } & 21 & 31 & 10 & 6 & 4 & 1 & 2.23 & 73 \\ \text { YouTube } & 14 & 31 & 18 & 6 & 2 & 2 & 2.41 & 73 \\ \text { Blogs } & 10 & 30 & 13 & 12 & 4 & 4 & 2.75 & 73 \\ \text { RSS feeds } & 7 & 20 & 19 & 7 & 6 & 13 & 3.33 & 72 \\ \text { LinkedIn } & 8 & 21 & 18 & 8 & 10 & 8 & 3.21 & 73 \\ \text { Pinterest } & 1 & 2 & 4 & 14 & 18 & 33 & 5.01 & 72 \\ \text { Google+ } & 4 & 12 & 13 & 11 & 13 & 20 & 4.05 & 73 \\ \text { Flickr } & 3 & 8 & 18 & 8 & 15 & 20 & 4.17 & 72 \\ \text { Delicious } & 1 & 4 & 4 & 6 & 9 & 48 & 5.25 & 72 \\ \text { Vimeo } & 6 & 13 & 7 & 10 & 5 & 31 & 4.22 & 72\end{array}$


Citizens: How helpful do you think each of the following social media tools would be in delivering government services?

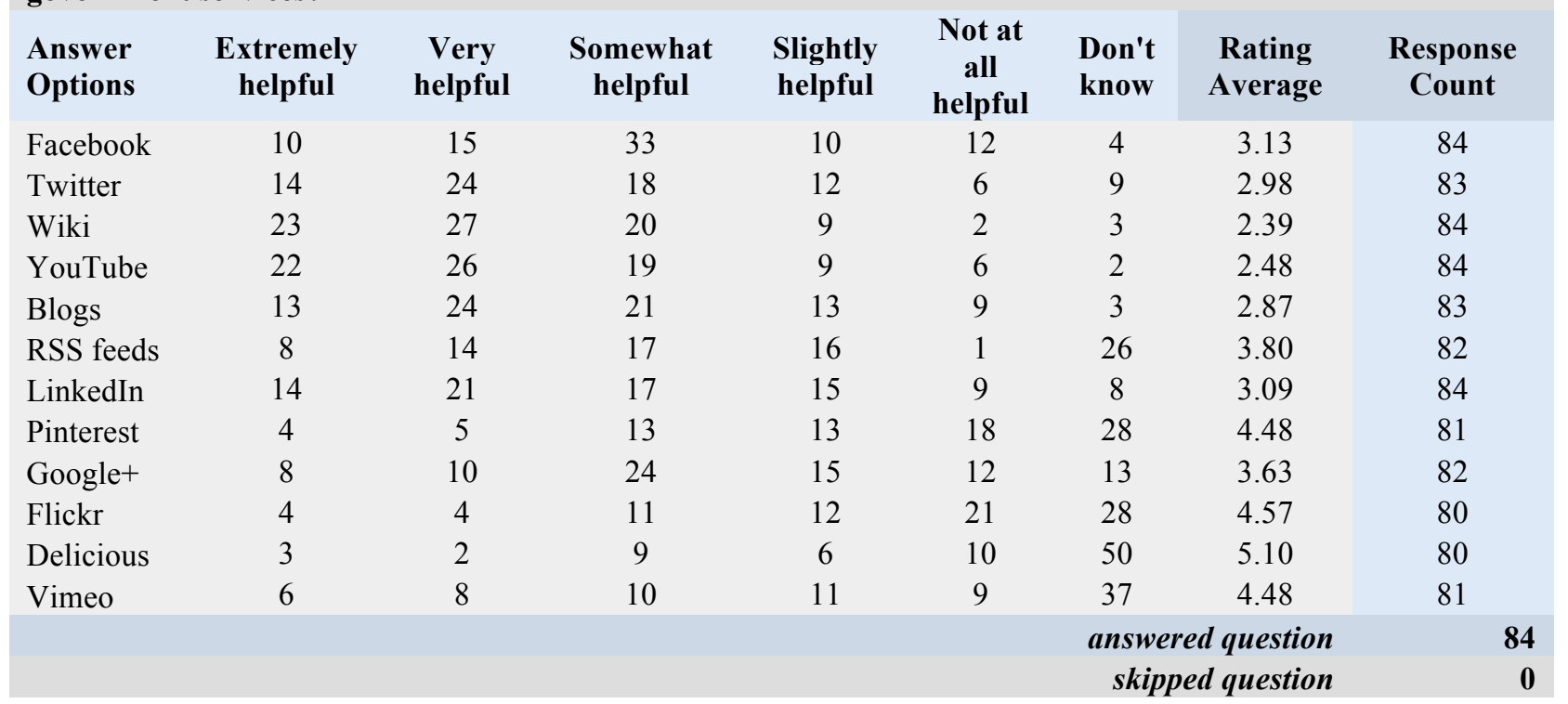




\section{References}

Abdallah, S., \& Khalil, A. (2009).Web 2.0 And E- Governments: An Exploration of Potentials and Realities in the Arab World.European and Mediterranean Conference on Information Systems,Izmir, TurkeyJuly13 ${ }^{\text {th }}-14^{\text {th }}$ 2009, pp 1-11.

ACT Government Social Media Policy Guidelines (2012), Retrieved from http://www.cmd.act.gov.au/_data/assets/pdf_file/0020/312581/Social_Media_Guidelines__May_2012.pdf, visited April 2013.

Agle, B. R., Mitchell, R. K., \&Sonnenfeld, J. A. (1999). Who Matters to Ceos? An Investigation of Stakeholder Attributes and Salience, Corpate Performance, and Ceo Values. Academy of management journal, 42(5), 507-525.

Alkhafaji, A. F. (1989). A stakeholder approach to corporate governance: Managing in a dynamic environment. Westport, CT: Quorum Books.

Andersen, K. N., Medaglia, R., \& Henriksen, H. Z. (2012). Social media in public health care: Impact domain propositions. Government Information Quarterly, 29(4), 462-469. doi: 10.1016/j.giq.2012.07.004

Anonymous (2008). New Technologies and Government of Canada Communications: Phase I- Qualitative Research with Canadians, Internal report, Phoenix Strategic Perspective Inc. Ottawa, Canada.

Anonymous (2009). Web 2.0 and Government: Secondary Analysis. Internal report, Phoenix Strategic Perspective Inc. Ottawa, Canada.

Anonymous (2011). Citizen-Centered Information. Findings (Internal journal of HRSDC). $6(1 \& 2) .1-24$.

Anonymous (2010).Social Media at Natural Resources Canada - On- Campus Recruitment, Retrieved from http://www.gcpedia.gc.ca/wiki/NRCan_On-

Campus_Recruitment_Social_Media_Pilot

Anttiroiko, A. V. (2010). Innovation in democratic e-governance: Benefitting from Web 2.0 applications in the public sector. International Journal of Electronic Government Research (IJEGR), 6(2), 18-36.

Bekkers, V., Edwards, A., \& de Kool, D. (2013). Social media monitoring: Responsive governance in the shadow of surveillance?. Government Information Quarterly, 30(4), 335-342. 
Bertot, J. C. (2003). The multiple dimensions of the digital divide: More than the technology 'haves' and 'have nots'. Government Information Quarterly, 20(2), 185-191. doi: 10.1016/S0740-624X(03)00036-4

Bertot, J. C., Jaeger, P. T., \& Grimes, J. M. (2010).Using ICTs to create a culture of transparency: E-government and social media as openness and anti-corruption tools for societies. Government Information Quarterly, 27(3), 264-271. doi: 10.1016/j.giq.2010.03.001

Bertot, J. C., Jaeger, P. T., \& Hansen, D. (2012). The impact of polices on government social media usage: Issues, challenges, and recommendations. Government Information Quarterly, 29(1), 30-40. doi: 10.1016/j.giq.2011.04.004

Bertot, J. C., Jaeger, P. T., Munson, S., \& Glaisyer, T. (2010). Social media technology and government transparency. Computer, 43(11), 53-59. doi: 10.1109/MC.2010.325

Birnbaum, M. H. (2004). Human research and data collection via the Internet. Annual Review Psychology, 55, 803-832.

Bonsón, E., Torres, L., Royo, S., \& Floresc, F. (2012). Local e-government 2.0: Social media and corporate transparency in municipalities. Government Information Quarterly, 29(2), 123-132. doi:10.1016/j.giq.2011.10.001

Borning, A., Friedman, B., Davis, J. L., Gill, B. T., Kahn Jr., P. H., Kriplean, T., \& Lin, P. (2009). Public participation and value advocacy in information design and sharing: Laying the foundations in advance of wide-scale public deployment. Information Polity: The International Journal of Government \& Democracy in the Information Age, 14(1), 61-74. doi: 10.3233/IP2009-0172

Boyd, S. (2007). Scoble Asks What is Social Media? Retrieved: October, 17, 2011, from: http://www.stoweboyd.com/post/1339189186/scoble-asks-what-is-social-media

Bray, R. (2008). Government faces Facebook reality. Retrieved 05/15, 2011, from http://www.itworldcanada.com/news/government-faces-facebook-reality/00507

Brenner, S. N., \& Cochran, P. (1991, March). The stakeholder theory of the firm: Implications for business and society theory and research. In International Association for Business and Society Proceedings (Vol. 449, p. 467).The Macmillan Company.

Briones, R. L., Kuch, B., Liu, B. F., \& Jin, Y. (2011). Keeping up with the digital age: How the american red cross uses social media to build relationships. Public Relations Review, 37(1), 37-43. doi: 10.1016/j.pubrev.2010.12.006

Bryman, A., \& Bell, E. (2011). Business Research Methods 3e. Oxford university press. 
Canada Joins International Open Government Partnership (2012), Retrieved from http://www.tbs-sct.gc.ca/media/nr-cp/2012/0418-eng.asp.

Carroll, A. B. (1979). A three-dimensional conceptual model of corporate performance. Academy of Management Review, 4, 497-505.

Chang, A. M., \& Kannan, P. K. (2008). Leveraging Web 2.0 in government. IBM Center for the Business of Government.

Chun, S. A., \& Luna Reyes, L. F. (2012).Social media in government. Government Information Quarterly, 29(4), 441-445. doi: 10.1016/j.giq.2012.07.003

Citizens @ the Centre: B.C. Government 2.0 (2011, December 05). Citizens' Services and Open Government, Retrieved from http://www.gov.bc.ca/citz/citizens_engagement/gov20.pdf

Clarkson, M. E. (1995). A stakeholder framework for analyzing and evaluating corporate social responsibility. Academy of Management Review, 20(1), 92-117.

Clement, T (2011, November). Check Against Delivery: Address by Tony Clement, President of the Treasury Board, at PSEngage. Treasury Board of Canada Secretariat, Retrieved from http://www.tbs-sct.gc.ca/media/ps-dp/2011/1122-eng.asp

Colledge, M. (2013). From 'Bowling Alone' to Bowling Online: The Link between Social Media and Social Capita. Ipsos Idea Spot. Retrieved from http://spotlight.ipsosna.com/index.php/news/from-bowling-alone-to-bowling-online-the-link-between-social-mediaand-social-capital/

Cook, N. (2008). Enterprise 2. 0: How social software will change the future of work Gower Publishing, Ltd.

Cormode, G., \& Krishnamurthy, B. (2008). Key differences between Web 1.0 and Web 2.0. First Monday, 13(6), Retrieved fromhttp://www.uic.edu/htbin/cgiwrap/bin/ojs/index.php/fm/article/view/2125/1972

Creswell, J. W., \& Clark, V. L. P. (2007). Designing and conducting mixed methods research.

Criado, J. I., Sandoval-Almazan, R., \& Gil-Garcia, J. R. (2013). Government innovation through social media. Government Information Quarterly, 30(4), 319-326.

Crilly, D. (2010). Predicting stakeholder orientation in the multinational enterprise: A midrange theory.Journal of International Business Studies, 42(5), 694-717. 
Dewing, M. (2010). Social media: 1. An Introduction. Library of Parliament, http://www.parl.gc.ca/Content/LOP/ResearchPublications/2010-03-e.htm

DiStaso, M. W., McCorkindale, T., \& Wright, D. K. (2011). How public relations executives perceive and measure the impact of social media in their organizations. Public Relations Review, 37(3), 325-328.

Donaldson, T., \& Preston, L. E. (1995). The stakeholder theory of the corporation: Concepts, evidence, and implications. Academy of management Review, 20(1), 65-91.

Dorris, M. (2008). Service transformation in government. The Public Manager, 25-28.

Dunlap, J. C., \&Lowenthal, P. R. (2009). Tweeting the night away: Using twitter to enhance social presence. Journal of Information Systems Education, 20(2), 129-135.

E-Government (2011, November 01). Definition of E-Government: The World Bank, Retrieved from http://web.worldbank.org/WBSITE/EXTERNAL/TOPICS/EXTINFORMATIONANDCOMMU NICATIONANDTECHNOLOGIES/EXTEGOVERNMENT/0,,contentMDK:20507153 menuP K:702592 pagePK:148956 piPK:216618 theSitePK:702586,00.html

Eighteenth Annual Report to the Prime Minister on the Public Service of Canada (2011), Clerk of the Privy Council, Retrieved from http://www.clerk.gc.ca/eng/feature.asp?pageId=275

Evan W, Freeman E. (1988). A stakeholder theory of the modem corporation: Kantian capitalism. In Ethical Theory and Business, Beauchamp T, Bowie N (eds.). Prentice-Hall: Englewood Cliffs, NJ; 75-93.

Facebook (2014). Facebook Newsroom. Retrieved from https://newsroom.fb.com/company-info/

Freeman, R. E. (1984). Strategic management: A stakeholder approach. Boston: Pitman.

Freeman, R. E. (2008). Ending the so-called 'Friedman-Freeman'debate. Business ethics quarterly, 18(2), 153-190.

Freeman, R. E., \& Reed, D. L. (1983). Stockholders and stakeholders: A new perspective on corporate governance. California Management Review, 25(3), 93-104

Freeman, R., McVea, J. (2001). A stakeholder approach to strategic management, in M. A. Hitt, R. E. Freeman\& J. S. Harrison (eds.), Handbook of Strategic Management, Oxford, UK: Blackwell Publishers, 189-207.

Friedman, A. L., \& Miles, S. (2006). Stakeholders: Theory and practice. Oxford University Press. 
Frooman, J. (1999). Stakeholder influence strategies. Academy of management review, 24(2), 191-205.

Fyfe, T., \& Crookall, P. (2010). Social media and public sector policy dilemmas. Toronto: Institute of Public Administration of Canada (IPAC).

GCpeida (2013), GCpedia, Retrieved from http://en.wikipedia.org/wiki/GCPEDIA

Gil-Garcia, J., Chun, S. A., \& Janssen, M. (2009). Government information sharing and integration: Combining the social and the technical. Information Polity: The International Journal of Government \& Democracy in the Information Age, 14(1), 1-10. doi: 10.3233/IP-20090176

Gillin, P. (2010). The New Conversation: Taking Social Media from Talk to Action. Harvard Business Review.

Goodijk, R. (2003) Partnership at corporate level: The meaning of the stakeholder model. Journal ofChange Management, 3(3):225-241.

Gore, A., Jr. (1993). From Red Tape to Results: Creating a government that works better and costs less. Washington DC: Government Printing Office. Retrieved from : http://govinfo.library.unt.edu/npr/library/nprrpt/annrpt/redtpe93/index.html.

Grossman, L. (2006). Time's person of the year: You. Time Magazine, 13.

Hasin, A. A., Kumar, V., Kumar, U., \& Shareef, M. A. (2011). Introduction to electronic government: Development and adoption. In M. Shareef, V. Kumar, U. Kumar \& Y. K. Dwivedi (Eds.), Stakeholder adoption of E-government services: Driving and resisting factors (pp. 1-13) IGI Global.

Heeks, R. (2006, July). Understanding and measuring e-Government: international benchmarking studies. In UNDESA workshop, "E-Participation and E-Government: Understanding the Present and Creating the Future", Budapest, Hungary (pp. 27-28).

Herring, S. C., Scheidt, L. A., Bonus, S., and Wright, E. (2004).Bridging the gap: A genre analysis of weblogs. Proc. HICSS'04, pp. 1-11.

Hong, S., \& Nadler, D. (2012). Which candidates do the public discuss online in an election campaign?: The use of social media by 2012 presidential candidates and its impact on candidate salience. Government Information Quarterly, 29(4), 455-461. doi: 10.1016/j.giq.2012.06.004

HR Focus (2010). Recruiting and marketing are top benefits of social media.HR Focus, 87(1), 1-3. 
Hrdinová, J., Helbig, N., \& Peters, C. S. (2010). Designing social media policy for government: Eight essential elements. Center for Technology in Government, University at Albany.

Individual Internet use and E-commerce (2010). Statistics Canada, Retrieved: March, 10, 2012, Retrieved from http://www.statcan.gc.ca/daily-quotidien/111012/dq111012a-eng.htm

Internet World Stats. (2012), Retrieved from: http://www.internetworldstats.com/stats.htm visited June 2012

Ipsos (2009), What? You Don't Have A Social Network Profile? Retrievedfromhttp://www.marketwire.com/press-release/what-you-dont-have-a-social-networkprofile-1006358.htm

Jackson, A., Yates, J., \& Orlikowski, W. (2007). Corporate blogging: Building community through persistent digital talk. System Sciences, 2007.HICSS 2007.40th Annual Hawaii International Conference on, 80-80.doi: 10.1109/HICSS.2007.155

Jaeger, P. T., \& Bertot, J. C. (2010). Designing, implementing, and evaluating usercentered and citizen-centered e-government. International Journal of Electronic Government Research (IJEGR), 6(2), 1-17.

Jawahar, I. M., \& McLaughlin, G. L. (2001). Toward a descriptive stakeholder theory: An organizational life cycle approach. Academy of Management Review, 26(3), 397-414.

Jensen, T., \& Sandström, J. (2011). Stakeholder theory and globalization: the challenges of power and responsibility. Organization Studies, 32(4), 473-488.

Kane, G. C., \& Fichman, R. G. (2009). The shoemaker's children: Using wikis for information systems teaching, research, and publication. MIS Quarterly, 33(1), 1-17.

Kaplan, A. M., \& Haenlein, M. (2010).Users of the world, unite! the challenges and opportunities of social media. Business Horizons, 53(1), 59-68. doi: 10.1016/j.bushor.2009.09.003

Kaplan, A. M., \& Haenlein, M. (2010).Users of the world, unite! the challenges and opportunities of social media. Business Horizons, 53(1), 59-68. doi: 10.1016/j.bushor.2009.09.003

Kavanaugh, A. L., Fox, E. A., Sheetz, S. D., Yang, S., Lin, T. L., Shoemaker, D. J., . . Xie, L. (2012). Social media use by government: From the routine to the critical. Government Information Quarterly, 29(4), 480-491. doi: 10.1016/j.giq.2012.06.002

Key, S. (1999). Toward a new theory of the firm: A critique of stakeholder "theory". Management Decision, 37(4), 317-328. doi: 10.1108/00251749910269366 
Keyes, J. (2013). Enterprise 2. 0: Social Networking Tools to Transform Your Organization. CRC Press.

Kim, D. J., Yue, K., Hall, S. P., \& Gates, T. (2009). Global diffusion of the internet XV: Web 2.0 technologies, principles, and applications: A conceptual framework from technology push and demand pull perspective. Communications of AIS, 24, 657-672.Retrieved from http://aisel.aisnet.org/cais/vol24/iss 1/38

Kuzma, J. (2010). Asian government usage of Web 2.0 social media. European Journal of ePractice, (9), 1-13.

Landsbergen, D. (2010, June). Government as part of the revolution: Using social media to achieve public goals. In Proceedings of the 10th European conference on e-government (pp. 243250).

Langtry, B. (1994). Stakeholders and the moral responsibilities of business.Business Ethics Quarterly, 4 (1), 431-443.

Lavender, A. L. (2013). Web 2.0 impact on business value at a federal government housing agency. (Ph.D., Capella University). ProQuest Dissertations and Theses, (1328401582).

Lee, G., \&Kwak, Y. H. (2012).An open government maturity model for social media-based public engagement. Government Information Quarterly, 29(4), 492-503. doi: 10.1016/j.giq.2012.06.001

Linders, D. (2012). From e-government to we-government: Defining a typology for citizen coproduction in the age of social media. Government Information Quarterly, 29(4), 446-454. doi: 10.1016/j.giq.2012.06.003

LinkedIn News Releases (2014). LinkedIn Announces Second Quarter 2014 Results. http://press.linkedin.com/News-Releases/340/LinkedIn-Announces-Second-Quarter-2014Results

Lombardi, R. (2008). Web 2.0: Government's social networking debate. Retrieved 05/15, 2011, from http://www.itworldcanada.com/news/web-2-0-governments-social-networkingdebate/01484

Madden, M. (2010). Older adults and social media. PewInternet and American Life Project, Washington, DC, Available from http://www.pewinternet. org.

Mainardes, E. W., Alves, H., \& Raposo, M. (2011). Stakeholder theory: Issues to resolve. Management Decision, 49(2), 226-252. 
Mergel, I. (2011). Using Wiki in Government: a guide for public managers, IBM Center for the Business of Government, Retrieved from

http://www.businessofgovernment.org/report/using-wikis-government-guide-public-managers

Mergel, I. (2012). The social media innovation challenge in the public sector, Information Polity, 17 (3-4), pp. 281-292.

Mergel, I. (2013a). Social media adoption and resulting tactics in the U.S. federal government. Government Information Quarterly, 30(2), 123-130. doi:

10.1016/j.giq.2012.12.004.

Mergel, I. (2013b). A framework for interpreting social media interactions in the public sector. Government Information Quarterly, 30(4), 327-334. doi:10.1016/j.giq.2013.05.015

McNutt, K. (2014). Public engagement in the web 2.0 era: Social collaborative technologies in a public sector context. Canadian Public Administration, 57(1), 49-70. doi:10.1111/capa.12058.

Miller, V. (2008). New media, networking and phatic culture. Convergence: The International Journal of Research into New Media Technologies, 14(4), 387-400. doi: $10.1177 / 1354856508094659$.

Mintzberg, H. (1996). Managing government, governing management. Harvard Business Review, 74(3), 75.

Mitchell, R. K., Agle, B. R., \& Wood, D. J. (1997). Toward a theory of stakeholder identification and salience: Defining the principle of who and what really counts. Academy of Management Review, 22(4), 853-886.

Moon, R. (2010). What can a corpus tell us about lexis?. The Routledge Handbook of Corpus Linguistics, 197.

Nam, T. (2012). Suggesting frameworks of citizen-sourcing via government 2.0. Government Information Quarterly, 29(1), 12-20. doi: 10.1016/j.giq.2011.07.005

Nath, A.K., Iyer, L.S., and Singh, R.S. (2011). Uses of Web 2.0 for Knowledge Management in Organizations: Multiple Case Studies. Proceedings of the Seventeenth Americas Conference on Information Systems, Detroit, Michigan August $4^{\text {th }}-7^{\text {th }} 2011$.

Nickols, F. 2003. Communities of practice. Collaborative learning environments sourcebook. Available online at http://www.criticalmethods.org/collab/v.mv?d=1_67.

Nineteenth Annual Report to the Prime Minister on the Public Service of Canada (2012), Clerk of the Privy Council, Retrieved from http://www.clerk.gc.ca/eng/feature.asp?pageId=300. 
O’ Reilly, T., \& Battelle, J. (2009). Web squared: Web 2.0 five years on. Retrieved 10/05, 2010, from http://www.web2summit.com/web2009/public/schedule/detail/10194

O'Reilly, T. (2005). What is web 2.0. Retrieved 01/07, 2011, from http://oreilly.com/web2/archive/what-is-web-20.html

O'Reilly, T. (2006). Web 2.0 Compact Definition: Trying Again. Retrieved from http://radar.oreilly.com/2006/12/web-20-compact-definition-tryi.html.

Picazo-Vela, S., Gutiérrez-Martínez, I., \& Luna Reyes, L. (2012). Understanding risks, benefits, and strategic alternatives of social media applications in the public sector. Government Information Quarterly, 29(4), 504-511. doi: 10.1016/j.giq.2012.07.002

Pieterson, W. (2010). Citizens and service channels: Channel choice and channel management implications. International Journal of Electronic Government Research (IJEGR), 6(2), 37-53.

Preble, J. F. (2005). Toward a comprehensive model of stakeholder management. Business and Society Review, 110(4), 407-431.

Rockwell, G. (2003). What is text analysis, really?. Literary and linguistic computing, 18(2), 209-219.

Rowley, J. (2011). e-government stakeholders-Who are they and what do they want? International Journal of Information Management,31(1), 53-62. doi: 10.1016/j.ijinfomgt.2010.05.005

Rowley, T. J. (1997). Moving beyond dyadic ties: A network theory of stakeholder influences. Academy of management Review, 22(4), 887-910.

Rubin, K. (2012, November 01). Feds enter Twitter/YouTube era: one more Harper government messaging tool. The Hill Times Online, Retrieved from http://www.hilltimes.com/open-government/2012/01/09/feds-enter-twitter/youtube-era-onemore-harper-government-messaging-tool/29152

Savage, G., Nix, T., Whitehead, C., \& Blair, J. (1991).Strategies for assessing and managing stakeholders. Academy of Management Executive, 5(2): 61-75.

Sedereviciute, K., \& Valentini, C. (2011). Towards a more holistic stakeholder analysis approach. mapping known and undiscovered stakeholders from social media.

. International Journal of Strategic Communication, 5(4), 221-239.

doi: http://dx.doi.org.proxy.library.carleton.ca/10.1080/1553118X.2011.592170

Shareef, M., A., Kumar, V., Kumar, U., \& Dwivedi, Y. K. (2011). e-Government Adoption Model (GAM): differing service maturity levels. Government Information Quarterly, 28, 17-35. 
Silcock, R. (2001). What is e-government. Parliamentary Affairs, 54(1), 88-101.

Smith, A. W. (2010). Government online: The internet gives citizens new paths to government services and information. Pew Research Center's Internet \& American Life Project.

Snead, J. T. (2013). Social media use in the U.S. executive branch. Government Information Quarterly, 30(1), 56-63.

Standard on Social Media Account Management (2013, April 01). Treasury Board of Canada Secretariat. Retrieved from http://www.tbs-sct.gc.ca/pol/doceng.aspx? section=text\&id=27033

Sutter, J. (2009). Tutorial: Introduction to Web 2.0. Communications of the Association for Information Systems, 25, 511-517.

Tapscott, D., \& Williams, A. D. (2006). Wikinomics: How mass collaboration changes everything. New York: Portfolio.

Thompson, J. K., Wartick, S. L., \& Smith, H. L. (1991).Integrating corporate social performance and stakeholder management: Implications for a research agenda in small business. Research in Corporate Social Performance and Policy, 12: 207-230.

Twitter (2014). About Twitter. Retrieved from https://about.twitter.com/company

Warner, J., \& Chun, S. A. (2009). Privacy protection in government mashups. Information Polity: The International Journal of Government \& Democracy in the Information Age, 14(1), 75-90. doi: 10.3233/IP-2009-0169

Waters, R. D., Burnett, E., Lamm, A., \& Lucas, J. (2009). Engaging stakeholders through social networking: How non-profit organizations are using Facebook. Public Relations Review, 35, pp. 102-106.

Weber, M. (1947). The Theory of Social and Economic Organization. Glencoe, Ill.: Free Press.

Welch, M. T. (2006). The emerging media revolution: considering the influence of new media forms on democratic society. (Unpublished Master of Arts in Communication and Leadership Studies). Gonzaga University.

Wigand, D. (2012). Communication and collaboration in a web 2.0 world. In M. J. Ed Downey (Ed.), Public service, governance and web 2.0 technologies - future trends in social media (pp. 1-18). Hershey PA, USA: Information Science Reference.

Wikipedia (2014). In Wikipedia, The Free Encyclopedia. Retrieved from http://en.wikipedia.org/wiki/Wikipedia 
Williams, T., \& Williams, R. (2008). Adopting social media: Are we leaders, managers or followers? Communication World, 25(4), 34-37.

Wilson, D. W., Lin, X., Longstreet, P., \& Sarker, S. (2011). Web 2.0: A Definition, Literature Review, and Directions for Future Research. Proceedings of the Seventeenth Americas Conference on Information Systems, Detroit, Michigan August $4^{\text {th }}-7^{\text {th }} 2011$.

Wright, D. K., \& Hinson, M. D. (2008). How blogs and social media are changing public relations and the way it is practiced. Public Relations Journal, 2(2), 1-21.

Xu Cheng, Dale, C., \& Jiangchuan Liu. (2008). Statistics and social network of YouTube videos. Quality of Service, 2008.IWQoS 2008. 16th International Workshop on, 229-238.

Yates, D., \& Paquette, S. (2011). Emergency knowledge management and social media technologies: A case study of the 2010 Haiti an earthquake. International Journal of Information Management,31(1), 6-13. doi: 10.1016/j.ijinfomgt.2010.10.001

$\begin{array}{lllll}\text { YouTube (2014). } & \text { Press } & \text { Room. } & \text { Retrieved }\end{array}$ https://www.youtube.com/yt/press/index.html

Zavattaro, S. M. (2013). Social media in public Administration's future: A response to farazmand. Administration \& Society, 45(2), 242-255. doi: 10.1177/0095399713481602

Zhang, Y. (2000). Using the Internet for survey research: A case study. Journal of the American Society for Information Science, 51(1), 57-68. 